INSTITUTO DE PESQUISAS ENERGÉTICAS E NUCLEARES

Autarquia associada à Universidade de São Paulo

\title{
ESTUDOS ARQUEOMÉTRICOS DO SÍTIO ARQUEOLÓGICO HATAHARA
}

\author{
Kelly Plaça Nunes
}

Dissertação apresentada como parte dos requisitos para obtenção do Grau de Mestre em Ciências na Área de Tecnologia Nuclear - Aplicações

Orientador:

Dr. Casimiro Sepúlveda Munita 
INSTITUTO DE PESQUISAS ENERGÉTICAS E NUCLEARES

Autarquia associada à Universidade de São Paulo

\title{
ESTUDOS ARQUEOMÉTRICOS DO SÍTIO ARQUEOLÓGICO HATAHARA
}

\author{
Kelly Plaça Nunes
}

Dissertação apresentada como parte dos requisitos para obtenção do Grau de Mestre em Ciências na Área de Tecnologia Nuclear - Aplicações

Orientador:

Dr. Casimiro Sepúlveda Munita 


\section{OFEREÇO}

Ao meu pai Júlio (in memorian), à minha irmã Karina e a minha querida mãe Maria, a quem seria impossível expressar minha gratidão pelo seu amor e pelas suas palavras de apoio em muitos momentos, me ajudando a concluir mais esta etapa em minha vida. 


\section{AGRADECIMENTOS}

À Deus, Senhor de toda a sabedoria, o qual me revestiu com paciência, força e capacidade, para que eu pudesse vencer todas as dificuldades e desafios.

Ao Prof. Dr. Casimiro Sepúlveda Munita, pela orientação e por ter exercido acompanhamento a este trabalho de pesquisa; pelo incentivo desde minha iniciação científica, e também pela confiança, em mim depositada.

Ao Prof. Enéas Furtado de Araújo, pelas agradáveis aulas ministradas no Mackenzie, fazendo com que fosse despertado em mim, o interesse pela Radioquímica.

À Divisão de Radioquímica do Instituto de Pesquisas Energéticas e $\mathcal{N}$ ucleares - IPEN, pela oportunidade de trabalho oferecida desde a minha Iniciação científica; e onde também, foi realizada a maior parte deste trabalho de Mestrado. Certamente, os aprendizados adquiridos nestes anos contribuíram fortemente para o meu amadurecimento.

À todos os Professores e Orientadores da Divisão de Radioquímica do IPEN, especialmente à Dra. Mitiko Saiki, pela amizade e pelo seu esforço em compartilhar conosco seus conhecimentos, sempre pertinentes, tanto em sala de aula, como nos laboratórios.

À Dra. Marina B. A. Vasconcellos e Dra. Vera A. Maihara, por todos os ensinamentos transmitidos nas disciplinas no IPENN, os quais foram muito importantes para a minha pós-graduação e também pela amizade.

Para o desenvolvimento deste trabalho de pesquisa, teve fundamental importância a participação do Prof. Dr. Eduardo Góes $\mathcal{N}$ eves, Dra. Helena Pinto Lima, Eduardo Kazuo e Tiago do Museu de Arqueologia e Etnologia da Universidade de São Paulo, que contribuíram principalmente com valiosas colaborações quanto a interpretação da parte arqueológica, gentileza com o fornecimento das cerâmicas para as análises, além da bibliografia.

À Prof. Dra. Sonia Hatsue Tatumi, do Laboratório de Vidros e Datações (LVD) da Faculdade de Tecnologia $S P$, que permitiu a realização das datações das cerâmicas por termoluminescência e especialmente ao Elcio e Diego, que pacientemente auxilaram com a parte experimental, bem como, com a interpretação dos resultados de $\tau \mathcal{T L}$ 
Ao Prof. Dr. Shigueo Watanabe do Instituto de Física da Universidade de São Paulo pela contribuição quanto ao estudo da técnica da datação por termoluminescência.

Ao Prof. Dr. Oswaldo Baffa Filho e ao Dr. Luiz Carlos Oliveira, pela imensa colaboração com as análises de temperatura de queima das cerâmicas no Laboratório de Ressonância Magnética do Departamento de Física na Universidade de São Paulo em Ribeirão Preto.

Ao Dr. Juan C. R. Mittani, pelos esclarecimentos quanto à técnica da RPE e resultados.

Ao Dr. Emílio Soares da Universidade Federal do Amazonas, pela interpretação das análises de argila.

Ao Dr. Paulo T. M. S. Oliveira, pela ajuda com a parte estatística quanto aos resultados de $\mathcal{A} \mathcal{A} \mathcal{N}$.

Ao Dr. Jorge E. S. Sarkis, pelas ótimas sugestões.

Aos meus amigos: Meiri, Larissa, Rita, Cris, Paola, Michel, Selma, Andreza, Fábio, Luciana, Osman, Roseane, Edson Moreira, Edson Alves, Guilherme, Regina e Fábio Toledo, pela ajuda, amizade e alegrias vivenciadas durante todo este período no IPES.

À minha amiga Inês, pela amizade e apoio nos momentos difíceis surgidos no decorrer da produção deste trabalho.

Agradeço à Coordenação de Aperfeiçoamento de Pessoal de Nível Superior (CAPES - NN130004/2007-3) e a Fundação de Amparo à Pesquisa do Estado de São Paulo (FAPESP - Processos $\mathcal{N}^{\circ}$ 06/59237-6 e 06/57343-3), pela concessão da bolsa de estudo e o suporte financeiro para a execução deste trabalho.

Enfim, agradeço a todas as pessoas que de alguma forma ajudaram a tornar possível minha chegada ao fim de mais esta caminhada. 
"Tomai interesse por esses recintos sagrados que chamamos de laboratórios. Façais o possivel para que eles se multipliquem. Eles representam o templo do futuro, da riqueza e do bem-estar social. $\mathscr{E}$ por intermédio deles que a humanidade melhora, cresce e também onde se aprende a ler os segredos da natureza $e$ da harmonia universal. Enquanto as obras do homem são quase sempre obras de barbárie, de fanatismo e de destruição (...)".

(Marie Curie)

"Ainda que eu fale as linguas dos homens e dos anjos, se não tiver amor, serei como o bronze que soa ou como o címbalo que retine".

(1 Coríntios 13:1) 


\title{
ESTUDOS ARQUEOMÉTRICOS DO SÍTIO ARQUEOLÓGICO HATAHARA
}

\author{
Kelly Plaça Nunes
}

\section{RESUMO}

A reconstrução do passado e o entendimento de vários aspectos históricos e culturais das sociedades que se desenvolveram em sítios arqueológicos, têm sido possibilitados por meio de trabalhos arqueométricos realizados sobre as cerâmicas resgatadas destas áreas. O presente estudo procurou contribuir para o esclarecimento acerca de tais aspectos, com a aplicação de três métodos físicos de análise: análise por ativação com nêutrons (AAN), datação por termoluminescência (TL) e ressonância paramagnética eletrônica (RPE) aos fragmentos cerâmicos do sítio arqueológico Hatahara, localizado na Amazônia central. As concentrações elementares obtidas por AAN de 120 fragmentos cerâmicos foram interpretadas por meio da análise de agrupamentos e a análise discriminante. Os resultados mostraram a existência de cinco grupos distintos de cerâmicas. Esta informação, associada à interpretação arqueológica, pôde confirmar a existência de quatro fases distintas de ocupação para o sítio Hatahara. Com o objetivo de estabelecer uma cronologia para as ocupações, foram determinadas as idades de três fragmentos cerâmicos, por meio da datação por termoluminescência (TL). A datação de dois fragmentos mostrou resultados que não confirmam interpretações arqueológicas quanto às suas Fases de ocupação. No entanto, a datação do terceiro fragmento permitiu confirmar que o mesmo pertence à Fase Manacapuru. A determinação da temperatura de queima de quatro fragmentos cerâmicos foi estudada por meio da técnica da ressonância paramagnética eletrônica (RPE) e os resultados mostraram que apesar das cerâmicas analisadas pertencerem a três grupos distintos, não houve variações significativas quanto às suas respectivas temperaturas de queima. 


\title{
ARCHEOMETRIC STUDIES ON THE HATAHARA ARCHAEOLOGICAL SITE
}

\author{
Kelly Plaça Nunes
}

\begin{abstract}
The reconstruction of the past and the understanding of historical and cultural aspects of societies that developed at archeological sites have been enabled by archaeometric studies undertaken on ceramics located at these areas. This study aims to be a contribution to the elucidation of these aspects with the application of three physical methods of analysis: neutron activation analysis (NAA), thermoluminescence dating (TL) an electronic paramagnetic resonance (EPR) to ceramic fragments from the Hatahara archaelogical site, located at central Amazon. The elemental concentrations obtained by NAA for 120 ceramic fragments were interpreted by means of cluster analysis and discriminant analysis. The results showed the existence of five distinct ceramic groups. This information, supported by archaelogical interpretation, confirm the existence of four distinct occupation Phases at Hatahara site. In order to establish a chronology for the occupations, the ages of three ceramic fragments were determined by TL. The dating of two fragments did not confirm the archeological interpretation about their occupation Phases. However, the dating of the third fragment allowed the confirmation that it belongs to the Manacapuru Phase. The determination of the burning temperatures of four ceramic fragments was performed by EPR. It was observed that although the analyzed ceramic samples belong to three distinct groups, there was no significant variation on their burning temperatures.
\end{abstract}




\section{SUMÁRIO}

\section{Página}

1 INTRODUÇÃO

2 OBJETIVOS 08

3 ÁREA DE ESTUDO

$3.1 \mathrm{O}$ sítio arqueológico Hatahara $\quad 11$

3.2 Os montículos do sítio Hatahara 12

4 ASPECTOS TEÓRICOS DAS TÉCNICAS ANALÍTICAS UTILIZADAS 16

4.1 Análise por ativação com nêutrons (AAN) 16

4.1.1 Reação com nêutrons $\quad 19$

4.2 Termoluminescência (TL) 25

4.3 Ressonância paramagnética eletrônica (RPE) 28

4.4 Métodos estatísticos $\quad 29$

4.4.1 Análise de conglomerado $\quad 30$

4.4.2 Normalização e padronização dos dados 33

4.4.3 Valores discrepantes (outliers) 33

4.4.4 Análise discriminante 35

5 PARTE EXPERIMENTAL 36

5.1 Preparação das amostras de cerâmica para AAN 36

5.1.1 Procedimento analítico 36

5.2 Preparação das amostras de cerâmica para datação por TL 38

5.2.1 Procedimento analítico 38

5.3 Preparação das amostras de cerâmica para análise por RPE 43

5.3.1 Procedimento analítico 43

6 RESULTADOS E DISCUSSÃO

6.1 Controle de qualidade analítica $\quad 45$

6.1.1 Análise de conglomerado $\quad 52$

6.1.2 Análise discriminante $\quad 52$

6.1.3 Determinação da fonte de matéria-prima dos artefatos cerâmicos 57

6.2 Resultados obtidos na datação dos fragmentos cerâmicos por TL 59

6.3 Resultados obtidos para temperatura de queima das cerâmicas por RPE 66 
7 CONCLUSÕES

SUGESTÕES PARA TRABALHOS FUTUROS

REFERÊNCIAS BIBLIOGRÁFICAS 


\section{Lista de Tabelas}

Tabela 1. Características nucleares dos radioisótopos.

Tabela 2. Divisão dos compartimentos da leitora para medição de uma amostra. 41

Tabela 3. Resultados para o material de referência IAEA-Soil 7 Trace Elements in Soil, em $\mu$ g/g, a não ser 47 indicado.

Tabela 4. Resultados das concentrações elementares das amostras de cerâmica em $\mu \mathrm{g} / \mathrm{g}$, a não ser indicado.

Tabela 5. Parâmetros usados para o cálculo da idade pelo método da Dose equivalente.

Tabela 6. Parâmetros usados para o cálculo das idades pelo método da Paleodose.

Tabela 7. Resultados das temperaturas de queima para as amostras analisadas. 


\section{Lista de Figuras}

Figura 1. Vista aérea do sítio arqueológico Hatahara. 12

Figura 2. Trincheira aberta em 2002.

Figura 3. Seqüência de eventos que ocorrem em análise por ativação com nêutrons. 18

Figura 4. Esquema da emissão de termoluminescência por um cristal. 27

Figura 5. Esquema do procedimento experimental para AAN. 38

Figura 6. Esquema do procedimento experimental para datação por TL. 43

Figura 7. Espectro RSE de uma cerâmica indicando o valor do pico utilizado nas análises. 44

Figura 8. Dendograma das amostras de cerâmica usando distância Euclidiana e método de Ward. 55

Figura 9. Função discriminante 1vs função discriminante 2 das cerâmicas.

Figura 10. Dendograma das amostras de cerâmica (Fase Paredão e outras) usando distância Euclidiana e 55 método de Ward.

Figura 11. Função discriminante 1vs função discriminante2 das cerâmicas Paredão e outras. 56

Figura 12. Função discriminante 1vs função discriminante2 para as amostras de argila e cerâmicas. 57

Figura 13. Mapa geológico da área de estudo. 58

Figura 14. Curva de emissão da intensidade do sinal TL do pico de $375^{\circ} \mathrm{C}$ para a amostra 72.

Figura 15. Curvas de emissão TL de todas alíquotas para a amostra 72.

Figura 16. Curvas de emissão TL de todas as alíquotas para a amostra 85.

Figura 17. Curvas de emissão TL de todas as alíquotas para a amostra 104.

Figura 18. Representação dos sinais de todas as alíquotas para a amostra 72. 60

Figura 19. Representação dos sinais de todas as alíquotas para a amostra 85. 61

Figura 20. Representação dos sinais de todas as alíquotas para a amostra 104.

Figura 21. Fotografia de microscopia óptica por transmissão da amostra 85.

Figura 22. Fotografia de microscopia óptica por reflexão da amostra 104.

Figura 23. Curvas de crescimento com pontos ajustados para a amostra 72.

Figura 24. Curvas de crescimento com pontos ajustados para a amostra 85.

Figura 25. Curvas de crescimento com pontos ajustados para a amostra 104.

Figura 26. Sinal RPE da amostra 70. 66

Figura 27. Valor experimental de g obtido da amplitude máxima do sinal II em função da temperatura de 67 reaquecimento para a cerâmica 69.

Figura 28. Valor experimental de g obtido da amplitude máxima do sinal II em função da temperatura de reaquecimento para a cerâmica 70 .

Figura 29. Valor experimental de g obtido da amplitude máxima do sinal II em função da temperatura de reaquecimento para a cerâmica 95.

Figura 30. Valor experimental de g obtido da amplitude máxima do sinal II em função da temperatura de reaquecimento para a cerâmica 103. 


\section{INTRODUÇÃO}

Nos últimos 50 anos, a comunicação e troca de conhecimentos entre Arqueólogos, Historiadores, Físicos e Químicos acerca do estudo de materiais arqueológicos, mostram o quanto a interdisciplinaridade entre estas áreas tornou-se importante para classificação destes artefatos (HAYASHIDA, 2003). Nesta perspectiva, muitos trabalhos têm sido realizados gerando uma série de informações que, constantemente, se complementam caracterizando uma importante área da pesquisa, a Arqueometria.

O estudo de um artefato arqueológico pode fornecer informações a respeito dos povos que o confeccionaram. O artefato é uma expressão do comportamento e do pensamento humano; sendo assim, dados arqueológicos representam reflexos de um padrão de comportamento de um grupo de indivíduos que compõem uma sociedade, e, variam de sociedade para sociedade (CHILDE, 1956).

Há 150 anos, teve início a coleta sistemática de vários materiais na superfície e também por escavação de sítios arqueológicos em todo o mundo. Desde então, estes materiais passaram a ser vistos como instrumentos para a reconstrução do passado humano, com o desenvolvimento de tipologias e técnicas de escavação. Neste período, também foram publicados trabalhos que buscaram comparar os quatro estágios de desenvolvimento do homem com os artefatos, numa tentativa de relacioná-los com os povos que os produziram (BAHN, 1996).

Concomitantemente, alguns critérios tecnológicos para a elaboração de uma classificação tipológica de artefatos foram estipulados nos trabalhos de Pitt Rivers, o qual afirmou que a disposição das peças no artefato ou a maneira de fazê-lo, são parâmetros que fornecem informações acerca da tecnologia empregada na produção destes materiais (CHAPMAN, 1985). Já os trabalhos de Flinders Petri são marcados por preocupação com o passado, o qual deveria ser usado para melhor compreender o futuro (PETRI, 1972).

Hoje, a Arqueologia aplica uma variedade de ferramentas e métodos para o estudo dos artefatos históricos. Além da pesquisa e escavação, tem-se a análise ambiental com pólen ou registros glaciais, paleobotânica e paleozoologia, métodos de datação, 
modelos que utilizam abordagens desenvolvidas pela Sociologia e Etnologia e, por último, mas não o menor, a análise material dos artefatos encontrados (GEBHARD, 2003).

No tocante ao emprego de técnicas físicas e químicas em análises de materiais arqueológicos, teve início no século XVIII, a interação entre pesquisadores das ciências exatas e humanas para o estudo destes materiais (SPEAKMAN \& GLASCOCK, 2007). Gobel, em 1840, analisou grande número de amostras de objetos metálicos provenientes de escavações da Rússia, comparando as composições químicas destes objetos com outras de origem européia. Esse trabalho foi considerado como o primeiro grande impulso dado à caracterização de materiais arqueológicos com o uso de técnicas de análise química (HARBOTTLE, 1982).

Em 1850, o austríaco Jan Wocel sugeriu que para estabelecer a proveniência dos materiais arqueológicos, seriam viáveis estudos da composição química do material, de modo a obter informações quanto ao seu uso e manufatura (HARBOTTLE, 1990). Também, Damour, afirmou que tanto a Mineralogia como a Química deveriam auxiliar os Arqueólogos na interpretação dos dados arqueológicos coletados (DAMOUR, 1865). Em meados de 1967, Faraday, também desenvolveu trabalhos com cerâmicas e vidros com o apoio de técnicas analíticas (LEUTE, 1987).

A partir do século XIX a integração entre a Físico-química favoreceu ainda mais a contribuição aos estudos dos materiais arqueológicos e históricos. Um dos primeiros registros encontrados, mostrando fazer uso destas abordagens, foi a descoberta dos Raios-X em 1965, pelo cientista Wilhem Konrad Roentgen, que realizou a radiografia de uma pintura (GILARDONI, 1977). Estes são alguns dos exemplos vistos na literatura de que o uso de técnicas analíticas empregadas nestes estudos é muito antigo.

Desta forma, é possível notar a importância das técnicas físicas e químicas quanto à determinação das características contidas nos materiais arqueológicos. Estas características de natureza microscópica muitas vezes são indispensáveis à caracterização destes objetos, quando somadas às tipologias. Estas, sobretudo, baseiam-se na classificação dos fragmentos cerâmicos quanto à sua cor, decoração, dureza e textura. Também, quanto às suas formas, como a base, bojo (corpo do artefato) e borda. E ainda, a presença de temperos na pasta cerâmica e motivos (padrões de desenho).

A junção das informações obtidas por meio da interação entre técnicas e abordagens de diferentes áreas do conhecimento permite esclarecer como as antigas sociedades fizeram uso dos inúmeros utensílios que produziram, como também, do ambiente em que estavam inseridos. Assim, é possível inferir quanto à compreensão dos 
processos que se refletem na religião, bem como, as diretrizes que governam aspectos sociais, políticos e econômicos; ou mesmo, padrões e costumes intrínsecos de tais sociedades.

Desde o surgimento dos primeiros trabalhos arqueométricos em 1950, envolvendo estudos com cerâmicas, os principais itens abordados para a sua classificação são: a produção tecnológica, proveniência e uso das cerâmicas pelas sociedades antigas (TITE, 2008).

Para estudar a produção tecnológica de uma cerâmica, é necessário conhecer as técnicas de manufatura, técnicas decorativas, temperos utilizados, tratamento de superfície e temperatura de queima. Já os estudos de proveniência buscam elucidar com base na composição química, a fonte da matéria-prima usada na produção dos artefatos. A presença de depósitos, como cinzas ou resíduos orgânicos encontrados nos artefatos cerâmicos são indicadores do uso dos mesmos pelas sociedades antigas em sua vida cotidiana.

A palavra cerâmica se originou da expressão grega "keramos", que significa “coisa queimada" (RICE, 1987).

Após ser moldada pelo ceramista, é necessário que a pasta cerâmica passe por um processo de secagem, para que finalmente seja submetida a uma alta temperatura. Esta alta temperatura é capaz de atribuir rigidez à pasta, transformando-a num utensílio conforme a função a que será destinado, podendo ser usado como um vaso, vasilha, ou como urna funerária. Além de proporcionar a forma desejada à pasta cerâmica, a temperatura também faz que ocorram modificações em sua estrutura, tanto interna, como externa. Portanto, a temperatura em que a cerâmica foi queimada é um aspecto importante para a sua caracterização.

Do ponto de vista macroscópico, por meio da observação da cor de uma cerâmica arqueológica, é possível estudar as condições em que esta foi queimada. Para o processo da queima, exerce influência o tipo de queima, como também, o combustível utilizado e a quantidade de oxigênio presente durante a atmosfera da queima. Um tipo de queima bastante empregado antigamente para a fabricação de cerâmicas foi a fogueira a céu aberto, que favorece o surgimento rápido de altas temperaturas com grande aproveitamento do combustível no início da combustão (FELICÍSSIMO et al., 2004). Entretanto, na queima realizada em fornos, este tipo de queima rápida não ocorre.

Geologicamente, as cerâmicas são constituídas de argilas, nas quais os elementos químicos alumínio, oxigênio e silício ocorrem na forma de $\mathrm{Al}_{2} \mathrm{O}_{3}$ e $\mathrm{SiO}_{2}$ em quantidades maiores que $10 \%$, perfazendo a composição química básica da cerâmica. No 
entanto, como as argilas são provenientes de rochas sedimentares, as quais sofrem influência da ação do intemperismo, estes elementos podem variar tanto qualitativa, como quantitativamente na composição química da argila. Sendo assim, esta é formada de uma composição indefinida destes elementos. Também, são encontradas impurezas menores, tais como, óxidos de $\mathrm{Na}, \mathrm{Mg}, \mathrm{K}, \mathrm{Ca}$, Ti e Fe em concentrações que variam entre 1000 ppm a $5 \%$.

Já os elementos encontrados em $\mu \mathrm{g} / \mathrm{g}$, representados na composição da argila por concentrações menores, e também, por sua presença ser considerada "acidental", são os que trazem as melhores informações para os estudos arqueométricos (GLASCOCK et al., 2004).

No processo de manufatura de uma cerâmica, inicialmente obtém-se uma pasta de argila e, a esta pasta adicionam-se alguns ingredientes conhecidos por temperos, materiais não-plásticos, ou ainda, antiplásticos para aumentar sua resistência mecânica e térmica (VELDE \& DRUC, 1999). Temperos como as fibras vegetais, conchas, esponjas de água doce, também chamada de cauixí e cacos triturados de cerâmica são usados na produção de cerâmicas arqueológicas (FELICÍSSIMO et al., 2004). Porém, estes temperos podem variar de acordo com a região. No caso da Amazônia, é comum encontrar inclusões de cauixi, cariapé (entrecascas queimadas de árvores do gênero Licania), hematita, cacos triturados de cerâmica e em alguns casos, conchas (MACHADO, 2005).

Visto que as cerâmicas são formadas por uma mistura de argila e temperos que podem ser diferentes conforme o local, e ainda, somando-se estes fatores à influência do intemperismo, é necessário, portanto, considerar a ocorrência de maior variação nos elementos traço de argilas pertencentes a localidades diferentes, do que nos elementos traço de argilas de um mesmo local. Neste caso, cabe aplicar o Postulado da proveniência, que é, a diferença química entre duas fontes de argila. Diferença esta, que deve ser maior entre duas fontes distintas, do que dentro de uma mesma fonte (WEIGAND et al., 1977; GLASCOCK et al., 2004).

Assim, os estudos que objetivam determinar a fonte da matéria-prima usada na fabricação da cerâmica com base em sua assinatura química, partem do princípio de que cerâmicas com concentrações químicas diferentes pertencem, também, a locais diferentes.

Desde a década de 50, as técnicas analíticas utilizadas nos estudos de caracterização química de cerâmicas foram a Espectrometria de Emissão Óptica em Plasma com Acoplamento Indutivo (ICP-OES - Inductively Coupled Plasma with Optical Emission Spectrometry), Análise por Ativação com Nêutrons (NAA - Neutron Activation 
Analysis) (DIAS \& PRUDÊNCIO, 2007) e Fluorescência dos Raios-X (XRF - X Ray Fluorescence) (YOON et al., 2001). Atualmente, a Espectroscopia de Absorção Atômica (AAS -Atomic Absorption Spectroscopy) (TITE, 2008), a Espectrometria de Massa em Plasma com Acoplamento Indutivo (ICP-MS - Inductively Coupled Plasma Mass Spectrometry) (FORTINA et al., 2005), a Emissão de Raios X Induzida por Partículas (PIXE - Proton Induced X Ray Emission) e Emissão de Raios Gama Induzida por Partículas (PIGE - Proton Induced Gamma Ray Emission) (FELICÍSSIMO et al., 2005) são técnicas de análise também bastante empregadas nestes estudos.

AAN é uma técnica nuclear consagrada e de grande aplicabilidade em pesquisas que envolvem objetos históricos. A espectrometria de raios gama é a mais adequada entre outras técnicas analíticas, uma vez que a preparação das amostras é relativamente fácil e permite a determinação de vários elementos simultaneamente, com exatidão e precisão (MUNITA et al., 2003). Os objetos mais estudados por esta técnica incluem obsidianas (IOVINO et al., 2008), basaltos (JAMES et al., 2007), vidros (KULEFF \& DJINGOVA, 2007) e cerâmicas (ASARO \& ADAN-BAYEWITZ, 2007; HARBOTTLE \& HOLMES, 2007; KILIKOGLOU et al., 2007).

Trabalhos sobre tecnologia das cerâmicas têm mostrado a relação entre a temperatura de queima e as transformações ocorridas na sua microestrutura (MIRTI, et al., 2006), bem como em sua composição mineralógica. A técnica analítica mais comumente utilizada para determinar a temperatura de queima da cerâmica relacionada com as mudanças mineralógicas em sua estrutura, é a Difratometria de Raios X (XRD - X Ray Diffraction) (MARTINEAU et al., 2007).

As mudanças em sua microestrutura podem ser observadas diretamente pela Microscopia Eletrônica de Varredura (SEM - Scanning Electron Microscopy) (PACE, et al., 2008). A Espectroscopia de Ressonância Paramagnética (EPR - Electron Paramagnetic Ressonance) (KOUL, 1996); BENSIMON et al., (1999) também é usada para a determinação da temperatura de queima das cerâmicas. Outras técnicas como a Espectroscopia Mössbauer (BUSTAMANTE et al., 2007) e a Espectroscopia Raman (SENDOVA, et al., 2007) também são empregadas em estudos de materiais arqueológicos.

A Ressonância Paramagnética Eletrônica, além de ser usada em Arqueometria, é também uma ferramenta importante em outras áreas científicas, sendo utilizada para investigação molecular e estruturas cristalinas, reações químicas, Física, Medicina e Arqueologia (LEYBOLD, 2000). 
Juntamente com o advento das diversas técnicas analíticas usadas para determinar a fonte da matéria-prima nas cerâmicas, surgiram técnicas de datação, que possibilitaram determinar a idade destes artefatos. Sendo assim, datar os objetos históricos permite relacioná-los temporalmente com as sociedades às quais pertenceram. Inicialmente, a técnica utilizada para datação de amostras arqueológicas foi a datação por ${ }^{14} \mathrm{C}$, desenvolvida por Willard Frank Libby em 1940. Esta técnica conquistou grande importância em Arqueometria, difundindo-se rapidamente por laboratórios de todo o mundo (SPEAKMAN \& GLASCOCK, 2007).

Aitken, no início dos anos 60, desenvolveu a datação por termoluminescência, a qual mostrou-se bastante útil para datação de materiais cerâmicos. A partir deste período, durante os vinte e dois anos seguintes, a datação por TL continuou sendo aplicada a estes materiais, mas na década de 80, a TL começou também a ser aplicada na datação de sedimentos (WINTLE, 2008).

O sítio arqueológico Hatahara, localizado na Amazônia central, forma parte de um cenário adequado para o estudo dos principais aspectos abordados em Arqueometria. Devido ao fato de possuir grande quantidade de cerâmicas e terra preta antropogênica em toda sua extensão, além de apresentar quatro Fases distintas e concomitantes de ocupação pré-colonial, o sítio passou pela identificação, mapeamento e escavação, por meio de várias intervenções arqueológicas.

Estes trabalhos de campo proporcionaram revelar um caráter bastante complexo quanto à formação pré-colonial do sítio Hatahara, sendo pertinente a classificação das cerâmicas arqueológicas encontradas nesta área por meio de abordagens que utilizam técnicas analíticas. Estas se mostram indispensáveis para a determinação da fonte da matéria-prima utilizada na fabricação destes objetos (SANTOS, 2007), além de trazer esclarecimentos quanto ao intercâmbio cultural ou mesmo comercial ocorrido entre as sociedades antigas que ocuparam esta região.

Desta forma, os trabalhos realizados no sítio Hatahara são relevantes para a compreensão de seu processo de formação, na medida em que permite trabalhar também, com outras problemáticas, como, a cronologia destas ocupações, tamanho e duração das mesmas (MACHADO, 2005).

No presente trabalho, 127 fragmentos cerâmicos do sítio arqueológico Hatahara foram analisados. Os resultados das concentrações elementares obtidos por análise por ativação com nêutrons foram interpretados por meio de métodos estatísticos multivariados, como a análise de agrupamento e a análise discriminante, as quais forneceram grupos 
distintos de cerâmicas, confirmando dados culturais e históricos a respeito das antigas sociedades. Também, a aplicação da datação por termoluminescência permitiu extrair informações a respeito da cronologia de tais sociedades, assim como, pelo método da ressonância paramagnética eletrônica foi possível determinar a temperatura de queima de fragmentos cerâmicos pertencentes aos grupos distintos. 


\section{OBJETIVOS}

Os estudos arqueométricos apresentados neste trabalho tiveram o propósito de contribuir aos trabalhos arqueológicos realizados no sítio Hatahara, tendo como objetivo geral a classificação arqueométrica das cerâmicas, para determinar a fonte da matériaprima utilizada na produção destes artefatos. Para isso, foram determinados As, Ba, Ce, Co, Cr, Cs, Eu, Fe, Hf, K, La, Lu, Na, Nd, Rb, Sb, Sc, Sm, Ta, Tb, Th, U, Yb e Zn em 127 fragmentos cerâmicos e em 7 amostras de argilas próximas ao sítio arqueológico Hatahara, por meio do método da análise por ativação com nêutrons (AAN).

Determinou-se também, a idade de três fragmentos cerâmicos por termoluminescência (TL) e a temperatura de queima de quatro fragmentos cerâmicos, por meio do método da ressonância paramagnética eletrônica (RPE). 


\section{3 ÁREA DE ESTUDO}

O mapeamento arqueológico da região da Amazônia central iniciou-se em 1950, pelo engajamento dos arqueólogos Paul Hilbert e Mário Simões do Museu Paraense Emilio Goeldi. Esta atuação na região amazônica representa uma continuação dos trabalhos que se iniciaram em 1949, por Betty Meggers e Clifford Evans, especificamente na ilha de Marajó.

Esses trabalhos tiveram como objetivo mapear, arqueológicamente, a bacia amazônica a fim de classificar a tecnologia das cerâmicas encontradas nesta região. De uma forma bastante genérica, esta classificação formou-se por meio de categorias cronoestilísticas da variabilidade encontrada na cerâmica dos sítios arqueológicos da região amazônica, baseando-se na utilização de um atributo cultural, o antiplástico (tempero). Em alguns casos, considerou-se também a decoração destas cerâmicas (MACHADO, 2005).

$\mathrm{O}$ fato é que os arqueólogos catalogaram as cerâmicas da região apoiando-se no estudo destes atributos utilizados na produção dos artefatos, estabelecendo que estes parâmetros possam revelar características culturais de um mesmo grupo. Sobretudo, quando interagem mais intensamente entre si podem representar uma Fase arqueológica. Atrelado a este conceito, uma Tradição cultural pode ser entendida como Fases arqueológicas que compartilham de um mesmo conjunto de técnicas diagnosticadas pelos atributos (Apud LATINI et al., 2001). Embora estas duas definições estejam inteiramente inseridas no contexto da classificação das cerâmicas, ainda são alvos de intensas discussões em Arqueologia, no que se refere aos seus reais significados.

A partir de então, esta classificação deu origem a três Fases arqueológicas distintas para a Amazônia central, as quais são obtidas como referência de descrição tipológica para as cerâmicas. Até o momento, têm-se a Fase Manacapuru, datada entre o século V e IX d.C., Fase Paredão, datada entre o século VII e início do século XI d.C., ambas associadas à Tradição Borda Incisa, e Fase Guarita, datada entre o século X à XVI d.C., associada à Tradição Policrômica da Amazônia.

A área mapeada desde a década de 50 é a que corresponde, atualmente, à área de pesquisa, à qual estão integrados desde 1995, cerca de cem sítios arqueológicos. Dentre eles, o sítio Hatahara. 
A área de pesquisa ocupa um espaço físico de $900 \mathrm{~km}^{2}$ na Amazônia central, próximo à cidade de Manaus, no Estado do Amazonas. O clima característico é o tropical chuvoso úmido. Também são observadas temperaturas elevadas durante todo o ano, com a ocorrência de altos índices pluviométricos no inverno e baixos índices durante o verão. Esta área é demarcada pelo rio Solimões ao sul, pelo rio Negro ao norte e a leste, e a oeste pelo rio Ariaú. São encontrados dois tipos distintos de ecossistemas: os rios de águas pretas e rios de águas brancas (LIMA et al., 2006).

Os rios de águas pretas são rios que compõem a bacia do rio Negro. São rios que oferecem pequena quantidade de peixes, formando uma região de planície pouco desenvolvida. A paisagem nesta região se caracteriza pelo solo arenoso e inundado por águas ácidas e pobres em nutrientes trazidos por estes rios. Esta região é conhecida como zona de terra firme.

Já os rios de águas brancas compõem a bacia do rio Solimões. Diferentemente dos rios de águas pretas, trata-se de uma região de várzea, formando uma planície sazonalmente alagada e bastante desenvolvida no que se refere à produtividade pesqueira e às práticas agrícolas, devido à fertilização do solo inundado por estas cheias. A várzea, na Amazônia central, é bastante expressiva e chega a atingir alguns quilômetros. É comum encontrar muitos lagos, praias e ilhas.

A definição dos dois tipos de ecossistemas é relevante para a compreensão do estabelecimento das ocupações antrópicas na Amazônia central. Os solos de terra firme, localizados próximos ao rio Negro, possuem baixa fertilidade natural, o que conseqüentemente restringiu a fixação e o desenvolvimento das populações nesta região. Este fato pode ser evidenciado pela menor quantidade de fragmentos arqueológicos encontrados, como também, pela presença de sítios arqueológicos menores em extensão.

Em contrapartida, quando efetuada a comparação com os sítios de várzea, observa-se que estes possuem maior quantidade de fragmentos cerâmicos, como também, se mostram abundantes e extensos, acompanhando o tamanho do rio Solimões.

Tendo em vista a inserção dos sítios nas localidades descritas, encontram-se nos dois contextos geográficos, sítios arqueológicos que apresentam tanto grande quantidade de vestígios arqueológicos, como terra preta antropogênica. A presença destes elementos em sítios arqueológicos como o sítio Açutuba, Cachoeira, Lago Grande, Osvaldo e Hatahara, inseridos nestas regiões, revela o que se denomina de sítios multicomponensiais. Tais sítios fazem parte de trabalhos de escavações sistemáticas desde 1999 e enquadram-se 
num contexto assinalado não somente pela presença de ocupações pré-coloniais distintas, como também, pela ocorrência simultânea destas ocupações (MACHADO, 2005).

Estes registros arqueológicos, bem como, sua disposição e variabilidade nas camadas arqueológicas escavadas destes sítios, fazem com que os mesmos sejam interpretados como o resultado de distintos processos de ocupação, como também, por uma associação entre características naturais e culturais (BINFORD, 1981).

Os trabalhos de intervenção arqueológica têm possibilitado a realização de estudos arqueométricos sobre uma grande quantidade de cerâmicas resgatadas nestas áreas (NUNES et al., 2007a; 2007b; 2008; TOYOTA et al., 2004; 2005). Dos sítios arqueológicos citados, Açutuba, Lago Grande e Hatahara representam sítios multicomponensiais.

\subsection{O sítio arqueológico Hatahara}

O sítio arqueológico Hatahara pertence ao município de Iranduba, a $30 \mathrm{~km}$ a sudoeste de Manaus e compreende uma região localizada na margem esquerda do rio Solimões, próxima à confluência com o rio Negro (REBELLATO, 2007). O sítio é formado por uma fazenda com $160.000 \mathrm{~m}^{2}$ de área (NEVES, 2003), encontrando-se próximo a uma planície na Amazônia central, a várzea, onde esta é pouco extensa.

Por se tratar de uma região onde é tipicamente comum a ocorrência de enchentes sazonais provenientes do rio Solimões, o sítio possui um solo bastante enriquecido pelo depósito de nutrientes trazidos por tais inundações. Espécies como o milho, arroz e feijão, representam as mais cultivadas, sendo também encontradas inúmeras plantações de mamão, mandioca, banana e mangueiras. Conforme pode ser observado na Figura 1, o sítio Hatahara está situado em um barranco, o qual se encontra adjacente a área de várzea (NEVES, 2003).

A localização geográfica do sítio Hatahara na região do rio Solimões favoreceu o desenvolvimento de sociedades antrópicas. Provavelmente, os grupos de pessoas que viveram neste local, além de usufruírem os produtos resultantes das práticas agrícolas, também se beneficiaram da grande disponibilidade e quantidade de peixes oferecida pelo rio Solimões. O sítio Hatahara é marcado por grande extensão que acompanha o rio Solimões, como também, pela presença de grande quantidade de fragmentos cerâmicos. Na realidade, o que chamou atenção para o sítio foi a grande quantidade de material cerâmico, aliada também, a uma grande quantidade de terra preta, que é um tipo de solo rico em matéria orgânica, presente em toda sua superfície. 


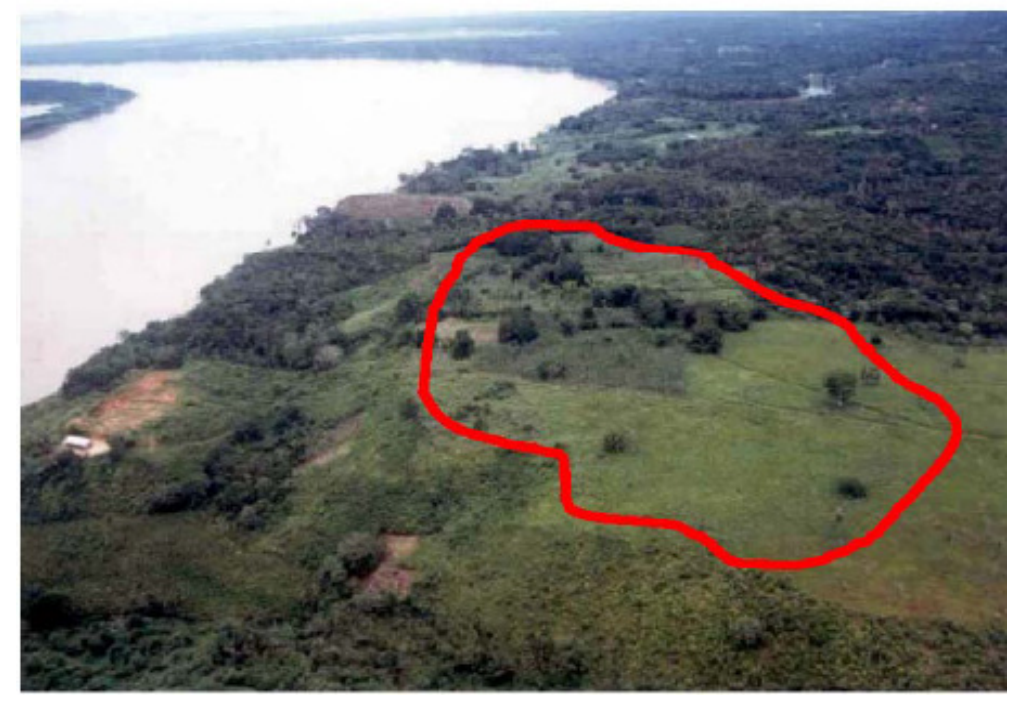

Figura 1. Vista aérea do sítio arqueológico Hatahara (Foto Neves, 1999; sinalização Grosch, 2005).

Quanto à formação da terra preta, acredita-se que sua existência nestas áreas seja decorrente de grande atividade de pessoas, estando, contudo, relacionada com a ocupação humana e seu desenvolvimento, além da presença de fauna e flora aquáticas (NEVES, 2004). Desta forma, a atividade humana foi responsável por causar alteração na composição química da terra preta, na qual é encontrada grande quantidade de fosfato.

Neste âmbito, cabe salientar que a presença de terra preta é mais freqüente em níveis estratigráficos do sítio que correspondem às Fases de ocupações mais recentes. Ou melhor, a terra preta se encontra quase sempre em camadas onde há grande quantidade de fragmentos cerâmicos, mostrando maior ocupação correspondente a estas Fases. Este aspecto é verificado, especialmente, quanto à Fase Paredão.

\subsection{Os Montículos do sítio Hatahara}

Além da cerâmica e terra preta, foram observadas algumas estruturas no terreno que chegam a atingir aproximadamente cerca de $1.50 \mathrm{~m}$ de altura e $3 \mathrm{~m}$ de diâmetro. Consideradas peculiares na formação do sítio Hatahara, tais estruturas receberam o nome de Montículos e estão distribuídos num total de treze. Desde 1999, quando se iniciaram os trabalhos de campo, até o momento, foram escavados dois montículos. O primeiro compreende $12 \mathrm{~m}^{2}$ totalizando seis unidades de escavação nesta área, formando uma trincheira de $9 \mathrm{~m}$ de comprimento por $1 \mathrm{~m}$ de largura (Figura 2). No segundo montículo foram abertas três unidades de escavação com $1 \mathrm{~m}^{2}$ cada. 


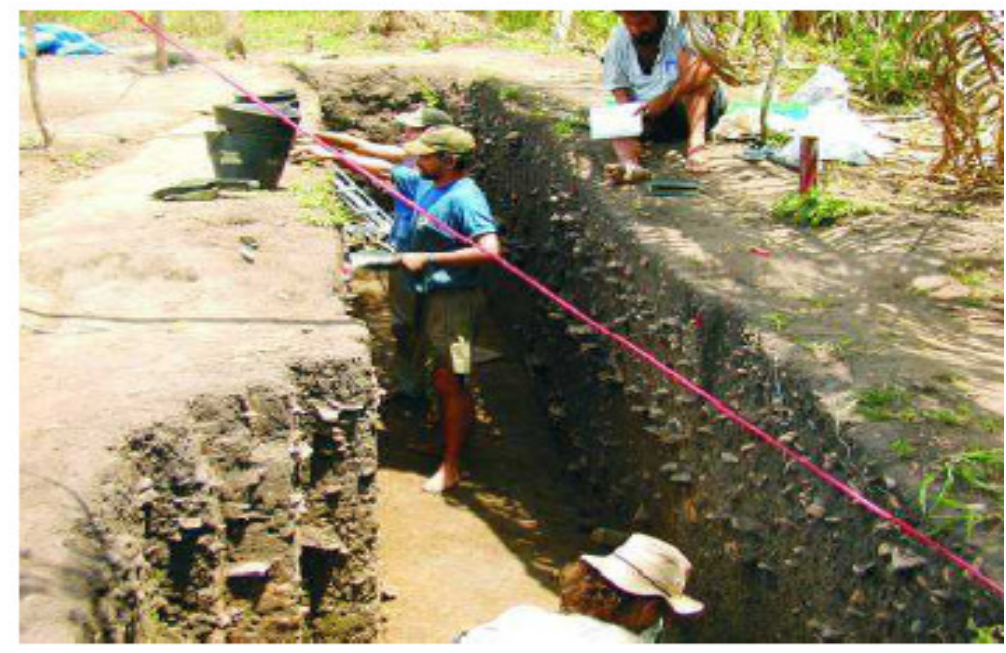

Figura 2. Trincheira aberta em 2002. Foto: Bartone, 2002.

De forma sucinta, o primeiro montículo apresenta cinco camadas distintas do ponto de vista vertical no terreno, iniciando-se da camada mais profunda até a superfície: Camada I - é formada por um solo típico da região, denominado de latossolo amarelo. Essa camada foi pouco escavada, quase não apresenta fragmentos cerâmicos e está relacionada à Fase mais antiga de ocupação no sítio, a Fase Açutuba;

Camada II - composta pela presença de poucas cerâmicas da Fase Manacapuru, com mistura do latossolo amarelo da camada inferior e terra preta da camada acima. É considerada como sendo a primeira a dar origem à terra preta nesta região;

Camada III - composta pela presença de densidade média de cerâmicas pertencentes à Fase Paredão, como também, uma mistura parcial de latossolo amarelo e terra preta, restos de fauna e flora, além de sepultamentos humanos;

Camada IV - composta por mistura de muitas cerâmicas da Fase Paredão e Guarita, terra preta e restos de fauna;

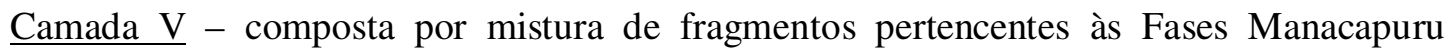
(pouca quantidade), Paredão (pouca quantidade) e Guarita (densidade média), associada à grande quantidade de terra preta.

$\mathrm{Na}$ escavação do segundo montículo também foram estabelecidas cinco camadas arqueológicas, porém, com alguns detalhes a serem apontados. As semelhanças com relação ao primeiro montículo que podem ser mencionadas em sua estratigrafia são a grande quantidade de fragmentos cerâmicos, assim como, grande quantidade de vestígios faunísticos. 
Quanto às diferenças, observou-se que na camada III do segundo montículo, não ocorreram sepultamentos humanos. E na sua camada II foi encontrado apenas latossolo amarelo, o que no primeiro montículo ocorre na sua camada mais profunda. Considerando a disposição dos fragmentos cerâmicos que compõem as camadas estratigráficas destes montículos, bem como, a presença concomitante de cerâmicas relacionadas a Fases distintas nestas camadas, conclui-se que, o sítio Hatahara possui uma formação multicomponensial.

No que se refere à origem dos montículos, ou seja, se todos foram construídos de forma natural ou artificial, não se pode afirmar que todos são artificiais, uma vez que pode haver as duas possibilidades. Quanto à ocorrência artificial, é possível que estas estruturas possam ter desempenhado tanto funções funerárias, em virtude da presença de sepultamentos, como funções de lixeiras, devido ao acúmulo de dejetos domésticos.

Em REBELLATO (2007), foram apresentadas as análises realizadas no solo de áreas próximas aos montículos do sítio Hatahara, visando estudar a ocorrência dos mesmos por meio da determinação dos teores de $\mathrm{Ca}, \mathrm{K}, \mathrm{P}$ e $\mathrm{Mg}$, que são indicadores de nutrientes do solo. Os resultados mostraram que embora altos os teores destes elementos, não foi possível mostrar variação significativa que comprovasse origem artificial. Ou seja, estes solos já possuíam sua constituição definida quando foram utilizados para a construção dos montículos.

Somente com relação a um único montículo, situado isoladamente no extremo leste do sítio, foi possível determinar origem natural, uma vez que foi encontrada próxima a sua localização baixa quantidade de material cerâmico, como também, baixas concentrações de nutrientes do solo. No extremo oeste do sítio, com relação a outro montículo isolado, foram encontrados altos níveis de $\mathrm{K}$, devido a cinzas de fogueiras; $\mathrm{Mg}$, em virtude de dejetos vegetais e $\mathrm{Ca}$, pela presença de ossos. Com relação aos montículos localizados na parte central do sítio, foi encontrada grande quantidade de material arqueológico e terra preta, o que permite relacionar estes montículos à presença das atividades humanas principalmente nesta área.

O mesmo não pode ser afirmado com relação a outros montículos, que refletem uma relação com estruturas funerárias ou lixeira. $\mathrm{O}$ fato é que tanto a presença de dejetos, como de sepultamentos, elevam os níveis de $\mathrm{C}, \mathrm{Ca}, \mathrm{N}$ e $\mathrm{P}$.

Portanto, o sítio Hatahara é marcado por complexas variáveis envolvidas no processo do entendimento de sua formação pré-colonial. Ao examinar o arco que percorre desde que localizado em 1997, com subseqüentes escavações, até o início da aplicação de 
metodologias diversas associadas a análises provenientes das ciências da terra ao estudo da cerâmica, bem como à sua disposição na estratigrafia dos montículos, observa-se que, gradualmente, os trabalhos e questões relacionadas à ocupação no sítio passam por constante refinamento, exigindo continuidade das análises no sentido de investigação das componentes que participam e se articulam dentro deste processo. 


\section{ASPECTOS TEÓRICOS DAS TÉCNICAS ANALÍTICAS UTILIZADAS}

\subsection{Análise por ativação com nêutrons (AAN)}

A análise por ativação com nêutrons surgiu na década de 30. Desenvolvida com base nos fundamentos da Física Nuclear e da Química Inorgânica, esta técnica analítica converteu-se com o passar dos anos em um instrumento bastante útil para várias áreas da pesquisa.

A primeira ativação nuclear ocorreu em 1934, quando Irene Juliot Curie e Fréderic Joliot bombardearam os núcleos atômicos de alumínio, boro e magnésio com partículas alfa, produzindo radioisótopos artificiais.

Mas, foi em 1936 que Georg Hevesy (1885-1966) e sua estudante Hilde Levy (1909-2003) verificaram que ao irradiar com uma fonte de $\mathrm{Ra}(\mathrm{Be})$, óxidos de terras raras, estes ficavam radioativos. Então, perceberam que os elementos em uma amostra podem ser usados para análise qualitativa e quantitativa. Este episódio foi o marco do descobrimento da análise por ativação com nêutrons e em 1943, Hevesy e Levy ganharam o Prêmio Nobel de Química pelo desenvolvimento do método da análise (MUNITA, 2005).

A partir de então, a técnica começou a se difundir em pequenos laboratórios e após a Segunda Guerra, adquiriu grande importância nos Estados Unidos, que se tornou o grande centro de aprendizagem para cientistas de várias partes do mundo.

Em Arqueologia, a primeira aplicação do método da análise por ativação com nêutrons ocorreu em 1954, quando Robert Oppenheimer (na época, Diretor do Instituto de Estudos avançados da Universidade de Princeton) sugeriu aos seus colegas R.W. Dodson e E. Sayre a possibilidade de usar a AAN para estudos da determinação da fonte da matériaprima usada na produção de cerâmicas arqueológicas de uma pequena coleção de cerâmicas do Mediterrâneo.

Em 1957, foram publicados os resultados destas análises por Sayre e Dodson, mostrando diferença entre as amostras de diferentes regiões, porém, similaridade para as cerâmicas da mesma região (SPEAKMAN \& GLASCOCK, 2007).

Dez anos depois, em 1967, um grupo de pesquisadores da NASA foi enviado à Universidade de Cornell em Nova York para realizar estudos sobre métodos para 
determinação de elementos traço em minerais e materiais geológicos. Dentro destes métodos, destacou-se a análise por ativação com nêutrons, que passou a ser empregada como técnica sensível para determinação destes elementos (TRAVESI, 1975). Na década de 70, houve grande incentivo ao desenvolvimento da análise por ativação com nêutrons, com a invenção dos detectores de alta resolução de germânio.

\section{AAN - Princípio físico}

A análise por ativação com nêutrons se baseia na medida da radioatividade induzida nos elementos da amostra, pela irradiação com nêutrons. Tal fenômeno ocorre por meio de uma reação nuclear, resultando na formação de radioisótopos. Estes irão emitir partículas para se estabilizarem dando origem ao processo de decaimento radioativo. Durante o decaimento as partículas que estão sendo emitidas possuem energia, que será medida em um detector.

Para este trabalho, as partículas de interesse são os raios gama, os quais são emitidos de acordo com a meia-vida de cada radioisótopo, podendo ela ser curta, intermediária ou longa, definindo desta forma, seu tempo de decaimento. Esta meia-vida é definida como o tempo em que o número de átomos radioativos se reduzirá à metade. Desta maneira, já que a energia dos raios gama e meia-vida são parâmetros característicos para cada radioisótopo, é possível realizar a determinação qualitativa e quantitativa dos elementos presentes nas amostras.

A seqüência de eventos que ocorrem numa reação nuclear típica utilizada na análise por ativação com nêutrons inicia quando um nêutron interage com um núcleo alvo por meio de uma colisão inelástica, formando um núcleo composto num estado excitado. A energia de excitação do núcleo composto é devida à energia de ligação do nêutron com o núcleo. O núcleo composto formado quase que, instantaneamente, adquire uma configuração mais estável por meio da emissão de raios gama prontos característicos.

Em muitos casos, esta nova configuração produz um núcleo radioativo que também sofre um relaxamento por emissão de um ou mais raios gama de decaimento, mas a uma velocidade mais lenta, de acordo com o tempo de meia-vida do núcleo radioativo. Esta seqüência de eventos é ilustrada na Figura 3 (IAEA, 1990). 


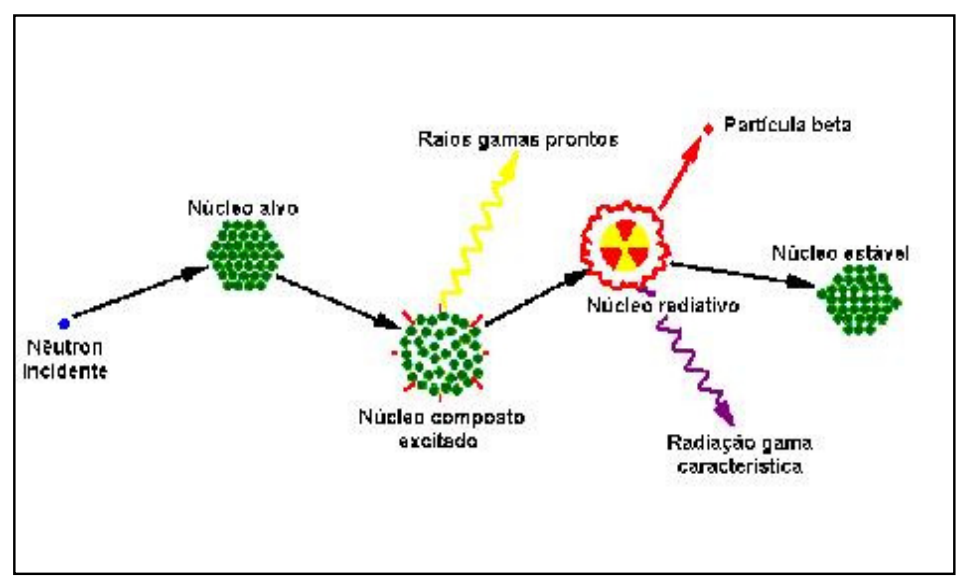

Figura 3. Seqüência de eventos que ocorrem em análise por ativação com nêutrons.

Os reatores nucleares são as fontes de nêutrons utilizadas em análise por ativação com nêutrons. Para este trabalho foi usado o reator nuclear IEA-R1 do Instituto de Pesquisas Energéticas e Nucleares - IPEN-CNEN/SP. O núcleo deste reator está imerso em uma piscina, com dispositivos especiais, como tubos e canais para irradiação das amostras.

Durante o funcionamento do reator, ocorre o processo de fissão nuclear, no qual os nêutrons são produzidos com fluxo que pode variar entre $10^{11}$ a $10^{16} \mathrm{~cm}^{-2} \mathrm{~s}^{-1}$. Este fluxo é conveniente em análise por ativação com nêutrons, de modo que a ocorrência destas reações nucleares depende da energia do nêutron incidente e do núcleo bombardeado.

$\mathrm{O}$ processo de fissão nuclear inicia-se quando o material físsil, ${ }^{235} \mathrm{U}$, é bombardeado por um nêutron e sofre um processo de captura de nêutrons, produzindo um núcleo composto que imediatamente se divide em dois núcleos radioativos, chamados de produtos de fissão.

A reação libera nêutrons (n) e grande quantidade de energia (200 MeV), conforme exposto na equação 1. Em cada reação de fissão, os nêutrons produzidos produzem novas fissões capazes de produzir uma reação em cadeia, que, controlada, mantém o reator em funcionamento com alto fluxo de nêutrons usados para irradiação das amostras (TRAVESI, 1975).

$$
{ }^{235} U+{ }_{0}^{1} n \rightarrow\left({ }^{236} U\right) \rightarrow P . F .+{ }_{0}^{1} n+Q
$$




\subsubsection{Reação com nêutrons}

A reação que ocorre com os nêutrons em análise por ativação é chamada de captura de nêutrons e está representada na equação 2:

$$
{ }_{19}^{39} K+{ }_{0}^{1} n \rightarrow{ }_{19}^{40} K+\gamma
$$

Inicialmente, o núcleo $\left({ }_{19}^{39} K\right)$ captura um nêutron (n) produzindo um radioisótopo deste núcleo $\left({ }_{19}^{40} K\right)$, mas com número de massa maior devido à sua interação com o nêutron. Devido a esta interação, o radioisótopo é formado com alta energia e desta forma, libera raios gama $(\gamma)$ estabilizando-se.

Então, a mesma reação (2) pode ser escrita de forma abreviada:

$$
{ }_{19}^{39} K(n, \gamma){ }_{19}^{40} K
$$

onde:

${ }_{19}^{39} K$ = isótopo do elemento potássio $(\mathrm{K})$;

$n=$ nêutron (partícula incidente);

$\gamma=$ raio gama (partícula emitida);

${ }_{19}^{40} K$ =radioisótopo do elemento potássio (núcleo radioativo).

Para que uma reação nuclear ocorra, é necessário considerar a secção de choque da reação, $\sigma$. A secção de choque é uma área da superfície do núcleo atômico que deve ser atingida pela partícula incidente, sendo o seu valor dependente do núcleo atômico e de sua energia, a qual é transferida ao núcleo composto (KELLER, 1981; KELLNER et al., 1998). De forma genérica, a secção de choque pode ser definida como a medida da probabilidade de uma reação nuclear ocorrer.

A determinação das concentrações elementares das amostras analisadas pode ser realizada por meio de dois métodos: o método absoluto e o método relativo. 


\section{Método absoluto}

A determinação das concentrações elementares pelo método absoluto pode ser realizada por meio da medida direta das energias e da intensidade da radiação emitida. Neste caso, é necessário medir com precisão a atividade induzida nos átomos da amostra em estudo pela absorção de nêutrons. Sendo assim, a atividade pode ser determinada considerando-se que, na análise, estão envolvidos os seguintes processos:

a) O primeiro é a formação do radioisótopo, a partir da irradiação do núcleo com um nêutron, representado por meio de uma reação nuclear:

$$
C(n, \gamma) \rightarrow{ }^{*} d
$$

(b) Em seguida, tem-se o decaimento do radioisótopo:

$$
{ }^{*} d \rightarrow e
$$

O número de radioisótopos formados * $d$ é proporcional aos parâmetros: número de átomos do núcleo alvo $\left(N_{a}\right)$, fluxo de nêutrons $(\phi)$ e à secção de choque $(\sigma)$.

Sendo assim, a formação do radioisótopo ${ }^{*} d$ em função do tempo pode ser expressa pela relação:

$$
d \frac{N_{d}}{d_{t}}=N_{a} \phi \sigma
$$

onde:

$N_{a}=$ número de átomos do núcleo alvo $a$;

$N_{d}=$ número de átomos do radioisótopo $d$;

$\phi=$ fluxo de nêutrons em $\mathrm{cm}^{-2} \mathrm{~s}^{-1}$;

$\sigma=$ secção de choque, em $\mathrm{cm}^{2}$.

O decaimento do radioisótopo ${ }^{*} d$ ocorre a uma taxa de $\lambda_{d} N_{d}$, portanto a formação total de * $d$ será dada pela equação diferencial de Leibnitz: 


$$
d \frac{N_{d}}{d_{t}}=N_{a} \phi \sigma-\lambda_{d} N_{d}
$$

onde:

$\lambda_{d}=$ constante de decaimento do radioisótopo.

A solução desta diferencial é a seguinte equação:

$$
N_{d}=\frac{\left\{N_{a} \phi \sigma\left[1-e^{-\lambda_{d} t_{i}}\right]+N_{d 0} e^{-\lambda_{d} t_{i}}\right\}}{\lambda_{d}}
$$

Considerando que $t_{i}$ é o tempo de irradiação e considerando que nenhum * $d$ foi originado antes da irradiação $\left(t_{i}=0\right.$, portanto $\left.N_{d 0}=0\right)$, a equação (8) pode ser expressa:

$$
N_{d}=\frac{N_{a} \phi \sigma\left[1-e^{-\lambda_{d} t_{i}}\right]}{\lambda_{d}}
$$

Por meio da equação (9) é possível calcular o número de átomos radioativos originados $\left(N_{d}\right)$ em um tempo de irradiação $\left(t_{i}\right)$, desde que sejam conhecidos os parâmetros $\lambda_{d}, N_{a}, \phi$ e $\sigma$.

Em termos de desintegrações por segundo $(d p s)$, tem-se a atividade $D$ do radioisótopo que é expressa por:

$$
D=\lambda_{d} N_{d}
$$

Após um tempo $t_{i}$, no final da irradiação, e substituindo-se a equação (9) em (10), obtém-se:

$$
D=N_{a} \phi \sigma\left[1-e^{-\lambda_{d} t_{i}}\right]
$$

E $A$, é a atividade média experimental:

$$
A=z D
$$


onde:

$z=$ coeficiente de detecção.

Substituindo a equação (11) em (12), obtém-se a expressão para calcular a atividade após um certo tempo de irradiação $\left(t_{i}\right)$ :

$$
A=z N \phi \sigma\left[1-e^{-\lambda t_{i}}\right]
$$

onde:

$\lambda=\frac{\ln 2}{T_{1 / 2}} ;$

$T_{1 / 2}=$ meia vida do radioisótopo.

então:

$-\lambda t_{i}=-0,693 \mathrm{t}_{\mathrm{i}} / T_{1 / 2} \mathrm{e}$

Pela substituição do valor de $\lambda$ na equação (13) tem-se:

$$
A=z N \phi \sigma\left[1-e^{\frac{-0,693 t_{i}}{T_{1 / 2}}}\right]
$$

A equação (14) representa a atividade em função do número de átomos. Desta forma, é possível calcular a massa de um determinado elemento presente na amostra, substituindo $N$ na fórmula do número de Avogadro:

$$
N=\frac{\left(N_{A V} m f\right)}{M}
$$

onde:

$N_{A V}=$ número de Avogadro;

$m=$ massa do elemento na amostra;

$f=$ abundância isotópica do núcleo alvo;

$M=$ massa atômica do elemento. 
Por meio da substituição da equação (15) em (14), obtém-se a fórmula para o cálculo da atividade absoluta da massa de um elemento a partir de um certo tempo $t_{i}$ de irradiação:

$$
A=\frac{z \phi \sigma N_{A V} m f\left[1-e^{\frac{-0,693 t_{i}}{T_{1 / 2}}}\right]}{M}
$$

Desse modo, de acordo com a equação (16), podemos determinar a massa (m) de um dado elemento, desde que sejam conhecidos $f, \sigma, \theta$, meia-vida e sua massa atômica $(M)$. São considerados constantes $N_{A V}, f, \lambda$ e $\sigma$; contudo, podem variar, visto que o fluxo de nêutrons pode sofrer alterações, como também, a secção de choque que varia com a energia do nêutron incidente.

Neste caso, a precisão da determinação dependerá da energia da radiação detectada e das condições da medida. Portanto, a atividade absoluta da amostra, é extremamente sensível à eficiência de contagem, devendo-se levar em consideração, por exemplo, parâmetros como a geometria, tempo morto, etc. $\mathrm{O}$ método absoluto tem sido utilizado com pouca freqüência, tendo em vista que a sua precisão é muito baixa.

\section{Método relativo}

O método relativo em análise por ativação foi o método utilizado neste trabalho e é também conhecido por método comparativo. Neste caso, a amostra e o padrão são irradiados juntos e em condições muito próximas, com o objetivo de evitar erros devido à heterogeneidade do fluxo de nêutrons. Da mesma forma, as medidas das atividades devem ser realizadas em condições também idênticas, de modo que a precisão do método não seja afetada (BALLA et al., 2004). Isto significa que é feita a comparação entre a atividade da amostra em estudo $\left(A_{a}\right)$, com a atividade de um material, denominado de padrão $\left(A_{p}\right)$, cuja concentração elementar é conhecida.

Considerando estas condições, pode-se escrever a fórmula da atividade absoluta (16) para um mesmo elemento da amostra e padrão:

$$
A_{a}=\frac{z \phi \sigma N_{A V} m_{a} f\left[1-e^{\frac{-0,693 t_{i}}{T_{1 / 2}}}\right]}{M}
$$




$$
A_{p}=\frac{z \phi \sigma N_{A V} m_{p} f\left[1-e^{\frac{-0,693 t_{i}}{T_{1 / 2}}}\right]}{M}
$$

onde:

$a=$ amostra;

$p=$ padrão;

$A_{a}$ e $A_{p}=$ atividades da amostra e padrão, considerando um tempo de decaimento $t_{d}=0$.

Dividindo-se a equação (17) pela equação (18):

$$
\frac{A_{a}}{A_{p}}=\frac{m_{a}}{m_{p}}
$$

onde:

$m_{a}=$ massa do elemento na amostra;

$m_{p}=$ massa do elemento no padrão.

Deve-se considerar que a amostra e padrão são medidos em diferentes tempos de decaimento, sendo $t$ o tempo de decaimento (FRIEDLANDER et al, 1981):

$$
A=A_{0} e^{-\lambda t}
$$

Substituindo a relação (20) em (19), obtém-se:

$$
m_{a}=\frac{m_{p \cdot} A_{a} \cdot e^{\lambda\left(t_{a}-t_{p}\right)}}{A_{p}}
$$

onde:

$\lambda=\frac{0,693}{T_{1 / 2}} ;$

$t_{a}$ e $t_{p}=$ tempos de decaimento da amostra e padrão;

$A_{a}=$ contagens do radioisótopo da amostra para tempo de decaimento $t_{a}$;

$A_{p}=$ contagens do mesmo radioisótopo no padrão para tempo de decaimento $\mathrm{t}_{\mathrm{p}}$. 
Sabendo que $C_{a}$ é a concentração do elemento na amostra:

$$
C_{a}=\frac{m_{a}}{M_{a}}
$$

onde:

$M_{a}=$ massa total da amostra.

Pela substituição de $m_{a}$ da equação (22) na equação (21), obtém-se a fórmula:

$$
C_{a}=\frac{A_{a} m_{p} e^{\frac{0,693\left(t_{a}-t_{p}\right)}{T_{1 / 2}}}}{A_{p} M_{a}}
$$

A equação (23) é utilizada em análise por ativação com nêutrons para o cálculo das concentrações dos elementos. Pode-se observar a partir da equação (23), que todos os parâmetros que podem influenciar nas atividades do material em estudo e padrão, se cancelam, tornando a análise independente destes fatores.

O método que tem sido utilizado mais comumente é o método relativo, uma vez que os fatores que variam no método absoluto (fluxo, tempo de irradiação, secção de choque, eficiência de contagem) são praticamente desprezíveis (MUNITA, 2005).

\subsection{Termoluminescência (TL)}

A datação por Termoluminescência (TL) é uma técnica muito utilizada em estudos arqueoméricos para determinação da idade de fragmentos cerâmicos encontrados em sítios arqueológicos. Sua aplicação a estes materiais teve início há cerca de 50 anos, quando foi desenvolvida por Martin Aitken na década de 60 (WINTLE, 2008).

$\mathrm{O} \mathrm{SiO}_{2}$ é um dos minerais mais abundantes na crosta terrestre, apresentando-se na forma de um monocristal de tamanho variado, de alguns milímetros a metros (o maior encontrado na região central do Brasil pesa 64 toneladas) e na forma de grãos de micrômetros a milímetros formando sedimentos ou misturados na argila e outros solos. $\mathrm{O}$ feldspato também se encontra em diversas partes da crosta terrestre, porém, em muito menor proporção do que o quartzo. Isto significa que quando a argila é usada para a 
produção de cerâmicas, estas conterão necessariamente considerável porcentagem de grãos de quartzo e muito pequena de feldspato (MITTANI, 1998).

Os materiais cerâmicos quando aquecidos, após serem expostos à radiação ionizante apresentam a propriedade de emitir luz. Devido à absorção de energia por estes materiais a partir destas radiações ionizantes, há emissão induzida de luz e este fenômeno é conhecido como termoluminescência (TL). Esta propriedade é exibida pela maioria dos cristais naturais, como o quartzo e o feldspato.

A primeira observação sobre emissão termoluminescente foi feita por Robert Boyle em 1663, quando notou que cristais de diamante emitiam luz após serem submetidos a um aquecimento. Até 1950, a Termoluminescência era utilizada para realizar medidas de exposição à radiação nuclear, com a dosimetria de isótopos radioativos. F. Daniels sugeriu em 1953, a datação de rochas por meio da termoluminescência e o uso desta técnica estendeu-se também a datação de peças arqueológicas (AITKEN et al., 1968). Simultaneamente, Randal e Wilks, desenvolviam um modelo matemático para explicar o fenômeno das curvas de emissões termoluminescentes.

No Brasil, as primeiras datações por TL foram feitas por Szmuk \& Watanabe em 1971, com a datação de vasos cerâmicos e urnas funerárias encontradas no interior do Estado de São Paulo (SZMUK \& WATANABE, 1971; MATSUOKA et al., 1984).

Em 1969, tem-se no Brasil, a primeira Dissertação de Mestrado na área de datação, sob Orientação do Prof. Dr. Shigueo Watanabe. Atualmente, muitos materiais resgatados de vários sítios arqueológicos em todo o Brasil são datados por TL no Laboratório de Vidros e Datações (LVD) da Faculdade de Tecnologia (FATEC/SP) (TATUMI et al., 2003; WATANABE et al., 2005).

\section{TL - Princípio físico}

No momento em que a radiação ionizante incide sobre o material, transfere elétrons de uma região chamada de banda de valência (BV) para uma outra banda, a banda de condução (BC). Na tentativa de retornar para a banda de valência, uma parte dos elétrons pode ficar retida em níveis de energia denominados de armadilhas de elétrons. Estes níveis de energia são ocasionados pela existência dos chamados defeitos na rede cristalina do cristal (KITTEL, 1978; LOPEZ et al., 1988), os quais estão localizados numa outra banda, chamada banda proibida (BP). Devido à saída do elétron da banda de valência, forma-se uma armadilha de buraco. 
Então, na banda de condução há elétrons móveis que podem ser atraídos por uma armadilha de elétrons, tornando-se aprisionados nestas regiões. Quando é aplicada uma fonte térmica sobre o material, estes elétrons aprisionados recebem uma quantidade de energia que os "liberta" desta armadilha, podendo se recombinar com um buraco no chamado centro de recombinação, emitindo neste momento, a luz TL.

Estas transições eletrônicas podem ser observadas na Figura 4 que mostra a radiação ionizante sendo absorvida, gerando um par elétron-buraco e promovendo um elétron à banda de condução (BC). Elétron e buraco se difundem pela rede cristalina até se recombinarem com carga oposta ou serem aprisionadas em defeitos existentes na banda proibida (na Figura 4 localiza-se entre a banda de condução e a banda de valência). Quando a carga local é positiva, as armadilhas são atrativas para elétrons. E quando a carga local é negativa, as armadilhas são atrativas para buracos.

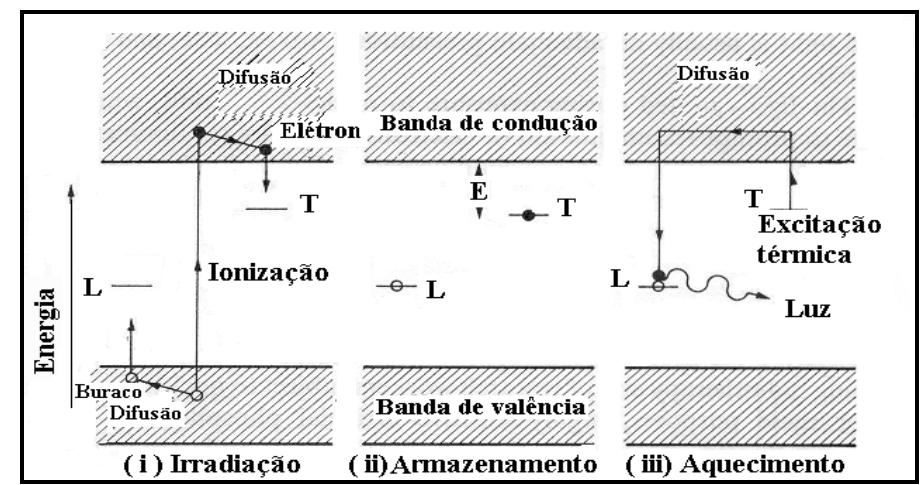

Figura 4. Esquema da emissão de termoluminescência por um cristal.

Freqüentemente, as cerâmicas antigas são encontradas subterrâneas, por isso, a partir do momento que são enterradas recebem radiação ionizante da radioatividade natural da terra vizinha.

Portanto, a intensidade do sinal de TL da amostra tem relação direta com o período de exposição a um fluxo de radiação nuclear natural proveniente dos elementos radioativos presentes no solo e na própria cerâmica, além de uma parcela de radiação cósmica. Quanto maior a permanência do cristal no solo, maior a intensidade do sinal $\mathrm{T}$ acumulado. Os principais elementos radioativos que fornecem a energia necessária para o sinal de TL são Th, U e K, presentes no local em que foi encontrada a cerâmica.

Quando a argila moldada é fortemente aquecida para dar origem a uma cerâmica, qualquer termoluminescência induzida nos grãos de quartzo e feldspato nela 
contidos é totalmente eliminada. Este é o marco zero da datação. A partir desse momento a radiação natural (aqui se incluem os raios cósmicos) passa a induzir a TL. Sendo assim, se for determinada a TL acumulada durante o tempo que a cerâmica esteve no subsolo, conhecendo a TL induzida nos grãos de quartzo por unidade de dose de radiação, pode ser calculada a dose de radiação total (acumulada) (MITTANI, 1998):

$$
D_{a c}=(T L) \text { acumulada / (TL) por unidade de dose }
$$

Assim, os métodos de datação por TL buscam determinar a dose de radiação acumulada pela amostra ao longo dos anos que se passaram após o processo de queima. Esta dose é chamada de Paleodose $(\mathrm{P})$ e conhecendo-se a taxa à qual o material foi irradiado, comumente chamada de Dose Anual (D.A), obtém-se diretamente a idade (I) da amostra por meio da seguinte relação:

$$
I=\frac{P}{D A}
$$

onde:

$P=$ Paleodose (Gy);

$D A=$ Dose anual (Gy/ano).

\subsection{Ressonância paramagnética eletrônica (RPE)}

A temperatura de queima de uma cerâmica proporciona a base para o entendimento da tecnologia empregada pelos povos antigos na fabricação destes utensílios. Vários métodos de analises térmicas como TL, LOE e RPE são usados para determinar a temperatura de queima de um fragmento cerâmico, baseando-se, sobretudo, nos estudos da mudança das características físicas que ocorrem quando a argila sofreu o aquecimento. Genericamente, a técnica da Ressonância paramagnética eletrônica baseia-se na medida do campo magnético no qual centros paramagnéticos entram em ressonância com uma radiação monocromática com freqüência na faixa das microondas.

\section{RPE - Princípio físico}

Quando o spin eletrônico da última camada de um íon dentro de um cristal está sobre a ação de um campo magnético externo, a direção do spin inicialmente em direção 
aleatória alinha-se conforme a direção do campo magnético, ficando o spin paralelo ao campo ou contrário a este. Estas duas direções são energeticamente diferentes, isto é, temos dois estados para o spin. A diferença de energia entre estes dois estados do spin devido ao campo magnético externo é conhecida como efeito Zeeman e depende do campo magnético externo $M$, e do momento magnético do elétron $g \beta M$ (MITTANI, 2003):

$$
E_{Z}=g \beta M
$$

onde:

$g=$ fator espectroscópico ou fator eletrônico para o elétron livre;

$\beta$ = magnéton de Bohr;

$M=$ o número quântico magnético $M=1 / 2$ e $M=-1 / 2$ para o caso quando $S=1 / 2$.

O fator espectroscópico $g$ tem valor de 2.0023 para o elétron livre, mas pode variar, dependendo da molécula na qual o elétron se encontra. Elétrons em um estado de menor energia, $-1 / 2$, podem ser excitados a estados de maior energia, $+1 / 2$ por radiação eletromagnética de freqüência apropriada satisfazendo a condição:

$$
h v=g \beta M
$$

A ressonância ocorre quando a direção do spin muda de um estado para o outro, devido à absorção da energia de uma onda eletromagnética igual à diferença dos dois estados de energia do spin.

\subsection{Métodos estatísticos}

A aplicação da Estatística aos dados arqueológicos já tinha sido sugerida em 1975. O emprego da Estatística, assim como da similaridade como forma de diferenciar grupos de artefatos faz com que a quantidade, aos poucos, se transforme em qualidade (CARANDINI, 1975).

As técnicas estatísticas multivariadas representam ferramentas bastante poderosas para a interpretação de dados arqueológicos, sendo amplamente usadas em Arqueometria (MOMMSEN et al., 1988; BAXTER, 2006). Estas técnicas, nãosupervisionadas e supervisionadas, como são conhecidas, vêm acompanhadas de modernos 
programas computacionais, que fornecem visualização e interpretação bastante eficiente no que se refere ao tratamento de dados arqueológicos. Tendo em vista que em estudos com amostras arqueológicas normalmente é gerado um grande conjunto de dados de concentrações elementares, é necessária a aplicação de técnicas estatísticas multivariadas, as quais se mostram mais adequadas nestes casos, em relação às técnicas estatísticas convencionais.

Por meio da aplicação destas técnicas aos dados de concentrações elementares dos fragmentos cerâmicos, é possível estudar a fonte da matéria-prima utilizada na fabricação dos mesmos. Para isso, inicialmente procura-se investigar quantos grupos distintos de cerâmicas estão envolvidos nas análises para em seguida, identificar e quantificar as similaridades e diferenças entre os grupos de cerâmicas estudadas.

Os estudos de caracterização de artefatos e a determinação da fonte de matériaprima usada na produção dos mesmos tornam possível confirmar características culturais e históricas dos povos antigos, ajudando os Arqueólogos a entender melhor complexas formas de desenvolvimento entre estas sociedades, interações sociais e intercâmbios comerciais (BUSTAMANTE et al., 2007).

Neste trabalho a Análise de conglomerado e a Análise discriminante foram as técnicas estatísticas multivariadas utilizadas. A primeira refere-se ao que na literatura é conhecida como técnica estatística não-supervisionada. Os dados de concentrações elementares são submetidos à análise não-supervisionada com o objetivo de identificar previamente uma estrutura desconhecida nestes dados, ou seja, o número de grupos distintos de cerâmicas.

O objetivo é conhecer quantas fontes distintas de matéria-prima foram usadas. Feito isso, a estrutura, depois de conhecida, está pronta para ser submetida à análise discriminante. Esta, por ser uma análise minuciosa, torna possível alocar amostras de cerâmicas nos grupos, como também, identificar características que no final da aplicação da análise, são associadas às classificações arqueológicas das cerâmicas.

\subsubsection{Análise de conglomerado}

A análise de conglomerado, análise de agrupamentos ou "cluster analysis" é uma técnica estatística multivariada utilizada para produzir padrões de comportamento em resultados experimentais por meio da formação de grupos homogêneos de amostras. $\mathrm{O}$ objetivo principal da técnica é agrupar as amostras semelhantes de acordo com suas características. A análise de conglomerado tem sucedida aplicabilidade em várias áreas do 
conhecimento. Situações como, conhecer o perfil dos consumidores de uma empresa, ou até mesmo conhecer a organização espacial de um grupo de pessoas que habitou um sítio arqueológico, são questões que podem ser esclarecidas com aplicação da análise de conglomerado.

No primeiro exemplo, deseja-se encontrar respostas como: os consumidores têm um perfil homogêneo em relação às características levantadas? Se o perfil não é homogêneo, é possível identificar grupos homogêneos? No segundo exemplo é necessário ter uma idéia mais precisa da dispersão das peças. Há locais com alta concentração de peças? Quantos? Com base nestas questões, a seguir são identificadas as etapas da aplicação de uma análise de agrupamentos:

1) Escolha do critério de parecença. Nesta etapa, deve-se definir o critério que será utilizado na determinação dos grupos; no caso, a proximidade dos pontos (distância euclidiana entre as observações). As medidas de parecença têm um papel central nos algoritmos de agrupamentos.

2) Definição do número de grupos. O número de grupos pode ser definido $a$ priori, por meio de algum conhecimento que se tenha sobre os dados (por exemplo, se os dados referem-se a características de espécimes de insetos e sabe-se que existem três espécies, o pesquisador pode forçar a criação de três grupos), conveniência de análise (ao segmentar um mercado, o pesquisador pode, por simplicidade estar interessado na construção de apenas dois agrupamentos) ou ainda pode ser definido posteriormente com base nos resultados da análise.

3) Formação dos grupos. Nesta etapa deve-se definir o algoritmo que será utilizado na identificação dos grupos.

4) Validação do agrupamento. Deve-se garantir que de fato as variáveis têm comportamento diferenciado nos diversos grupos. Nesta etapa, é comum supor que cada grupo seja uma amostra aleatória de alguma subpopulação.

5) Interpretação dos grupos. Ao final do processo de formação de grupos é importante caracterizar os grupos formados.

Para formação dos grupos é necessário adotar critérios bem definidos. Um critério razoável para formação dos grupos é considerar a proximidade entre os pontos, visto que pontos que estão próximos representam regiões cujas amostras são similares. Logo, esta técnica exige a definição de um coeficiente de parecença para indicar a proximidade entre as amostras. 
$\mathrm{Na}$ literatura são citadas duas medidas de parecença: medidas de similaridades (quanto maiores os valores mais similares são as amostras) e medidas de dissimilaridades (quanto maior, menor a similaridade entre as amostras) (JOHNSON \& WICHERN, 1992). A partir da definição do critério de parecença é construída uma matriz de parecença como ponto de partida do método de agrupamento. Os elementos da matriz de similaridade ou dissimilaridades são determinados, geralmente a partir das diversas medidas de distância (MASSART \& KAUFMAN, 1983). Entre as medidas de distância a mais utilizada é a distância Euclidiana. Em um espaço p-dimensional, a distância Euclidiana é dada pela equação:

$$
d\left(x_{A}, X_{B}\right)=\sqrt{\left(x_{A_{1}}-X_{B_{1}}\right)^{2}+\left(x_{A_{2}}-X_{B_{2}}\right)^{2}+\cdots+\left(x_{A_{p}}-X_{B_{p}}\right)^{2}}=\sqrt{\left(\tilde{X}_{X}-\tilde{X}_{B}\right)^{T}\left(\tilde{X}_{A}-\tilde{X}_{B}\right)^{2}}
$$

onde:

$\tilde{X}_{A}$ e $\tilde{X}_{B}$ representam os vetores das amostras.

Após a construção da matriz de parecença o próximo passo da técnica é optar por um algoritmo de agrupamento. Há diversos algoritmos para formação dos grupos, os quais de forma geral podem ser classificados em métodos hierárquicos e de partição. Os métodos hierárquicos são formados a partir de uma matriz de parecença. Num primeiro passo, a matriz é utilizada para identificar os pares de objetos que são mais similares. A partir desse instante esse par é agrupado e será considerado como sendo um único objeto.

Isso requer que se defina uma nova matriz de parecença; em seguida identificase o par mais semelhante, que formará um novo grupo. Através da análise do histórico do agrupamento, pode-se definir posteriormente o número de grupos existentes nos dados. O que diferencia esses métodos é a regra para a redefinição da matriz de parecença a cada união de pares de objetos. Os métodos de partição ou não-hierárquicos, buscam definir partições de $n$ objetos (amostras) em $k$ grupos de acordo com algum critério estabelecido previamente (JOLLIFFE et al., 1995). Para o presente trabalho, foi utilizado o método hierárquico, método de Ward.

Os agrupamentos formados por meio da técnica de conglomerado podem ser representados graficamente por meio de dendogramas. Estes gráficos apresentam os elementos e os respectivos pontos de fusão ou divisão dos grupos formados em cada estágio. A inspeção visual dos dendogramas permite a identificação dos grupos. Apesar de 
sua simplicidade, a análise de conglomerado tem sido utilizada com bastante sucesso como ponto de partida para outras técnicas estatísticas mais refinadas, permitindo que assim, se produzam grupos mais homogêneos e de fácil identificação (JOLLIFFE, 1989).

\subsubsection{Normalização e padronização dos dados}

Em dados de concentrações elementares de cerâmicas é observada uma distribuição normal logarítmica (BAXTER, 1999). Além disso, as concentrações são determinadas em porcentagem e em nível de traço. Devido a estas razões, antes da aplicação de técnicas estatísticas multivariadas, as concentrações elementares são transformadas em $\log _{10}$, tornando-se este, um procedimento usual em estudos arqueométricos.

Desta forma, este procedimento, além de normalizar os dados, tende a estabilizar a variância das variáveis (concentrações) a fim de compensar as diferenças de magnitude das mesmas, adquirindo igual peso na análise estatística multivariada.

\subsubsection{Valores discrepantes (outliers)}

Um problema bastante comum em análise de dados é a presença de valores discrepantes. Entende-se por um valor discrepante, uma amostra que apresenta um comportamento atípico, ou seja, é caracterizada por significativa discrepância em relação aos outros valores da base de dados. Há várias causas possíveis para a ocorrência de valores discrepantes:

- Erros de medida;

- Erros de transcrição ou digitação;

- Erro ao considerar uma unidade amostral que não pertence à população de interesse;

- Variabilidade natural dos dados.

Com exceção do último item, todas as demais causas estão relacionadas a erros e, conseqüentemente, a identificação de valores discrepantes nestas situações exige sua retirada da base de dados final. Há vários métodos de identificação de valores discrepantes. Quando se trata do estudo de uma única variável, o processo de identificação de amostras discrepantes é simples. Até mesmo por observação gráfica é possível identificar a presença destas amostras. Entretanto, quando estão sendo analisadas amostras multivariadas, este tipo de inspeção não é suficiente para identificar amostras discrepantes, as quais devem ser 
eliminadas, visto que podem levar a resultados enganosos com relação à interpretação dos dados.

$\mathrm{Na}$ literatura há poucos trabalhos mostrando a identificação de valores discrepantes em amostras que envolvem mais de uma variável (BAXTER, 1999). A maioria dos métodos propostos é gráfica, como o dendograma, que é uma análise subjetiva obtida da análise por agrupamento. No entanto, autores sugerem que a distância de Mahalanobis $\left(D_{i}^{2}\right)$ é mais viável para a detecção de amostras outliers em dados multivariados (GRUBBS, 1950).

Quanto à influência do valor crítico na detecção de valores discrepantes em resultados arqueométricos, foram realizados estudos para verificar a influência do valor crítico na detecção de valores discrepantes em arqueometria (OLIVEIRA \& MUNITA, 2003). Os autores compararam 3 critérios (teste $F$, teste do $\chi^{2}$ e lambda Wilks) e encontraram que o critério de Wilks é o mais conveniente para este tipo de estudo.

Considerando uma base de dados com $n$ amostras e $p$ variáveis medidas, a distância $\left(D_{i}^{2}\right)$ é calculada. Se $\bar{X}$ é a média do vetor e $S$ é a matriz de covariância amostral, então:

$$
S=\sum_{i=1}^{n}\left(X_{i}-\overline{\mathrm{X}}\right)\left(X_{i}-\overline{\mathrm{X}}\right)^{T} / n-1
$$

$\mathrm{e}$

$$
D_{i}^{2}=\left(X_{i}-\overline{\mathrm{X}}\right)^{T} S^{-1}\left(X_{i}-\overline{\mathrm{X}}\right)
$$

onde:

$X_{i}-\bar{X}$ é o vetor da diferença entre os valores da medida em um grupo e a média dos valores de outro grupo;

$T=$ matriz transposta.

A identificação de valores discrepantes por meio de $D_{i}^{2}$ é feita calculando-se o $D_{i}{ }^{2}$ para cada grupo de amostras e efetuando-se o teste de hipóteses por meio da comparação deste valor com o valor crítico. Na literatura, tem sido sugerido que a determinação dos valores críticos da distância Mahalanobis deve ser efetuada por meio da 
distribuição $F$, especialmente quando o número de amostras é pequeno (PENNY, 1987). Entretanto, Wilks sugeriu que o valor crítico para a distância Mahalanobis fosse calculado por meio da expressão (31). Se $D_{i}^{2}$ for maior que este valor crítico a amostra é considerada discrepante (WILKS, 1963).

$$
\frac{p(n-1)^{2} F_{p, n-\mathrm{p}-1, \alpha / \mathrm{n}}}{n\left(n-\mathrm{p}-1+\mathrm{p} F_{\mathrm{p}, \mathrm{n}-\mathrm{p}-1, \alpha / \mathrm{n}}\right)}
$$

onde:

$n$ = número de amostras;

$\mathrm{p}=$ número de variáveis;

$F=$ distribuição de Fischer;

$\alpha=$ nível de significância $(0,05)$.

\subsubsection{Análise discriminante}

A análise discriminante é uma técnica estatística multivariada utilizada com o objetivo de discriminar populações e/ou classificar amostras em populações previamente definidas. Desta forma, os principais objetivos da técnica são encontrar funções das variáveis originais (funções discriminantes) que expliquem as diferenças entre as populações e que permitam alocar novas amostras em populações envolvidas na análise.

Diferentemente da análise de agrupamento, a análise discriminante é uma técnica supervisionada. Isto significa que é necessário o conhecimento prévio das populações as quais as amostras pertencem. Para aplicação da análise discriminante o número de populações deve ser bem definido.

Estas características diferem da análise de agrupamento visto que neste caso não se conhece previamente quantas populações estão envolvidas nas análises. A grande vantagem desta técnica em relação à técnica de conglomerado é que fornece grupos individuais mais homogêneos facilitando as observações dos grupos. 


\section{PARTE EXPERIMENTAL}

\subsection{Preparação das amostras de cerâmica para AAN}

Inicialmente, os fragmentos cerâmicos foram lavados com água Milli Q. Utilizando uma escova de cerdas finas, foi feita a limpeza dos fragmentos e em seguida, foram colocados para secar ao ar. Com o objetivo de evitar contaminação nas análises foi removida parte da superfície do fragmento utilizando-se uma lima rotativa de carbeto de tungstênio, adaptada a uma furadeira com velocidade variável. Depois de removida a superfície, cerca de 500mg de amostra, na forma de pó, foram obtidos fazendo-se de 3 a 5 orifícios na parte interna do fragmento. Esse pó foi recolhido e secado em estufa a $104^{\circ} \mathrm{C}$ por 24 horas e armazenado em dessecador (MUNITA et al., 2003).

As amostras de argila foram trituradas em almofariz de ágata, a fim de se obter a amostra na forma de pó. Esse pó foi recolhido, secado em estufa a $104^{\circ} \mathrm{C}$ por 24 horas e armazenado em dessecador.

\subsubsection{Procedimento analítico}

Cerca de $120 \mathrm{mg}$ de cada amostra de argila e cerâmica juntamente com 120mg do material de referência Standard Reference Material - NIST-SRM 1633b Constituent Elements in Coal Fly Ash, utilizado como padrão, foram pesados em invólucros de polietileno e selados com ferro. Estes invólucros foram embalados em folhas de papel alumínio. As amostras e o padrão foram irradiados em dispositivos denominados "coelhos", no reator nuclear de pesquisa IEA-R1 do IPEN-CNEN/SP, por uma hora, sob um fluxo de nêutrons térmicos da ordem de $8,92 \times 10^{12} \mathrm{~cm}^{-2} \mathrm{~s}^{-1}$.

Após 7 dias de irradiação, realizou-se a primeira medida das amostras, sendo determinados As, K, La, Lu, Na, Sm, U e Yb. Após trinta dias de decaimento, realizou-se a segunda medida, sendo determinados $\mathrm{Ba}, \mathrm{Ce}, \mathrm{Co}, \mathrm{Cr}, \mathrm{Cs}$, Eu, Fe, Hf, Nd, Rb, Sb, Sc, Ta, $\mathrm{Tb}$, Th e Zn, que possuem meia-vida longa (MUNITA, 2005). A Tabela 1 apresenta algumas das características nucleares destes radioisótopos. 
Tabela 1. Características nucleares dos radioisótopos.

\begin{tabular}{|c|c|c|c|}
\hline ELEMENTO & RADIOISÓTOPO & $T_{1 / 2}$ & $\mathrm{E}_{\gamma}^{*}(\mathrm{keV})$ \\
\hline As & ${ }^{76}$ As & $26,3 \mathrm{~h}$ & 559,1 \\
\hline $\mathrm{Ba}$ & ${ }^{131} \mathrm{Ba}$ & $11,5 \mathrm{~d}$ & 496,3 \\
\hline $\mathrm{Ce}$ & ${ }^{141} \mathrm{Ce}$ & $32,5 \mathrm{~d}$ & 145,4 \\
\hline $\mathrm{Cr}$ & ${ }^{51} \mathrm{Cr}$ & $27,72 \mathrm{~d}$ & 320,1 \\
\hline $\mathrm{Cs}$ & ${ }^{134} \mathrm{Cs}$ & $2,06 \mathrm{a}$ & 795,8 \\
\hline Co & ${ }^{60} \mathrm{Co}$ & $5,27 \mathrm{a}$ & 1332,5 \\
\hline $\mathrm{Eu}$ & ${ }^{152} \mathrm{Eu}$ & $13,4 \mathrm{a}$ & 1408,0 \\
\hline $\mathrm{Fe}$ & ${ }^{59} \mathrm{Fe}$ & $44,6 \mathrm{~d}$ & 1099,3 \\
\hline $\mathrm{Hf}$ & ${ }^{181} \mathrm{Hf}$ & $42,4 \mathrm{~d}$ & 482,2 \\
\hline $\mathrm{K}$ & ${ }^{42} \mathrm{~K}$ & $15,52 \mathrm{~h}$ & 1524,6 \\
\hline $\mathrm{La}$ & ${ }^{140} \mathrm{La}$ & $47,27 \mathrm{~h}$ & 1596,2 \\
\hline $\mathrm{Lu}$ & ${ }^{177 m_{\mathrm{mu}}}$ & $161 \mathrm{~d}$ & 208,4 \\
\hline $\mathrm{Na}$ & ${ }^{24} \mathrm{Na}$ & $15 \mathrm{~h}$ & 1368,5 \\
\hline $\mathrm{Nd}$ & ${ }^{147} \mathrm{Nd}$ & $10,99 \mathrm{~d}$ & 531,0 \\
\hline $\mathrm{Rb}$ & ${ }^{86} \mathrm{Rb}$ & $18,7 \mathrm{~d}$ & 1077,0 \\
\hline $\mathrm{Sb}$ & ${ }^{86} \mathrm{Sb}$ & $60,2 \mathrm{~d}$ & 1691,0 \\
\hline $\mathrm{Sc}$ & ${ }^{46} \mathrm{Sc}$ & $83,8 \mathrm{~d}$ & 889,3 \\
\hline $\mathrm{Sm}$ & ${ }^{153} \mathrm{Sm}$ & $47,1 \mathrm{~h}$ & 103,2 \\
\hline $\mathrm{Ta}$ & ${ }^{182} \mathrm{Ta}$ & $115 \mathrm{~d}$ & 1221,4 \\
\hline $\mathrm{Tb}$ & ${ }^{160} \mathrm{~Tb}$ & $72,4 \mathrm{~d}$ & 879,4 \\
\hline Th & ${ }^{233} \mathrm{~Pa}^{1}$ & $27,0 \mathrm{~d}$ & 312,2 \\
\hline $\mathrm{U}$ & ${ }^{239} \mathrm{~Np}^{2}$ & $2,35 \mathrm{~d}$ & 228,2 \\
\hline $\mathrm{Yb}$ & ${ }^{175} \mathrm{Yb}$ & $4,19 \mathrm{~d}$ & 396,3 \\
\hline $\mathrm{Zn}$ & ${ }^{65} \mathrm{Zn}$ & $243,8 \mathrm{~d}$ & 1115,5 \\
\hline
\end{tabular}

${ }^{1}$ Th é determinado por meio da reação ${ }^{232} \mathrm{Th}(\mathrm{n}, \gamma){ }^{233} \mathrm{Th} \stackrel{\beta^{-}}{\longrightarrow}{ }^{233} \mathrm{~Pa}$

${ }^{2} \mathrm{U}$ é determinado por meio da reação ${ }^{238} \mathrm{U}(\mathrm{n}, \gamma){ }^{239} \mathrm{U} \stackrel{\beta^{-}}{\longrightarrow}{ }^{239} \mathrm{~Np}$

* Energia da radiação gama usada 
Para a realização das medidas de atividade gama, foi utilizado um detector de Ge hiperpuro da Canberra, modelo 2519, com resolução de $1,90 \mathrm{keV}$ no pico de $1332 \mathrm{keV}$ do ${ }^{60} \mathrm{Co}$, uma placa S-100 MCA, com 8192 canais e eletrônica associada. Os espectros de raios gama foram obtidos e analisados por meio do programa Genie-2000 NAA Processing Procedure, desenvolvido pela Canberra. A preparação das amostras para AAN, bem como o procedimento analítico está ilustrado a seguir na Figura 5.

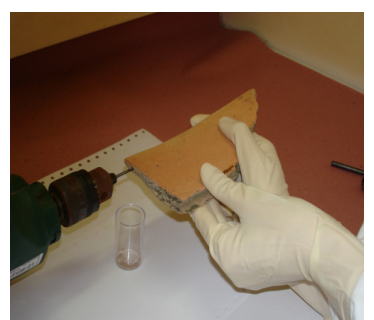

(a)

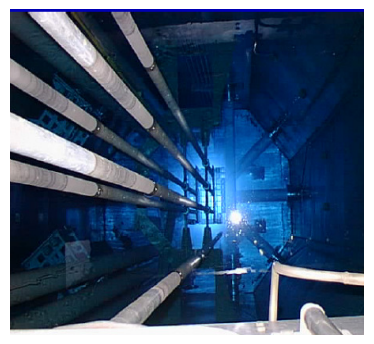

(d)

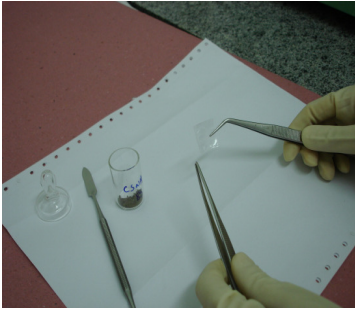

(b)

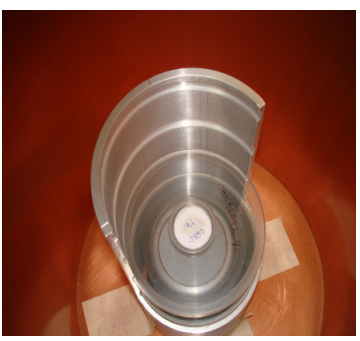

(e)

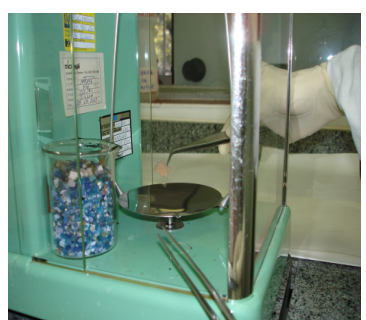

(c)

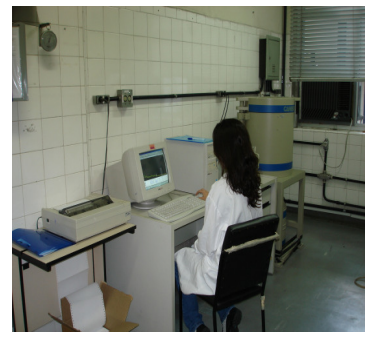

(f)

Figura 5. Esquema do procedimento experimental para AAN. (a) Orifícios na parte interna do fragmento; (b) Invólucros de polietileno; (c) Pesagem em balança analítica; (d) Reator nuclear; (e) Espectrômetro de raios gama; (f) Medida das atividades gama e cálculo das concentrações elementares.

\subsection{Preparação das amostras de cerâmica para datação por TL}

Os fragmentos selecionados para serem datados por TL foram as amostras 72, 85 e 104. Estes fragmentos foram escolhidos com base na classificação tipológica e química da cerâmica. O primeiro fragmento pertence à Fase Paredão e os demais pertencem à Fase Manacapuru.

\subsubsection{Procedimento analítico}

Todo o procedimento para a determinação da Paleodose foi feito numa sala com luz vermelha (sala escura). Isto se fez necessário a fim de que as amostras pudessem conservar seu sinal natural de TL. Inicialmente, para eliminar a parte do fragmento cerâmico que esteve em contato com a luz, foi feita a limpeza da superfície dos fragmentos 
cerâmicos com o auxílio de uma lixa, retirando-se cerca de $2 \mathrm{~mm}$ de espessura de cada uma das faces de cada um dos fragmentos. Em seguida, estes "cacos" de cerâmica foram quebrados e triturados em almofariz de alumina, obtendo-se a amostra na forma de pó. Estas amostras foram colocadas em Bécker devidamente identificados com seus respectivos códigos.

Prosseguiu-se com a separação dos cristais de quartzo dos demais componentes contidos na amostra por meio do seguinte tratamento químico: banho em solução de $\mathrm{H}_{2} \mathrm{O}_{2}$ por três horas e enxágüe repetitivo com água destilada a fim de retirar a solução escura formada pela reação da solução acima com a amostra; banho em solução de HF $24 \%$ por uma hora a fim de eliminar os carbonatos contidos nas amostras e enxágüe repetitivo com água destilada a fim de retirar o ácido; banho em solução de $\mathrm{HCl} 10 \%$ por uma hora a fim de retirar os fluoretos originados da reação com $\mathrm{HF}$ e enxágüe repetitivo com água destilada a fim de retirar o ácido.

Feito isto, as amostras foram secadas em estufa a $60^{\circ} \mathrm{C}$ por uma hora. Por fim, foi feito o peneiramento para selecionar os grãos de quartzo utilizando a granulometria entre $75 \mu \mathrm{m}$ e $180 \mu \mathrm{m}$. Com os cristais de quartzo já selecionados, prosseguiu-se à etapa de medição do sinal de TL das amostras. Nesta etapa, foram utilizados dois métodos: o protocolo da Regeneração de múltiplas alíquotas e o das Doses adicionais.

O protocolo da regeneração de múltiplas alíquotas visa estimar o valor de $\mathrm{P}$ que é obtido por interpolação (para as amostras 85 e 104) e o das Doses adicionais visa estimar o valor da Dose equivalente $(\mathrm{Q})$ que é obtido por extrapolação (para a amostra 72) por meio da medição do sinal de TL de diversas alíquotas de uma mesma amostra. Uma alíquota consiste de uma determinada massa de cristal de quartzo proveniente da amostra a ser datada cujo sinal de emissão TL é medido.

\section{Regeneração de múltiplas alíquotas}

Segundo o protocolo de regeneração de múltiplas alíquotas, o sinal de TL de uma alíquota pode ser: natural, residual ou devido à aplicação de uma dose conhecida de laboratório. Com a medição dos sinais provenientes das alíquotas irradiadas em laboratório é construída uma curva de crescimento para cada amostra. $\mathrm{O}$ eixo das abscissas representa as doses aplicadas em laboratório enquanto o eixo das ordenadas representa a intensidade do sinal de TL do pico de $375^{\circ} \mathrm{C}$, que é o pico de emissão TL característico do quartzo, utilizado para datação. 
Em seguida, os valores de intensidade do sinal de $\mathrm{TL}$ do pico de $375^{\circ} \mathrm{C}$ das alíquotas naturais são colocados sobre a curva de crescimento na forma de retas paralelas ao eixo das abscissas. As projeções dos pontos de intersecção das retas com a curva de crescimento sobre eixo das abscissas são os valores estimados de P. Como é medida mais de uma alíquota natural, o número de valores de $\mathrm{P}$ estimado é igual ao número de alíquotas naturais medidas. Com o conjunto dos valores de $\mathrm{P}$, é determinado um valor médio. Este valor médio é a Paleodose estimada para a amostra.

\section{Procedimento adotado para o protocolo de regeneração de múltiplas alíquotas}

A fim de diminuir os sinais de TL a um valor residual, uma parcela de cada amostra foi colocada no forno a uma temperatura de $500^{\circ} \mathrm{C}$ pelo tempo de 15 minutos. Com relação à parcela restante de cada amostra, esta foi mantida na sala escura a fim de conservar o sinal natural de TL. Em seguida, a parcela de cada amostra que foi levada ao forno foi dividida em quatro partes iguais, sendo cada parte, colocada em envelopes de papel de seda.

As amostras foram colocadas em placas de acrílico protegido por filme vermelho e posteriormente lacrado com fita adesiva. Em seguida, após serem retiradas as placas, as amostras foram irradiadas (1, 2, 3 e 4Gy) no IPEN-CNEN/SP, usando uma fonte de ${ }^{60} \mathrm{Co}$.

As doses a serem aplicadas são estimadas com base na idade esperada para a cerâmica. Por exemplo, se temos uma cerâmica com idade de queima estimada em 1000 anos e sabemos devido à determinação da concentração dos elementos radioativos contidos na cerâmica e a medição da radiação cósmica incidente na região onde a amostra foi coletada, que a Dose anual está em torno de 1,9mGy/ano, logo, a Paleodose estimada para esta amostra será, de acordo com a equação (25), de aproximadamente 1,9Gy, o que justifica a escolha das doses de laboratório entre 1 e $4 \mathrm{~Gy}$. Durante todo o procedimento, as amostras foram protegidas de qualquer contato com a luz de intensidade acima da presente na sala escura e/ou menor comprimento de onda.

Depois de irradiadas, as amostras retornaram para a sala escura do LVD, onde os envelopes de papel de seda foram substituídos por envelopes de papel alumínio. Com as amostras irradiadas nestes novos envelopes, elas foram levadas ao forno a uma temperatura de $200^{\circ} \mathrm{C}$ por dez minutos. Este procedimento descrito é denominado tratamento térmico (TT), e se faz necessário a fim de eliminar os centros de recombinação instáveis que, caso não fossem, forneceriam valores superestimados de $\mathrm{P}$. 
Em seguida, foram feitas medições das intensidades do sinal de TL juntamente com as amostras que conservaram o sinal natural. Para isto, foi utilizada uma leitora da Daybreak Nuclear System Inc, contendo divisões para medição de no máximo vinte alíquotas por medida. Foram utilizadas dezoito divisões, sendo seis divisões para alíquotas naturais de uma determinada amostra, e doze divisões para as alíquotas irradiadas em laboratório da mesma amostra. A Tabela 2 descreve de maneira detalhada a divisão dos compartimentos da leitora para medição de uma amostra:

Tabela 2. Divisão dos compartimentos da leitora para medição de uma amostra.

\begin{tabular}{cc}
\hline $\begin{array}{c}\mathrm{N}^{\mathrm{o}} \text { do compartimento da } \\
\text { Daybreak }\end{array}$ & $\begin{array}{c}\text { Tipo de sinal de TL } \\
\text { medido na alíquota }\end{array}$ \\
\hline 0 & Vazio \\
$1,2,3,4,5$ e 6 & Natural \\
7,8 e 9 & $1 \mathrm{~Gy}$ \\
10,11 e 12 & $2 \mathrm{~Gy}$ \\
13,14 e 15 & $3 \mathrm{~Gy}$ \\
16,17 e 18 & $4 \mathrm{~Gy}$ \\
19 & Vazio \\
\hline
\end{tabular}

A fim de manter a massa das alíquotas constante, foi utilizado um dosador de amostra, sendo a massa de cada alíquota de aproximadamente $10 \mathrm{mg}$ e a mesma colocada sobre pequenos discos de alumínio para facilitar o processo de medição na leitora. A medição do sinal de TL foi realizada a um taxa de aquecimento de $10^{\circ} \mathrm{C} / \mathrm{s}$, com a temperatura variando da temperatura ambiente até $500^{\circ} \mathrm{C}$. Também foram utilizados os seguintes filtros na fotomultiplicadora: BG-39 e Kopp 7-59, os quais deixam passar fótons com comprimento de onda na região do visível.

Terminadas as medições, os dados foram transferidos do programa de controle da Daybreak para o "software" de análise matemática Origin, versão 8.0. Para análise dos sinais de TL, foram tomados os procedimentos anteriormente descritos para construção da curva de crescimento. Este procedimento foi aplicado para a determinação da idade dos fragmentos cerâmicos 85 e 104. 


\section{Doses adicionais}

Segundo o protocolo das doses adicionais, a intersecção da curva de crescimento com o eixo das abscissas será a Dose equivalente $(\mathrm{Q})$ em módulo. O valor de intensidade no ponto 0 do eixo das abscissas é a intensidade do sinal de TL das alíquotas naturais. Já os valores das demais intensidades foram obtidas com alíquotas naturais irradiadas com doses adicionais de 1, 2, 3 e 4Gy.

Os procedimentos referentes ao protocolo das doses adicionais são idênticos aos descritos anteriormente para o protocolo da regeneração de múltiplas alíquotas, exceto com relação à queima das amostras no forno a temperatura de $500^{\circ} \mathrm{C}$ para "zerar" o sinal de TL das alíquotas a serem utilizadas para construção da curva de crescimento. Neste protocolo tal procedimento não é adotado, uma vez que as alíquotas cujos sinais fornecem os pontos para construção da curva de crescimento, recebem doses de radiação em laboratório sobre o sinal natural que elas já possuem.

Desta forma, a intensidade do sinal de emissão TL medido para estas alíquotas é uma soma do sinal natural que elas já possuem, somado ao sinal devido à dose de radiação aplicada em laboratório (TATUMI et al., 2005). Este procedimento foi aplicado para a determinação da idade do fragmento cerâmico 72 .

\section{Determinação da dose anual}

A determinação do valor de dose anual para cada amostra foi feita com base nos valores de concentração de $\mathrm{U}$, Th e K, calculados previamente por AAN. Com os valores de concentrações foram estimadas as contribuições de cada elemento devido à radiação $\gamma \mathrm{e}$ radiação $\beta$. Essas parcelas de radiação de cada um dos três elementos foram somadas à parcela de contribuição devido à radiação cósmica de regiões próximas ao local de origem da amostra.

A contribuição devido a radiação $\alpha$ não é considerada uma vez que assume-se que a mesma é eliminada durante o tratamento químico. A somatória destes valores é a dose anual de radiação incidente na amostra. Com o valor estimado de P e de DA pode ser calculada a idade das amostras cuja expressão foi mostrada anteriormente. A preparação das amostras para datação por termoluminescência, bem como o procedimento analítico está ilustrado na Figura 6. 


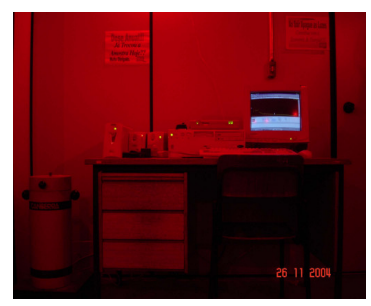

(a)

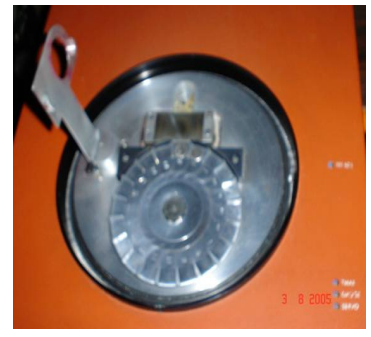

(d)

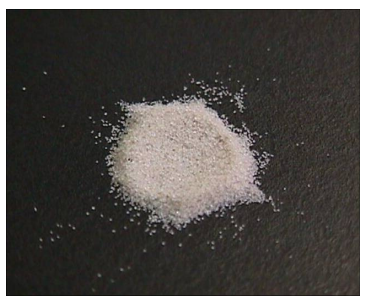

(b)

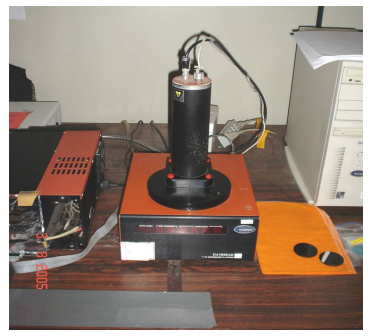

(e)

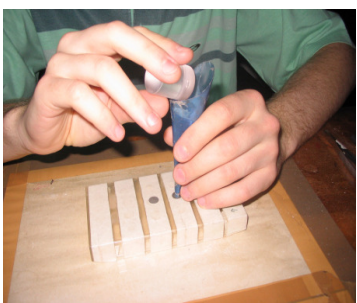

(c)

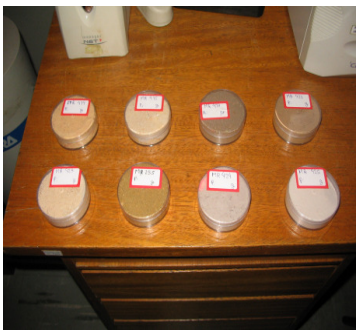

(f)

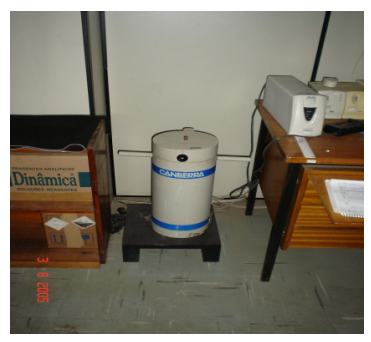

(g)

Figura 6. Esquema do procedimento experimental para datação por TL. (a) "sala escura"; (b) cristais de quartzo selecionados; (c) preparação das amostras para medição de sinais TL; (d) compartimentos com as divisões da leitora Daybreak Nuclear System onde foram medidos os sinais TL; (e) Leitora Daybreak; (f) amostras separadas para as medidas de dose anual; (g) Medição da dose anual.

\subsection{Preparação das amostras de cerâmica para análise por RPE}

Para a determinação da temperatura de queima das cerâmicas, foram utilizadas as amostras de cerâmicas 69, 70, 95 e 103, sendo que as amostras 69 e 70 pertencem à Fase Paredão, a amostra 95 pertence à Fase Manacapuru e a amostra 103 pertence a uma Fase desconhecida, conforme a classificação arqueológica.

\subsubsection{Procedimento analítico}

Para cada amostra, foram pesadas 11 alíquotas de aproximadamente 70mg, resultando em 44 alíquotas. Isto é necessário, porque cada amostra será submetida a dez temperaturas diferentes, sendo que uma alíquota representa uma amostra natural, não sendo submetida ao reaquecimento em laboratório, conforme realizado com as outras alíquotas de cada amostra. Então, cada alíquota foi submetida a um tratamento térmico 
utilizando-se as seguintes temperaturas: 400, 450, 500, 550, 600, 650, 700, 750, 800 e $850^{\circ} \mathrm{C}$, respectivamente. Esse intervalo foi escolhido presumindo que a temperatura de queima estava nesse intervalo, uma vez que a maioria das cerâmicas arqueológicas possui temperaturas de queima entre 500 e $850^{\circ} \mathrm{C}$. Uma taxa de aquecimento de $10^{\circ} \mathrm{C} / \mathrm{min}$ foi escolhida.

Após serem mantidas no forno por cerca de 20 min após atingir a temperatura previamente determinada, as amostras foram analisadas em um espectrômetro de RSE da Varian operando na freqüência de 9,4GHz (banda X) com freqüência de modulação de 100 $\mathrm{kHz}$ a uma amplitude de 0,4 mT. As amostras foram colocadas em tubos de vidros de aproximadamente $4,3 \mathrm{~mm}$ de diâmetro.

Para eliminar a possível interferência do tubo de vidro, foi feita uma medida com o tubo vazio e depois subtraída do espectro referente à análise da amostra juntamente com o tubo. Uma varredura de $4000 \mathrm{G}$ foi tomada em 2 min e a constante de tempo foi de $100 \mathrm{~ms}$. Os espectros foram analisados a temperatura ambiente.

Na figura 7, tem-se um exemplo do espectro RSE de uma cerâmica, indicando o valor do pico utilizado nas análises. O sinal II (amplitude máxima) indica o valor experimental de $g$ obtido em função da temperatura de reaquecimento.

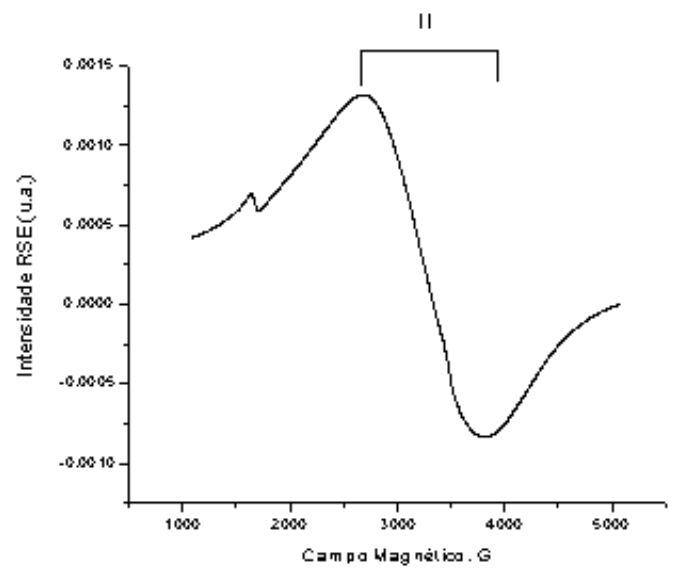

Figura 7. Espectro RSE de uma cerâmica indicando o valor do pico utilizado nas análises. 


\section{RESULTADOS E DISCUSSÃO}

\subsection{Controle de qualidade analítica}

Com o propósito de estudar o controle de qualidade do método analítico foram determinadas as concentrações As, Ce, Co, Cr, Cs, Eu, Fe, Hf, K, La, Lu, Na, Nd, Rb, Sb, Sc, Sm, Ta, Tb, Th, U, Yb e Zn por AAN, em 18 amostras do material de referência IAEA Soil7. Para avaliar quantitativamente o desempenho de um método analítico se faz necessário o cálculo de alguns parâmetros estatísticos como a média, desvio padrão, nível de confiança da média, homogeneidade no conjunto de resultados, a precisão e a exatidão.

Um problema que freqüentemente surge após a obtenção de uma série de resultados analíticos é da rejeição de um ou mais valores anômalos ou aberrantes. Para que essa rejeição não assuma um caráter subjetivo foram desenvolvidos, pelos matemáticos, vários critérios estatísticos. No presente trabalho, foi adotado o critério do $r_{\text {máx }}$ e $r_{\text {mín }}$ (NALIMOV, 1963), assim definido pela expressão:

$$
r_{i}=\frac{\left|x_{i}-\bar{x}\right|^{2}}{s \sqrt{\frac{n-1}{n}}}
$$

onde $x_{i}$ é $x_{\text {máx }}$ (os valores de $\mathrm{x}_{\mathrm{i}}$ máximo) ou $x_{\text {mín }}$ (os valores de $\mathrm{x}_{\mathrm{i}}$ mínimo) no conjunto. Esse critério foi aplicado a cada conjunto de resultados obtidos por uma mesma medida. Os valores de $r_{\text {máx }}$ e $r_{\text {mín }}$ experimentais foram comparados com os valores tabelados para um nível de significância de 0,05 e com n-2 grau de liberdade. O desvio padrão é uma grandeza que permite tirar conclusões a respeito da reprodutibilidade do método analítico, ou seja, das dispersões dos resultados obtidos em torno da estimativa da média e é calculado pela expressão:

$$
s=\sqrt{\frac{\sum_{i-1}^{n}\left(x_{i}-\bar{x}\right)^{2}}{n-1}}
$$

onde $x_{i}$ são os resultados obtidos e $\bar{x}$ é a média dos resultados e $n$ o número de amostras. O desvio padrão caracteriza a incerteza que acompanha cada um dos $n$ resultados. O desvio padrão relativo, o qual representa a precisão, foi calculado por meio da expressão: 


$$
D P R=\frac{s}{x} 100
$$

$\mathrm{Na}$ Tabela 3, pode-se observar que em todos os casos o valor do $\mathrm{r}$ calculado foi menor que o valor do $\mathrm{r}$ tabelado, indicando que o conjunto de resultados para um mesmo elemento é homogêneo em um nível de confiança de 95\%. Também, encontram-se todos os resultados dos valores encontrados e certificados, bem como, os resultados das concentrações elementares para o material de referência IAEA-Soil7.

O desvio padrão relativo, DPR, para a maioria dos elementos foi menor ou igual a $10 \%$. O elemento que tem um DPR > 10\% é o Sm. Os resultados mostraram que a maioria dos elementos apresentou uma precisão $\leq 10 \%$. Esta precisão é considerada, por vários autores, adequada na escolha dos elementos químicos para estudos de caracterização química de objetos arqueológicos, utilizando métodos estatísticos multivariados (MUNITA et al., 2000).

Os elementos Co e Ta embora tenham apresentado uma precisão menor que $10 \%$, foram eliminados porque existem evidências de contaminação pela broca de tungstênio durante a preparação da amostra (ATTAS et al., 1984). O Zn também foi eliminado porque sofre interferência no espectro de raios gama do pico do Sc (PERLMAN \& ASARO, 1971). Embora o As, Ba, Nd, Rb e Sb tenham mostrado boa precisão, estudos anteriores, mostraram que não são elementos confiáveis para serem inseridos na base de dados por apresentarem uma grande dispersão nas concentrações das cerâmicas (MUNITA et al., 2004).

Portanto, os elementos escolhidos para serem determinados por AAN nas cerâmicas do sítio arqueológico Hatahara foram $\mathrm{Ce}, \mathrm{Cr}, \mathrm{Cs}, \mathrm{Eu}, \mathrm{Fe}, \mathrm{Hf}, \mathrm{K}, \mathrm{La}, \mathrm{Lu}, \mathrm{Na}, \mathrm{Sc}$, $\mathrm{Tb}$, Th, U e Yb. Na tabela 4 estão apresentadas as concentrações elementares destes elementos. Após determinadas as concentrações elementares, estas foram transformadas em $\log _{10}$ para compensar os elementos que são determinados em porcentagem e em nível de traço. A seguir, foram estudadas as amostras discrepantes ou outliers, por meio da distância Mahalanobis $\left(D_{i}\right)$, usando-se o critério lambda Wilks como valor crítico.

As amostras que ultrapassaram o valor crítico foram eliminadas e o mesmo procedimento foi repetido para as amostras restantes. O procedimento terminou quando as amostras apresentaram valores de distâncias de Mahalanobis menores que o valor crítico. Por meio deste cálculo foi possível encontrar 7 amostras discrepantes (indicadas em negrito). 
Tabela 3. Resultados para o material de referência IAEA-Soil7 Trace Elements in Soil, em $\mu \mathrm{g} / g$, a não ser indicado.

\begin{tabular}{|c|c|c|c|c|c|c|c|c|c|c|c|}
\hline Amostra & $\mathrm{Na}(\mathrm{mg} / \mathrm{g})$ & $\mathrm{K}(\mathrm{mg} / \mathrm{g})$ & As & $\mathrm{La}$ & $\mathrm{Nd}$ & $\mathrm{Sm}$ & $\mathrm{Yb}$ & Lu (ng/g) & $\mathrm{U}$ & $\mathrm{Sc}$ & $\mathrm{Cr}$ \\
\hline 1 & 2,3 & 8,8 & 11,2 & 31 & 18 & 10,3 & 2,3 & 376,6 & 2,4 & 8,6 & 72,1 \\
\hline 2 & 2,3 & 13 & 12,7 & 30,7 & 23,1 & 2,2 & 2,3 & 377,5 & 2,4 & 8,7 & 70,3 \\
\hline 3 & 2,5 & 11,4 & 16,5 & 32,4 & 17,4 & 5,3 & 2,4 & 418,6 & 2,1 & 9,4 & 70,7 \\
\hline 4 & 2,4 & 11,2 & 14,8 & 31,4 & 21,4 & 6,7 & 2,3 & 387,5 & 2,8 & 8,7 & 76,5 \\
\hline 5 & 2,3 & 13,2 & 9,3 & 30 & 20,4 & 4,6 & 2,2 & 366,7 & 2,2 & 8,3 & 69,7 \\
\hline 6 & 2,5 & 16,9 & 18,6 & 31 & 22,9 & 3,7 & 2,2 & 352,7 & 2,9 & 8,9 & 72,2 \\
\hline 7 & 2,4 & 15,1 & 18,3 & 29,3 & 26,2 & 1,5 & 2,5 & 347,1 & 2 & 8,3 & 68,8 \\
\hline 8 & 2,4 & 10,5 & 16,1 & 30,5 & 24 & 3,2 & 2,4 & 373,4 & 2,9 & 8,6 & 70 \\
\hline 9 & 2,4 & 15,3 & 14,3 & 31,5 & 21,9 & 10,7 & 2,4 & 383,4 & 2,7 & 8,7 & 65 \\
\hline 10 & 2,3 & 10,5 & 20,2 & 32 & 16,2 & 7,3 & 2,5 & 391,6 & 2,4 & 8,8 & 66,9 \\
\hline 11 & 2,5 & 14,4 & 15,6 & 32,4 & 30,1 & 4,6 & 2,3 & 365,8 & 3,1 & 9,1 & 69,8 \\
\hline 12 & 2,3 & 14,2 & 12,8 & 29,7 & 26,5 & 1,1 & 2,3 & 343 & 3,1 & 8,5 & 70,7 \\
\hline 13 & 2,4 & 17,2 & 14,2 & 31,1 & 16,4 & 4,2 & 2,4 & 352 & 2,5 & 8,7 & 69,9 \\
\hline 14 & 2,3 & 11,8 & 14,9 & 30,6 & 25,7 & 2,4 & 2,1 & 419 & 1,4 & 8,5 & 70 \\
\hline 15 & 2,5 & 13,1 & 14,9 & 31,4 & 25,6 & 0,8 & 2,2 & 353,4 & 2,8 & 9 & 73,4 \\
\hline 16 & 2,6 & & 20,6 & 30,6 & & 4,8 & 2,1 & 381,4 & 2 & 8,6 & 69,8 \\
\hline 17 & 2,2 & & 14,9 & 28,5 & & 9,8 & 2,3 & 350,6 & 2,5 & 7,9 & 63,1 \\
\hline 18 & 2,2 & & 15,4 & 30,3 & & 12,5 & & 342,5 & 2,2 & 8,4 & 68,7 \\
\hline $\mathrm{r} \min$ & 1,6 & 1,8 & 2,1 & 2,3 & 1,6 & 1,3 & 1,8 & 1,3 & 2,5 & 2,3 & 2,4 \\
\hline$r \max$ & 2,1 & 1,7 & 1,9 & 1,6 & 1,9 & 2,1 & 1,7 & 2,1 & 1,5 & 2,3 & 2,3 \\
\hline $\mathrm{r} \operatorname{tab}(0,05 ; \mathrm{n}-2)$ & 2,6 & 2,5 & 2,6 & 2,6 & 2,5 & 2,6 & 2,6 & 2,6 & 2,6 & 2,6 & 2,6 \\
\hline média \pm dês. pad. média & $2,4 \pm 0,1$ & $13,1 \pm 0,6$ & \multicolumn{5}{|c|}{$15,3 \pm 0,730,8 \pm 0,222,4 \pm 1,15,3 \pm 0,82,3 \pm 0,1$} & $371,3 \pm 5,5$ & \multicolumn{3}{|c|}{$2,5 \pm 0,18,7 \pm 0,169,9 \pm 0,7$} \\
\hline Valor certificado & 2,4 & 12,1 & $13,4 \pm 0,8$ & $28 \pm 1,0$ & $30 \pm 6,0$ & $5,1 \pm 0,4$ & $2,4 \pm 0,4$ & & \multicolumn{3}{|c|}{$2,6 \pm 0,68,3 \pm 0,160 \pm 12,6$} \\
\hline DPR (precisão) & $4,2 \%$ & $4,6 \%$ & $4,6 \%$ & $0,6 \%$ & $4,9 \%$ & $15,1 \%$ & $4,3 \%$ & $1,5 \%$ & $4,0 \%$ & $1,1 \%$ & $1,0 \%$ \\
\hline $\begin{array}{c}\text { (certif - exp) / certif } * 100 \\
\text { (exatidão) }\end{array}$ & & $8,3 \%$ & $14,2 \%$ & $10,0 \%$ & $25,3 \%$ & $3,9 \%$ & $4,2 \%$ & & $3,8 \%$ & $4,8 \%$ & $16,5 \%$ \\
\hline
\end{tabular}


Tabela 3. Continuação.

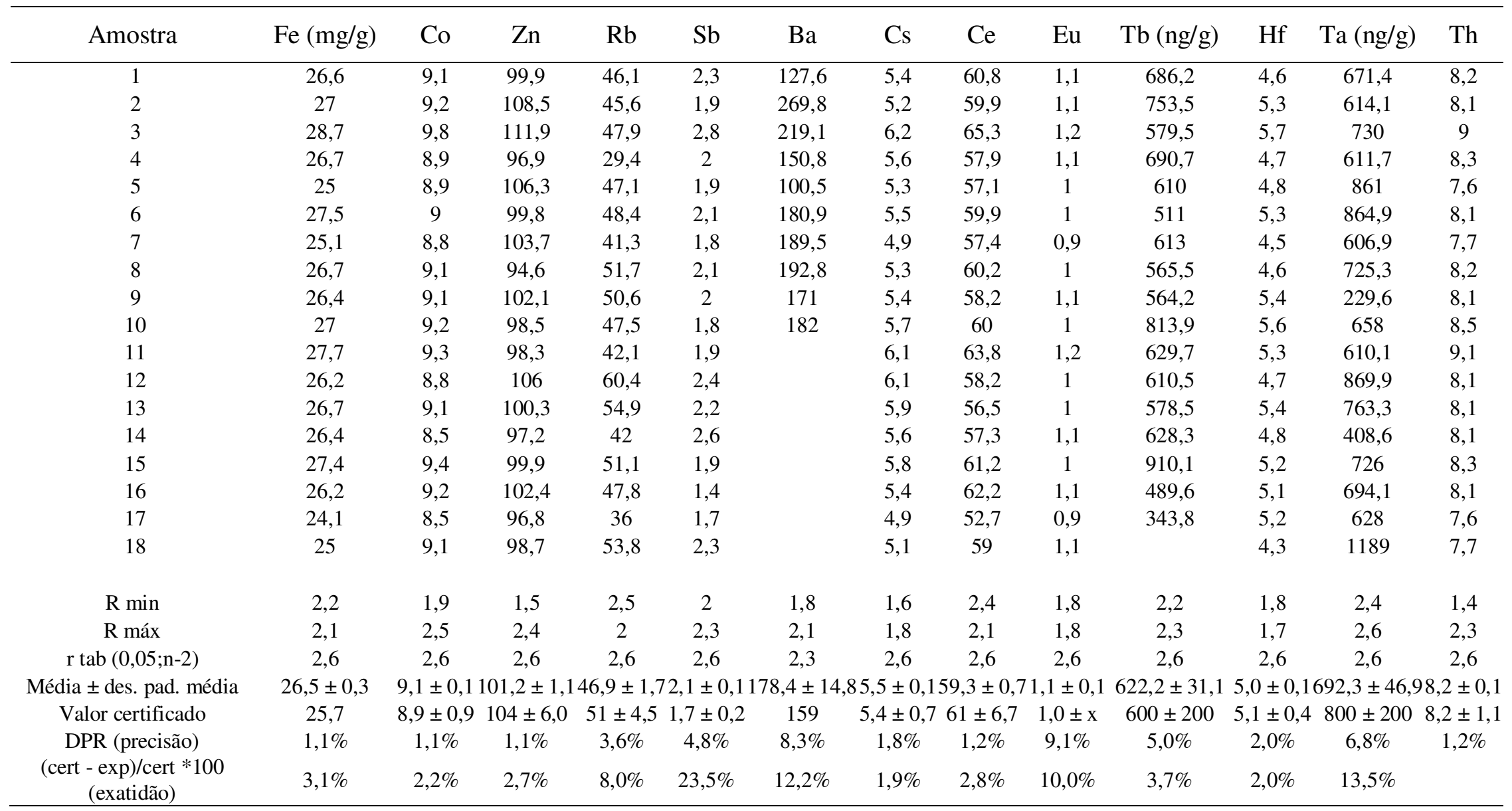


Tabela 4. Resultados das concentrações elementares das amostras de cerâmica em $\mu \mathrm{g} / \mathrm{g}$, a não ser indicado.

\begin{tabular}{|c|c|c|c|c|c|c|c|c|c|c|c|c|c|c|c|}
\hline Amostra & $\mathrm{Na}(\%)$ & $\mathrm{K}(\%)$ & $\mathrm{La}$ & $\mathrm{Yb}$ & $\mathrm{Lu}$ & U & $\mathrm{Ce}$ & $\mathrm{Cr}$ & Cs & $\mathrm{Eu}$ & $\mathrm{Fe}(\%)$ & $\mathrm{Hf}$ & $\mathrm{Sc}$ & $\mathrm{Tb}$ & Th \\
\hline 01 & 0,1 & 0,8 & 37,4 & 2,4 & 0,3 & 3,5 & 69,8 & 69,0 & 4,7 & 0,8 & 3,3 & 8,0 & 13,7 & 0,6 & 15,1 \\
\hline 02 & 0,3 & 1,5 & 42,4 & 3,1 & 0,4 & 4,2 & 83,6 & 63,0 & 6,2 & 1,3 & 3,6 & 4,6 & 16,5 & 1,0 & 15,0 \\
\hline 03 & 0,1 & 0,7 & 45,2 & 3,5 & 0,5 & 3,8 & 80,6 & 66,1 & 4,2 & 1,2 & 1,6 & 17,6 & 13,6 & 0,7 & 18,0 \\
\hline 04 & 0,2 & 1,5 & 41,8 & 3,0 & 0,4 & 3,7 & 80,3 & 76,0 & 7,9 & 1,3 & 4,4 & 5,7 & 18,7 & 0,8 & 17,7 \\
\hline 05 & 0,4 & 1,7 & 42,0 & 3,7 & 0,4 & 3,4 & 81,5 & 75,0 & 7,0 & 1,5 & 4,1 & 5,4 & 19,3 & 0,8 & 16,4 \\
\hline 06 & 0.1 & 0.5 & 50.6 & 3.2 & 0.4 & 3.6 & 90.8 & 60.8 & 2.9 & 1.4 & 1.7 & 9.6 & 13.2 & 0.8 & 16.6 \\
\hline 07 & 0,3 & 1,0 & 68,3 & 4,9 & 0,5 & 4,5 & 231,0 & 68,0 & 9,0 & 2,2 & 3,6 & 7,9 & 15,8 & 1,4 & 16,5 \\
\hline 08 & 0,3 & 1,5 & 41,4 & 2,9 & 0,4 & 3,5 & 78,1 & 73,4 & 9,0 & 1,4 & 3,5 & 4,4 & 18,5 & 0,8 & 15,5 \\
\hline 09 & 0,1 & 1,0 & 31,0 & 2,0 & 0,3 & 2,7 & 70,5 & 45,1 & 5,1 & 1,0 & 2,1 & 3,2 & 12,2 & 0,6 & 10,6 \\
\hline 10 & 0,4 & 1,0 & 34,6 & 2,4 & 0,4 & 3,0 & 68,2 & 50,5 & 5,6 & 1,2 & 2,7 & 4,6 & 13,2 & 0,7 & 10,8 \\
\hline 11 & 0,4 & 1,2 & 32,3 & 2,4 & 0,4 & 2,5 & 60,9 & 49,7 & 8,5 & 1,0 & 2,8 & 4,6 & 12,8 & 0,7 & 10,9 \\
\hline 12 & 0,2 & 0,9 & 20,1 & 1,8 & 0,3 & 0,5 & 39,5 & 47,7 & 5,4 & 1,7 & 2,9 & 3,5 & 11,4 & 0,5 & 8,7 \\
\hline 13 & 0,3 & 1,2 & 39,7 & 2,5 & $\mathbf{0 , 3}$ & 0,8 & 78,6 & 52,5 & 6,4 & 1,3 & 3,1 & 4,3 & 14,3 & 0,7 & 13,0 \\
\hline 14 & 0,1 & 0,6 & 34,9 & 3,1 & 0,5 & 4,5 & 66,2 & 61,5 & 4,9 & 1,2 & 1,5 & 13,8 & 14,0 & 0,8 & 13,6 \\
\hline 15 & 0,1 & 1,1 & 28,8 & 2,2 & 0,4 & 3,1 & 53,8 & 56,6 & 6,9 & 0,9 & 3,4 & 5,2 & 13,3 & 0,8 & 10,5 \\
\hline 16 & 0,4 & 1,4 & 41,6 & 2,8 & 0,4 & 3,8 & 80,7 & 69,2 & 4,6 & 1,3 & 3,8 & 5,2 & 16,4 & 1,0 & 13,0 \\
\hline 17 & 0,4 & 1,2 & 38,7 & 2,7 & 0,5 & 2,7 & 76,5 & 54,7 & 6,9 & 1,5 & 3,1 & 4,0 & 15,5 & 0,9 & 12,9 \\
\hline 18 & 0,5 & 1,3 & 36,9 & 2,8 & 0,4 & 2,5 & 70,0 & 59,3 & 6,9 & 1,4 & 3,7 & 5,7 & 14,9 & 0,7 & 13,9 \\
\hline 19 & 0,3 & 0,8 & 31,4 & 2,5 & 0,5 & 2,4 & 61,4 & 52,0 & 5,0 & 1,1 & 2,9 & 6,3 & 11,2 & 0,7 & 9,7 \\
\hline 20 & 0,4 & 1,5 & 31,5 & 2,4 & 0,4 & 2,7 & 64,0 & 62,0 & 7,8 & 0,9 & 3,6 & 5,8 & 13,1 & 0,7 & 10,8 \\
\hline 21 & 0,4 & 1,1 & 39,0 & 2,8 & 0,4 & 2,9 & 71,7 & 61,6 & 4,4 & 1,2 & 3,7 & 4,8 & 14,7 & 0,5 & 12,3 \\
\hline 22 & 0,1 & 0,7 & 34,6 & 2,3 & 0,3 & 3,1 & 93,8 & 52,7 & 6,9 & 1,1 & 3,4 & 4,2 & 12,2 & 0,5 & 12,0 \\
\hline 23 & 0,1 & 0,3 & 41,0 & 5,2 & 0,9 & 5,5 & 77,4 & 60,4 & 3,1 & 1,2 & 1,5 & 31,4 & 11,4 & 0,8 & 17,0 \\
\hline 24 & 0,4 & 1,4 & 35,3 & 2,7 & 0,4 & 2,7 & 66,7 & 60,0 & 7,6 & 1,2 & 3,5 & 4,4 & 14,0 & 0,8 & 11,1 \\
\hline 25 & 0,5 & 1,2 & 25,4 & 2,6 & 0,4 & 3,3 & 52,1 & 59,5 & 5,9 & 0,8 & 3,4 & 5,2 & 14,0 & 0,9 & 11,6 \\
\hline 26 & 0,3 & 1,4 & 40,2 & 2,9 & 0,4 & 3,4 & 75,3 & 69,0 & 6,8 & 1,1 & 3,4 & 4,7 & 16,1 & 1,2 & 13,0 \\
\hline 27 & 0,4 & 1,0 & 31,2 & 2,3 & 0,3 & 2,6 & 61,2 & 52,3 & 6,0 & 1,0 & 3,1 & 4,7 & 12,3 & 0,8 & 10,9 \\
\hline 28 & 0,3 & 1,0 & 33,0 & 2,4 & 0,3 & 3,2 & 64,0 & 57,0 & 5,6 & 1,0 & 3,4 & 4,3 & 14,3 & 0,7 & 11,0 \\
\hline 29 & 0,1 & 0,5 & 28,2 & 2,2 & 0,3 & 2,8 & 57,3 & 40,8 & 5,5 & 1,0 & 2,1 & 4,6 & 9,1 & 0,8 & 8,8 \\
\hline 30 & 0,1 & 0,6 & 25,2 & 1,8 & 0,3 & 2,3 & 50,5 & 46,0 & 3,9 & 0,7 & 2,4 & 3,9 & 10,2 & 0,7 & 10,0 \\
\hline 31 & 0,3 & 1,0 & 34,3 & 2,4 & 0,3 & 2,3 & 68,7 & 58,5 & 3,5 & 1,1 & 3,1 & 4,9 & 13,2 & 0,9 & 13,1 \\
\hline 32 & 0,1 & 0,6 & 32,8 & 2,5 & 0,3 & 3,7 & 67,0 & 62,1 & 7,4 & 0,9 & 3,3 & 6,9 & 14,0 & 0,5 & 14,1 \\
\hline 33 & 0,2 & 1,3 & 45,7 & 3,0 & 0,4 & 3,6 & 86,0 & 70,2 & 6,4 & 1,5 & 3,1 & 4,6 & 17,6 & 1,4 & 15,5 \\
\hline 34 & 0,4 & 1,3 & 32,3 & 2,6 & 0,4 & 3,1 & 66,0 & 57,0 & 5,2 & 1,1 & 3,6 & 5,4 & 14,0 & 1,1 & 11,5 \\
\hline 35 & 0,3 & 1,7 & 39,4 & 2,9 & 0,4 & 3,1 & 71,6 & 57,7 & 5,0 & 1,2 & 3,2 & 5,1 & 14,5 & 0,8 & 12,1 \\
\hline 36 & 0,5 & 2,0 & 37,0 & 2,7 & 0,4 & 3,2 & 80,0 & 59,3 & 5,9 & 1,3 & 3,1 & 5,6 & 13,9 & 0,5 & 13,1 \\
\hline 37 & 0,2 & 1,9 & 41,2 & 2,9 & 0,4 & 3,6 & 74,7 & 57,8 & 7,4 & 1,1 & 2,5 & 5,0 & 14,5 & 0,4 & 15,2 \\
\hline 38 & 0,2 & 1,1 & 37,2 & 2,6 & 0,4 & 3,1 & 70,2 & 59,8 & 4,8 & 1,3 & 3,5 & 4,0 & 13,6 & 0,6 & 12,0 \\
\hline 39 & 0,3 & 1,3 & 37,8 & 2,5 & 0,4 & 2,8 & 69,5 & 58,9 & 7,7 & 1,1 & 3,0 & 4,5 & 13,6 & 0,6 & 12,8 \\
\hline 40 & 0,4 & 1,6 & 39,9 & 2,8 & 0,4 & 2,8 & 73,4 & 60,9 & 5,2 & 1,2 & 3,5 & 4,4 & 14,3 & 0,7 & 12,7 \\
\hline 41 & 0,5 & 1,3 & 37,8 & 2,8 & 0,4 & 2,6 & 73,5 & 53,6 & 7,0 & 1,3 & 3,4 & 5,4 & 13,6 & 0,4 & 12,2 \\
\hline 42 & 0,3 & 1,6 & 43,8 & 2,8 & 0,5 & 3,0 & 80,2 & 63,2 & 7,2 & 1,3 & 3,7 & 4,9 & 15,6 & 0,6 & 14,1 \\
\hline 43 & 0,1 & 0,8 & 49,2 & 3,0 & 0,5 & 3,3 & 90,5 & 57,9 & 4,8 & 1,6 & 3,0 & 5,2 & 14,0 & 0,7 & 14,3 \\
\hline 44 & 0,6 & 1,7 & 39,0 & 2,9 & 0,5 & 3,2 & 75,2 & 51,8 & 8,3 & 1,3 & 3,2 & 5,3 & 14,6 & 0,4 & 13,1 \\
\hline 45 & 0,2 & 1,3 & 39,8 & 2,7 & 0,5 & 3,3 & 75,6 & 64,1 & 8,8 & 1,3 & 2,6 & 5,8 & 13,8 & 0,4 & 13,6 \\
\hline 46 & 0,4 & 1,4 & 46,3 & 3,0 & 0,5 & 3,8 & 88,9 & 89,0 & 8,3 & 1,2 & 4,5 & 5,1 & 17,3 & 1,2 & 16,0 \\
\hline 47 & 0,7 & 2,0 & 39,0 & 3,3 & 0,5 & 2,9 & 75,2 & 60,9 & 5,7 & 1,3 & 4,6 & 6,2 & 14,1 & 1,1 & 13,7 \\
\hline
\end{tabular}


Tabela 4. Continuação.

\begin{tabular}{|c|c|c|c|c|c|c|c|c|c|c|c|c|c|c|c|}
\hline Amostra & $\mathrm{Na} \%$ & $\mathrm{~K} \%$ & $\mathrm{La}$ & $\mathrm{Yb}$ & $\mathrm{Lu}$ & $\mathrm{U}$ & $\mathrm{Ce}$ & $\mathrm{Cr}$ & Cs & $\mathrm{Eu}$ & $\mathrm{Fe} \%$ & $\mathrm{Hf}$ & Sc & $\mathrm{Tb}$ & Th \\
\hline 48 & 0,4 & 1,0 & 44,7 & 3,0 & 0,5 & 3,9 & 82,5 & 61,6 & 7,2 & 1,3 & 3,1 & 6,5 & 15,4 & 0,9 & 14,2 \\
\hline 49 & 0,2 & 1,4 & 37,4 & 2,6 & 0,4 & 3,6 & 68,8 & 56,0 & 5,2 & 1,1 & 3,7 & 5,2 & 14,4 & 0,7 & 14,5 \\
\hline 50 & 0,4 & 1,6 & 42,8 & 2,9 & 0,5 & 3,6 & 79,0 & 71,4 & 9,9 & 1,1 & 4,4 & 4,8 & 16,3 & 0,8 & 15,4 \\
\hline 51 & 0,3 & 1,6 & 35,1 & 2,9 & 0,4 & 3,9 & 67,5 & 67,0 & 9,0 & 0,9 & 2,6 & 6,9 & 14,6 & 0,4 & 13,4 \\
\hline 52 & 0,5 & 1,8 & 39,4 & 2,9 & 0,5 & 3,3 & 73,1 & 55,5 & 5,6 & 1,3 & 3,3 & 5,8 & 13,9 & 0,9 & 11,9 \\
\hline 53 & 0,4 & 1,5 & 37,9 & 1,9 & 0,4 & 3,0 & 68,2 & 61,8 & 7,4 & 1,0 & 3,2 & 4,9 & 14,4 & 0,3 & 11,9 \\
\hline 54 & 0,2 & 1,6 & 40,5 & 2,3 & 0,4 & 2,6 & 73,2 & 59,5 & 10,5 & 1,0 & 2,9 & 3,8 & 14,3 & 0,6 & 12,6 \\
\hline 55 & 0,2 & 1,3 & 31,3 & 2,6 & 0,4 & 3,0 & 56,4 & 57,8 & 9,1 & 0,7 & 2,8 & 5,9 & 13,7 & 0,4 & 12,7 \\
\hline 56 & 0,5 & 1,7 & 34,8 & 2,7 & 0,4 & 2,4 & 67,1 & 53,4 & 8,0 & 1,2 & 3,8 & 5,8 & 13,5 & 0,9 & 10,9 \\
\hline 57 & 0,5 & 2,6 & 43,8 & 3,3 & 0,5 & 2,7 & 80,0 & 62,9 & 8,6 & 1,4 & 3,6 & 5,7 & 16,2 & 1,3 & 14,4 \\
\hline 58 & 0,4 & 1,3 & 36,3 & 2,6 & 0,4 & 3,0 & 66,6 & 50,9 & 6,8 & 1,1 & 4,3 & 5,5 & 13,4 & 0,8 & 11,9 \\
\hline 59 & 0,4 & 1,3 & 39,2 & 2,5 & 0,4 & 2,7 & 71,8 & 63,3 & 6,1 & 1,2 & 3,1 & 6,6 & 14,4 & 0,7 & 14,7 \\
\hline 60 & 0,4 & 1,2 & 36,1 & 2,9 & 0,5 & 2,9 & 68,2 & 56,4 & 5,1 & 1,2 & 2,8 & 4,6 & 13,2 & 0,8 & 11,2 \\
\hline 61 & 0,4 & 1,1 & 29,3 & 2,3 & 0,4 & 3,0 & 56,3 & 58,3 & 7,5 & 0,9 & 3,6 & 4,8 & 13,2 & 0,5 & 11,7 \\
\hline 62 & 0,2 & 1,0 & 37,7 & 2,4 & 0,4 & 3,3 & 67,0 & 55,7 & 5,9 & 1,1 & 3,5 & 3,8 & 13,8 & 0,9 & 12,9 \\
\hline 63 & 0,3 & 1,4 & 33,3 & 2,5 & 0,4 & 2,6 & 61,0 & 52,0 & 5,9 & 0,9 & 2,2 & 5,6 & 11,4 & 0,6 & 12,1 \\
\hline 64 & 0,2 & 1,1 & 46,7 & 2,8 & 0,5 & 3,6 & 87,5 & 76,4 & 9,3 & 1,2 & 4,3 & 5,2 & 17,0 & 0,7 & 16,6 \\
\hline 65 & 0,2 & 1,2 & 39,7 & 2,4 & 0,4 & 3,3 & 75,4 & 61,6 & 6,9 & 1,1 & 3,7 & 3,8 & 14,7 & 0,8 & 12,9 \\
\hline 66 & 0,2 & 1,2 & 46,6 & 2,9 & 0,4 & 3,5 & 81,8 & 69,3 & 8,2 & 1,3 & 3,2 & 4,5 & 16,7 & 0,7 & 14,4 \\
\hline 67 & 0,2 & 1,2 & 38,8 & 2,5 & 0,4 & 3,2 & 70,9 & 58,4 & 5,7 & 1,1 & 3,6 & 3,2 & 14,0 & 0,5 & 12,5 \\
\hline 68 & 0,2 & 1,2 & 39,4 & 2,4 & 0,4 & 3,1 & 69,7 & 58,1 & 5,9 & 1,0 & 3,6 & 3,7 & 14,4 & 0,5 & 12,6 \\
\hline 69 & 0,1 & 1,0 & 49,2 & 3,0 & 0,4 & 3,3 & 91,5 & 76,1 & 6,3 & 1,5 & 3,7 & 5,4 & 17,5 & 1,0 & 15,7 \\
\hline 70 & 0,4 & 1,6 & 39,6 & 2,7 & 0,4 & 3,5 & 72,8 & 62,1 & 10,6 & 1,5 & 3,6 & & 16,4 & 0,6 & 14,2 \\
\hline 71 & 0,5 & 1,6 & 46,2 & 3,3 & 0,5 & 3,6 & 87,0 & 81,4 & 6,5 & 1,4 & 4,4 & 4,7 & 17,1 & 1,1 & 14,3 \\
\hline 72 & 0,4 & 1,2 & 37,5 & 3,0 & 0,4 & 3,6 & 68,1 & 59,3 & 4,8 & 1,1 & 4,5 & 6,6 & 13,5 & 1,0 & 12,4 \\
\hline 73 & 0,2 & 1,4 & 43,6 & 2,7 & 0,5 & 3,7 & 83,8 & 76,2 & 10,0 & 1,4 & 3,1 & 4,0 & 17,5 & 0,9 & 15,4 \\
\hline 74 & 0,3 & 1,3 & 41,7 & 3,1 & 0,5 & 3,8 & 78,7 & 62,1 & 5,7 & 1,5 & 3,5 & 6,5 & 15,9 & 1,0 & 14,4 \\
\hline 75 & 0,2 & 1,2 & 93,9 & 7,7 & 1,2 & 7,5 & 75,3 & 62,0 & 6,2 & 1,4 & 3,5 & 4,3 & 14,8 & 0,4 & 12,3 \\
\hline 76 & 0,2 & 1,2 & 50,1 & 3,3 & 0,5 & 2,6 & 96,8 & 65,2 & 7,6 & 1,8 & 3,4 & 5,0 & 16,9 & 1,0 & 14,7 \\
\hline 77 & 0,4 & & 39,9 & 2,6 & 0,4 & 2,8 & 76,6 & 58,9 & 8,0 & 1,4 & 3,5 & 3,6 & 15,1 & 0,7 & 13,1 \\
\hline 78 & 0,4 & 1,2 & 35,7 & 2,6 & 0,4 & 2,8 & 69,2 & 63,8 & 6,5 & 1,1 & 3,9 & 4,3 & 14,2 & 0,4 & 11,3 \\
\hline 79 & 0,7 & 1,2 & 35,4 & 2,8 & 0,4 & 2,2 & 68,7 & 54,6 & 3,5 & 1,4 & 4,0 & 5,8 & 13,4 & 0,8 & 11,4 \\
\hline 80 & 0,4 & 1,2 & 37,9 & 2,9 & 0,4 & 2,4 & 74,7 & 56,4 & 8,6 & 1,4 & 2,8 & 4,1 & 14,1 & 0,7 & 11,9 \\
\hline 81 & 0,2 & 1,2 & 46,2 & 3,2 & 0,6 & $\mathbf{3 , 3}$ & 86,7 & 76,4 & 2,6 & 1,5 & 4,7 & 4,8 & 17,3 & 1,0 & 15,5 \\
\hline 82 & 0,3 & 1,2 & 34,4 & 1,6 & 0,4 & 2,0 & 65,6 & 50,2 & 8,3 & 1,1 & 3,1 & 3,1 & 13,4 & 0,6 & 12,0 \\
\hline 83 & 0,2 & 1,2 & 39,9 & 2,3 & 0,4 & 2,9 & 72,4 & 57,1 & 6,2 & 1,2 & 4,4 & 3,6 & 14,9 & 0,5 & 12,3 \\
\hline 84 & 0,2 & 1,3 & 26,9 & 2,7 & 0,4 & 3,4 & 52,2 & 65,3 & 4,9 & 0,9 & 3,3 & 8,9 & 13,6 & 0,6 & 13,6 \\
\hline 85 & 0,5 & 1,6 & 38,9 & 2,8 & 0,4 & 2,9 & 74,7 & 61,5 & 8,6 & 1,3 & 3,6 & 4,5 & 14,4 & 0,5 & 12,0 \\
\hline 86 & 0,4 & 1,8 & 41,1 & 2,7 & 0,4 & 3,6 & 92,9 & 64,0 & 8,0 & 1,3 & 2,9 & 4,8 & 15,6 & 0,8 & 13,2 \\
\hline 87 & 0,2 & 1,2 & 38,8 & 2,6 & 0,4 & 3,3 & 71,1 & 62,4 & 6,6 & 1,2 & 3,3 & 5,5 & 14,2 & 0,8 & 13,2 \\
\hline 88 & 0,2 & 1,1 & 44,9 & 2,7 & 0,4 & 4,2 & 84,9 & 68,5 & 6,0 & 1,3 & 2,6 & 4,4 & 15,4 & 0,8 & 14,5 \\
\hline 89 & $\mathbf{0 , 3}$ & 1,4 & 32,2 & 1,8 & 1,1 & 2,8 & 56,8 & 47,4 & 4,4 & 0,9 & 2,8 & 3,6 & 11,2 & 0,4 & 10,2 \\
\hline 90 & 0,4 & 1,4 & 31,7 & 2,9 & 0,4 & 3,3 & 60,1 & 68,0 & 8,2 & 1,0 & 3,3 & 7,2 & 14,8 & 0,6 & 13,7 \\
\hline 91 & 0,1 & 0,8 & 29,5 & 3,2 & 0,5 & 3,7 & 63,3 & 62,7 & 3,2 & 1,2 & 1,6 & 9,8 & 11,1 & 0,7 & 11,1 \\
\hline 92 & 0,1 & 0,6 & 32,4 & 1,9 & 0,3 & 3,2 & 57,3 & 54,2 & 4,0 & 0,7 & 3,3 & 5,8 & 11,9 & 0,3 & 11,9 \\
\hline 93 & 0,3 & 1,2 & 34,8 & 2,6 & 0,4 & 2,7 & 63,7 & 52,2 & 4,3 & 1,2 & 4,1 & 4,6 & 13,6 & 0,4 & 12,0 \\
\hline 94 & 0,2 & 0,8 & 35,0 & 2,9 & 0,5 & 3,2 & 66,9 & 63,5 & 7,8 & 1,2 & 3,5 & 9,8 & 13,9 & 0,9 & 12,0 \\
\hline 95 & 0,2 & 0,6 & 34,7 & 1,8 & 0,4 & 3,3 & 62,3 & 55,4 & 5,9 & 0,8 & 2,8 & 6,4 & 12,4 & 0,4 & 12,4 \\
\hline
\end{tabular}


Tabela 4. Continuação.

\begin{tabular}{|c|c|c|c|c|c|c|c|c|c|c|c|c|c|c|c|}
\hline Amostra & $\mathrm{Na} \%$ & $\mathrm{~K} \%$ & $\mathrm{La}$ & $\mathrm{Yb}$ & $\mathrm{Lu}$ & $\mathrm{U}$ & $\mathrm{Ce}$ & $\mathrm{Cr}$ & Cs & $\mathrm{Eu}$ & $\mathrm{Fe} \%$ & Hf & $\mathrm{Sc}$ & $\mathrm{Tb}$ & Th \\
\hline 96 & 0,3 & 0,5 & 45,3 & 3,2 & 0,4 & 2,9 & 85,3 & 64,8 & 2,9 & 1,6 & 2,6 & 6,6 & 12,2 & 0,7 & 12,5 \\
\hline 97 & 0,2 & 1,2 & 36,0 & 2,5 & 0,4 & 2,8 & 67,9 & 59,0 & 4,8 & 1,2 & 3,3 & 3,8 & 14,6 & 0,6 & 12,1 \\
\hline 98 & 0,4 & 1,3 & 29,2 & 2,9 & 0,4 & 3,7 & 59,3 & 65,5 & 7,2 & 1,1 & 4,2 & 6,8 & 14,7 & 0,7 & 13,3 \\
\hline 99 & 0,2 & 1,3 & 41,0 & 3,0 & 0,5 & 3,7 & 78,5 & 69,2 & 6,5 & 1,3 & 3,6 & 5,0 & 16,6 & 0,9 & 14,7 \\
\hline 100 & 0,1 & 0,7 & 43,2 & 3,5 & 0,5 & 3,5 & 82,4 & 68,7 & 4,9 & 1,4 & 3,4 & 8,2 & 14,8 & 0,5 & 13,0 \\
\hline 101 & 0,4 & 1,5 & 40,8 & 3,1 & 0,5 & 2,9 & 77,4 & 62,4 & 6,2 & 1,3 & 3,4 & 4,6 & 15,2 & 0,6 & 12,9 \\
\hline 102 & 0,1 & 0,8 & 42,7 & 2,9 & 0,5 & 3,2 & 78,6 & 71,7 & 7,1 & 1,3 & 4,2 & 4,4 & 16,9 & 0,8 & 14,8 \\
\hline 103 & 0,3 & 1,1 & 36,2 & 2,6 & 0,4 & 3,0 & 66,2 & 51,7 & 5,4 & 1,0 & 3,8 & 5,2 & 12,7 & 0,6 & 10,5 \\
\hline 104 & 0,1 & 1,1 & 37,4 & 3,7 & 0,6 & 3,6 & 76,2 & 70,9 & 8,2 & 1,9 & 1,7 & 5,7 & 15,6 & 0,9 & 13,2 \\
\hline 105 & 0,2 & 1,0 & 32,7 & 2,6 & 0,4 & 3,6 & 67,1 & 54,2 & 4,9 & 1,3 & 2,7 & 3,6 & 13,5 & 0,6 & 11,8 \\
\hline 106 & 0,1 & 0,4 & 25,0 & 2,9 & 0,5 & 3,5 & 51,1 & 58,8 & 4,2 & 1,1 & 1,7 & 8,6 & 11,8 & 0,8 & 12,9 \\
\hline 107 & 0,1 & 0,5 & 26,4 & 3,0 & 0,5 & 3,5 & 58,7 & 53,1 & 3,8 & 1,4 & 1,7 & 9,1 & 11,8 & 0,8 & 13,3 \\
\hline 108 & 0,4 & 1,0 & 35,2 & 2,5 & 0,4 & 2,9 & 66,0 & 56,8 & 6,6 & 1,1 & 4,3 & 5,0 & 13,3 & 0,6 & 12,3 \\
\hline 109 & 0,4 & 1,2 & 35,4 & 2,6 & 0,4 & 3,5 & 66,8 & 58,5 & 6,4 & 1,1 & 4,2 & 5,1 & 13,4 & 0,8 & 12,2 \\
\hline 110 & 0,4 & 1,6 & 41,9 & 3,0 & 0,5 & 3,3 & 78,7 & 70,2 & 7,9 & 1,2 & 4,0 & 6,6 & 16,9 & 0,4 & 14,8 \\
\hline 111 & 0,1 & 1,4 & 40,8 & 3,1 & 0,5 & 3,4 & 64,5 & 78,9 & 6,9 & 1,2 & 3,6 & 7,0 & 15,8 & 0,8 & 15,6 \\
\hline 112 & 0,5 & 1,6 & 48,4 & 3,3 & 0,5 & 3,8 & 88,7 & 79,7 & 7,8 & 1,4 & 4,0 & 6,2 & 18,2 & 1,1 & 15,7 \\
\hline 113 & 0,4 & 1,4 & 38,8 & 3,0 & 0,4 & 2,9 & 75,1 & 62,3 & 5,8 & 1,5 & 2,8 & 4,3 & 15,2 & 0,6 & 12,3 \\
\hline 114 & 0,2 & 0,9 & 51,3 & 3,6 & 0,6 & 3,3 & 95,3 & 58,1 & 4,3 & 1,6 & 3,1 & 8,4 & 15,1 & 0,9 & 14,3 \\
\hline 115 & 0,5 & 1,8 & 50,2 & 3,6 & 0,6 & 4,1 & 94,9 & 71,5 & 8,7 & 1,3 & 4,3 & 6,4 & 18,8 & 0,9 & 15,9 \\
\hline 116 & 0,1 & 0,5 & 42,9 & 2,6 & 0,4 & 2,4 & 82,0 & 68,4 & 3,8 & 1,2 & 3,5 & 5,2 & 13,9 & 0,5 & 13,5 \\
\hline 117 & 0,3 & 1,1 & 35,5 & 2,4 & 0,4 & 1,9 & 65,6 & 60,7 & 4,7 & 1,1 & 3,5 & 4,4 & 12,7 & 0,5 & 12,5 \\
\hline 118 & 0,2 & 1,1 & 47,5 & 3,6 & 0,6 & 4,0 & 91,4 & 65,4 & 6,8 & 1,3 & 3,3 & 14,4 & 16,7 & 0,4 & 20,0 \\
\hline 119 & 0,2 & 1,3 & 46,4 & 3,6 & 0,6 & 3,8 & 91,9 & 66,4 & 6,9 & 1,4 & 3,4 & 13,4 & 16,4 & 0,3 & 18,9 \\
\hline 120 & 0,4 & 1,4 & 47,1 & 3,2 & 0,5 & 3,4 & 89,6 & 73,0 & 7,6 & 1,4 & 4,4 & 4,7 & 17,3 & 0,8 & 14,6 \\
\hline 121 & 0,1 & 1,1 & 43,5 & 3,4 & 0,5 & 3,3 & 81,8 & 63,1 & 6,8 & 1,1 & 3,4 & 7,2 & 15,4 & 0,5 & 15,3 \\
\hline 122 & 0,5 & 1,7 & 48,9 & 3,4 & 0,5 & 4,1 & 89,3 & 75,2 & 9,5 & 1,4 & 3,6 & 4,2 & 18,4 & 0,6 & 15,9 \\
\hline 123 & 0,3 & 0,8 & 37,4 & 2,7 & 0,4 & 3,1 & 72,7 & 66,1 & 3,2 & 0,8 & 2,7 & 9,0 & 12,2 & 0,6 & 13,2 \\
\hline 124 & 0,3 & 0,6 & 33,5 & 2,8 & 0,5 & 3,4 & 60,6 & 58,9 & 4,7 & 1,0 & 2,9 & 10,8 & 11,7 & 0,6 & 12,5 \\
\hline 125 & 0,3 & 1,7 & 60,6 & 3,6 & 0,6 & 3,6 & 103,0 & 62,5 & 7,8 & 1,8 & 3,5 & 6,3 & 17,8 & 1,2 & 17,5 \\
\hline 126 & 0,2 & 1,2 & 45,7 & 3,4 & 0,6 & 3,6 & 84,8 & 66,7 & 6,3 & 1,3 & 3,1 & 11,4 & 15,6 & 0,7 & 17,7 \\
\hline 127 & 0,2 & 1,2 & 48,3 & 3,7 & 0,6 & 3,6 & 90,3 & 64,5 & 6,1 & 1,4 & 3,2 & 11,6 & 16,3 & 0,9 & 18,5 \\
\hline
\end{tabular}




\subsubsection{Análise de conglomerado}

Após a remoção das amostras discrepantes, os resultados obtidos para as concentrações elementares de 120 fragmentos cerâmicos foram submetidos à análise estatística multivariada.

Inicialmente, usou-se a análise de agrupamentos. Esta análise forneceu a obtenção de uma visão mais ampla dos dados, uma vez que o dendograma representa toda a variação do conjunto de amostras. O dendograma (Figura 8) mostra as semelhanças entre as amostras de cerâmica e os agrupamentos formados. As amostras separaram-se em cinco grupos, mostrando a similaridade na composição química entre amostras reunidas em cada grupo. Isto permite inferir que há cinco fontes distintas de matérias-primas usadas na fabricação dos artefatos cerâmicos do sítio arqueológico Hatahara.

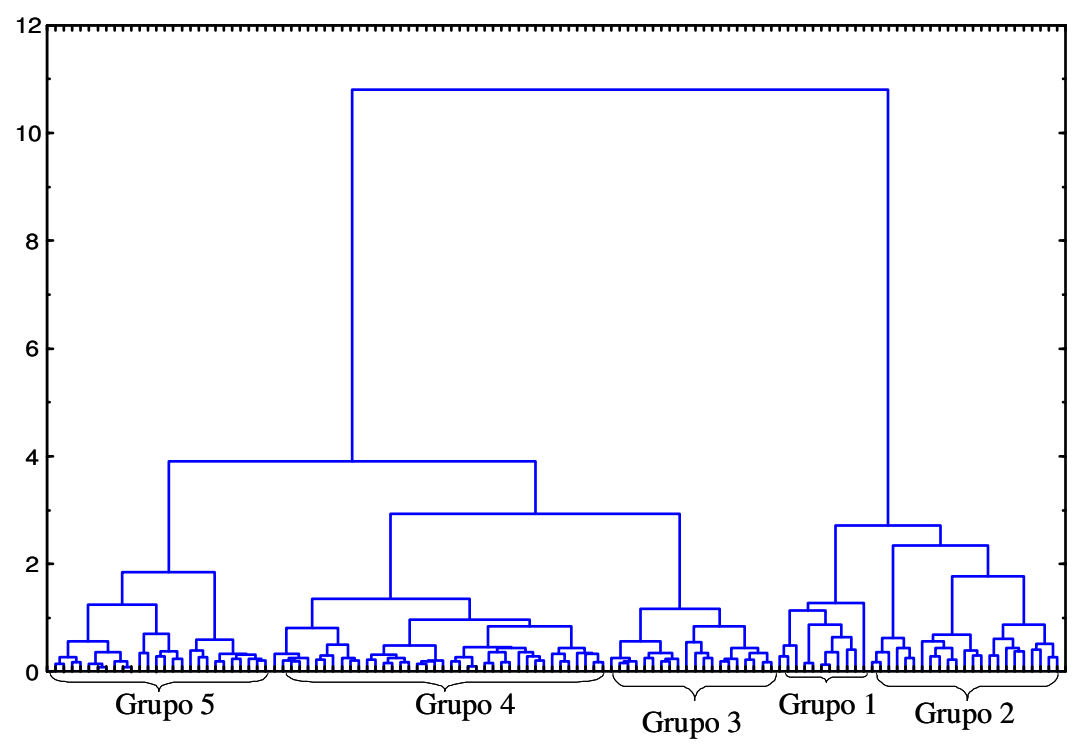

Figura 8. Dendograma das amostras de cerâmica usando distância Euclidiana e método de Ward.

\subsubsection{Análise discriminante}

Após conhecer quantos grupos estão envolvidos na análise, foi aplicada a análise discriminante para as amostras de cerâmicas. Esta análise, em relação à análise agrupamentos é considerada mais refinada, visto que já é conhecido o número de grupos participantes. A função discriminante 1 vs função discriminante 2 apresentada na Figura 9 mostra os cinco grupos com as amostras pertencentes a cada grupo, o que permite perceber 
que não ocorreu uma variação quanto ao número de grupos cerâmicos formados pelo dendograma.

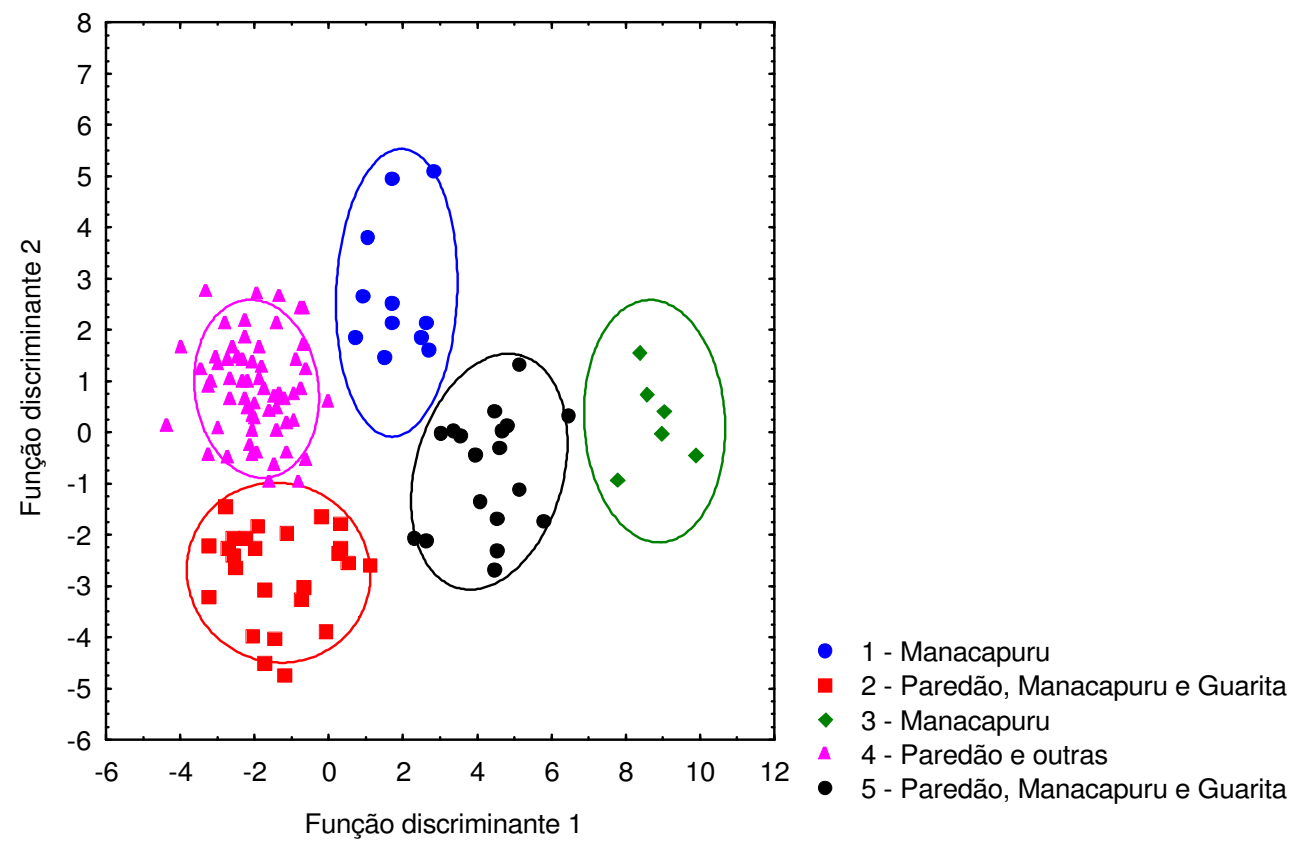

Figura 9. Função discriminante 1 vs função discriminante 2 das cerâmicas.

Do ponto de vista arqueológico, têm-se para o sítio arqueológico Hatahara pelo menos quatro distintas ocupações pré-coloniais (REBELLATO, 2007). Com base no perfil estratigráfico elaborado para os montículos escavados, disposto de forma vertical e ocupando aproximadamente $2.50 \mathrm{~m}$ de profundidade, tem-se a primeira e mais profunda camada com uma espessura de $20 \mathrm{~cm}$. Trata-se de uma região composta por pouco material arqueológico relacionado à Fase Açutuba, a qual representa a mais antiga ocupação do sítio, cujo tempo de permanência estendeu-se de 300 aC a 360 dC e é interpretada como uma Fase não associada à formação de terra preta antropogênica na região. Por meio da observação da Figura 9, vê-se que não foram encontradas cerâmicas relacionadas a esta Fase.

Seguindo uma sequiência na estratigrafia tem-se logo acima a segunda camada correspondente a uma espessura de $50 \mathrm{~cm}$, localizada aproximadamente entre $2.30 \mathrm{~m}$ e $1.80 \mathrm{~m}$. Nesta camada encontra-se pouca quantidade de fragmentos cerâmicos pertencentes à Fase Manacapuru, considerada ser a primeira a dar origem à terra preta. $\mathrm{O}$ tempo de ocupação da Fase Manacapuru na região se estende do século V ao século IX. Encontramse pertencentes a esta fase, cerâmicas de formas variadas, normalmente temperadas com 
cauixí. A decoração consiste essencialmente na modelagem de figuras abstratas, zoomorfas e antropomorfas, incisões simples paralelas retilíneas e curvilíneas e engobo vermelho, entre outros elementos. Características marcantes são: a presença de flanges labiais, normalmente usadas como suporte para decoração incisa, em linhas simples ou paralelas, com motivos curvilíneos e retilíneos; a aplicação, nos lábios, de apêndices modelados zoomorfos ou antropomorfos e a presença de lábios planos. Existe, portanto, uma variabilidade maior na tipologia das cerâmicas relacionadas a esta Fase.

Os grupos de cerâmicas 1 e 3 da função discriminante 1 vs função discriminante 2 da Figura 9 estão representados pelas cerâmicas pertencentes a Fase Manacapuru e foram agrupadas segundo a similaridade em suas composições químicas. A formação destes grupos mostrou consistência, uma vez que revelou somente a presença de cerâmicas relacionadas a esta Fase, porém, foi utilizada uma fonte de argila diferente para cada grupo destas cerâmicas. As características mais comuns nas cerâmicas do grupo 1 são a borda simples, incisões paralelas e curvilíneas com acanalado nos lábios. No grupo 3 as cerâmicas possuem como características flanges labiais com acanalado ou incisões paralelas.

Logo acima na estratigrafia se encontra a terceira camada, situada entre $1.80 \mathrm{~m}$ e $1.10 \mathrm{~m}$ de profundidade, ocupando, portanto, uma espessura de $70 \mathrm{~cm}$. Nela, se encontra terra preta parcialmente misturada com latossolo amarelo em sua parte inferior e terra preta na sua parte superior. Com relação à presença de fragmentos cerâmicos, esta camada possui densidade média de cerâmicas associadas à Fase Paredão, que ocupou o sítio desde o final do século VII até o século XI.

Acima desta região na estratrigrafia está localizada a quarta camada com $60 \mathrm{~cm}$ de espessura. Nesta camada encontra-se alta densidade de cerâmicas, tanto da Fase Paredão como da Fase Guarita. Com relação a esta parte da estratigrafia, notou-se que a quarta camada pôde ser dividida em três subcamadas, levando em consideração a densidade, tamanho e disposição dos fragmentos cerâmicos encontrados (MACHADO, 2005). Sendo assim, na primeira subcamada foi observada alta concentração de grandes fragmentos da Fase Paredão. Já a próxima subcamada, a camada intermediária, foi encontrada baixa densidade de cerâmicas, terra preta e restos de fauna. Na subcamada acima, a terceira e última subdivisão, encontraram-se novamente alta densidade de fragmentos cerâmicos das Fases Paredão e Guarita. 
A variabilidade entre as cerâmicas para a fase Paredão é pequena, se comparada aos outros complexos cerâmicos amazônicos. As formas mais comuns são os vasos com alça (fruteiras), cuias, algumas com pedestais e grandes urnas funerárias. A decoração é feita com pintura vermelha com motivos geométricos em espiral e apêndices antropomorfos (sempre aplicados nas urnas). O tempero mais utilizado também é o cauixí (LIMA et al., 2006).

Por meio da Figura 9 é possível perceber que há maior densidade de cerâmicas nos grupos em que há presença de cerâmicas da Fase Paredão (grupos 2, 4 e 5). Isto se deve ao fato de existir mais cerâmicas da Fase Paredão, do que cerâmicas de outras Fases. No grupo 2 a incidência de cerâmicas Paredão corresponde a 50\%, enquanto $25 \%$ do grupo conta com fragmentos da Fase Manacapuru e 25\% da Fase Guarita. Também, no grupo 4 a freqüiência maior de fragmentos corresponde à Fase Paredão, representando 65\% deste grupo. O restante, correspondente a 35\% das cerâmicas, merece maiores investigações, pois, de acordo com a interpretação arqueológica, estes fragmentos não se enquadram em nenhuma das características tipológicas referentes às Fases de ocupação do sítio.

Por esta razão, será apresentada uma análise a seguir, somente com relação ao grupo 4. Para isto, os resultados das concentrações elementares de 44 fragmentos deste grupo foram submetidos à análise de conglomerado.

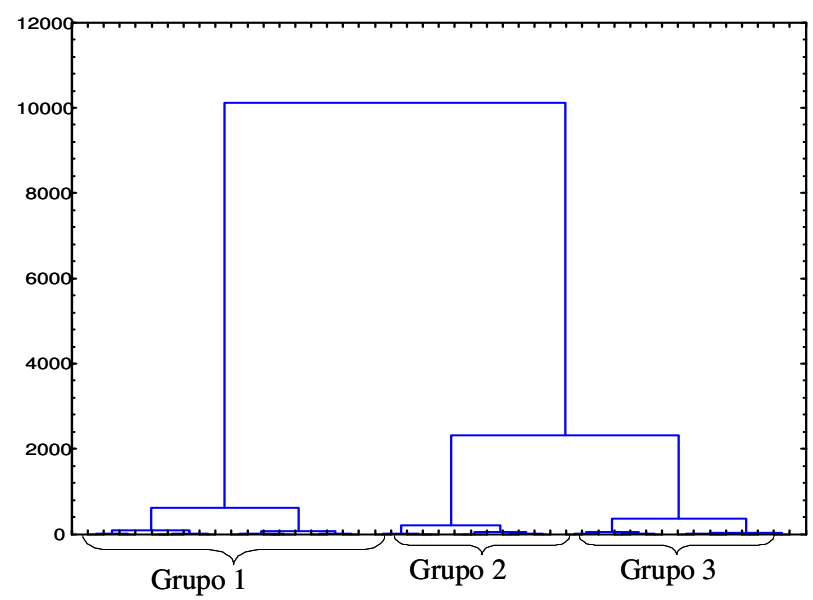

Figura 10. Dendograma das amostras de cerâmica (Fase Paredão e outras) usando distância Euclidiana e método de Ward.

O dendograma da Figura 10 mostra a separação destas amostras em três grupos distintos. Em seguida, estes resultados foram submetidos à análise discriminante. Na 
Figura 11 encontra-se a Função discriminante 1 vs função discriminante 2 para estas amostras.

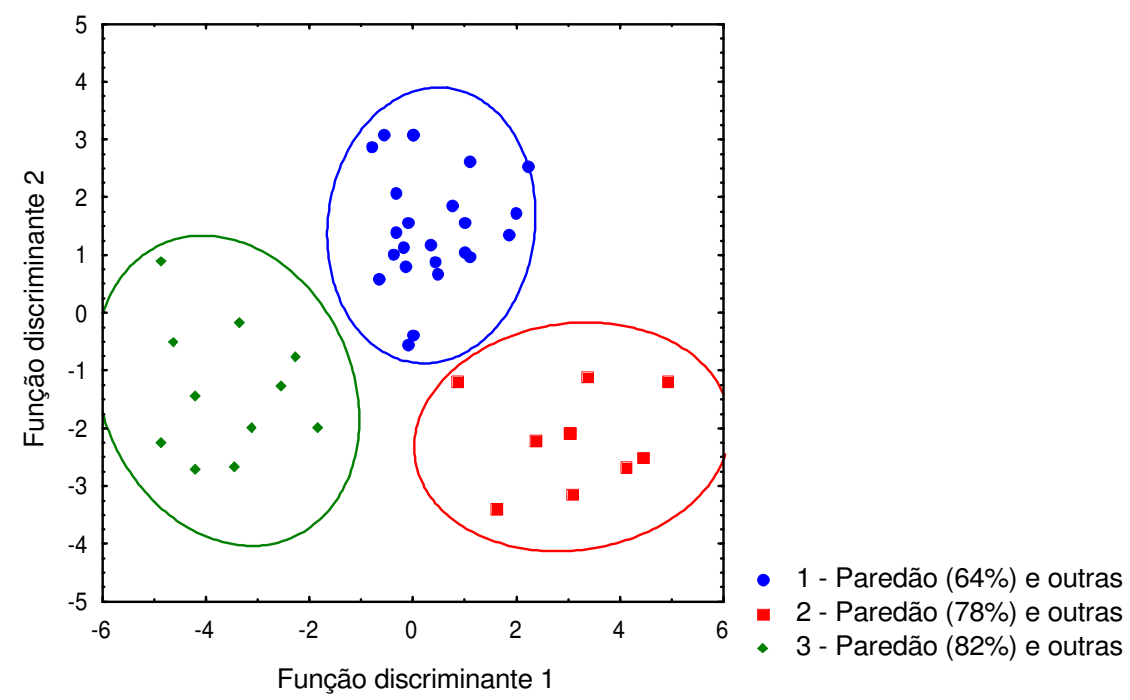

Figura 11. Função discriminante 1 vs função discriminante 2 das cerâmicas Paredão e outras.

Os resultados mostraram que as cerâmicas da Fase Paredão distribuíram-se entre os três grupos cerâmicos. As cerâmicas que não fazem parte de nenhuma das tipologias também se encontram formando parte dos três grupos destas cerâmicas. No primeiro grupo de cerâmicas Paredão, as cerâmicas de Fase desconhecida representam $36 \%$ deste grupo. No segundo grupo, estas cerâmicas representam $22 \%$ deste grupo. E no terceiro grupo estas cerâmicas representam 18\% deste grupo. Provavelmente, uma ou mais Fases ocuparam o sítio Hatahara e estiveram relacionadas à Fase Paredão.

A ocupação mais recente na Amazônia central é representada pela Fase Guarita, estendendo-se entre os séculos X e XVI. As cerâmicas correspondentes a esta Fase encontram-se na quinta e última camada, a qual apresenta grande quantidade de terra preta associada à densidade média de fragmentos cerâmicos. Há também, em menor quantidade, fragmentos da Fase Paredão e poucos fragmentos da Fase Manacapuru. Esta região na estratigrafia percorre uma região situada entre $50 \mathrm{~cm}$ e a superfície do sítio.

Cerâmicas da fase Guarita estão dispersas por sítios encontrados em toda a Amazônia central, sendo caracterizadas pela pintura policrômica (vermelho e preto) sobre engobo branco, pela presença de vasos típicos com flanges mesiais e decoração acanalada e também por urnas funerárias antropomorfas. O tempero mais utilizado é o cariapé. As cerâmicas associadas à Tradição Polícroma da Amazônia distribuem-se desde a Ilha de Marajó até o alto Amazonas. Cerâmicas da Tradição Polícroma foram produzidas por meio 
de técnicas complexas de decoração e estão associadas a sepultamentos em urnas identificados em sítios normalmente de grande porte e de ocupação longa.

Na Figura 9 o grupo 5 está representado por cerâmicas que remontam $50 \%$ à Fase Guarita, 25\% à Fase Paredão e 25\% à Fase Manacapuru. Para a fabricação dos artefatos que formam parte do grupo 5 foi usada uma única fonte de argila. Os resultados confirmam como as antigas sociedades ocuparam o sítio arqueológico Hatahara. A ocorrência de cerâmicas num mesmo grupo com classificações tipológicas diferentes, as quais se referem a Fases distintas de ocupação, com mesma fonte de matéria-prima, mostra a permanência concomitante das comunidades que se desenvolveram no sítio Hatahara, bem como, a interação entre seus padrões de comportamento e aspectos intrínsecos.

\subsubsection{Determinação da fonte de matéria-prima dos artefatos cerâmicos}

Depois de analisadas as amostras de cerâmica, o segundo passo foi incluir as concentrações elementares das amostras de argila na mesma base de dados das amostras de cerâmica, com o propósito de estudar a fonte da matéria-prima utilizada na produção destes artefatos. Para isso, foram coletadas sete amostras de argila próximas ao sítio Hatahara, sendo cinco amostras coletadas na margem do rio Solimões, em frente a Iranduba, a $6 \mathrm{~km}$ de distância do sítio. As outras duas amostras de argila foram coletadas próximas ao sítio Lago Grande, a aproximadamente 9km de distância do sítio Hatahara. A figura 12 mostra a função 1 vs função discriminante 2 para as sete amostras de argila, juntamente com as amostras de cerâmica.

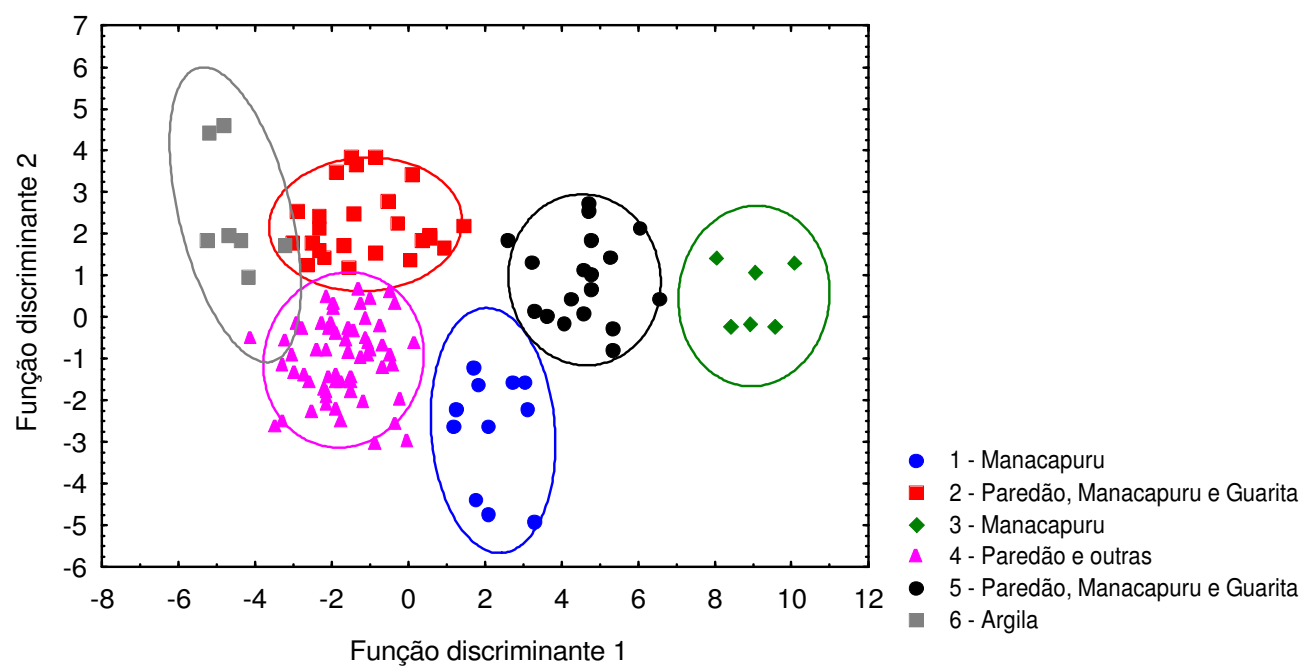

Figura 12. Função discriminante 1 vs função discriminante 2 para as amostras de argila e cerâmicas. 
Por meio da análise do gráfico, é possível notar o comportamento do grupo das argilas em relação ao grupo 2 das cerâmicas. O grupo 6 , representado pelo grupo das argilas, encontra-se bastante próximo ao grupo 2 formado em $50 \%$ por cerâmicas da Fase Paredão e 50\% dividido igualmente entre cerâmicas da Fase Manacapuru e Guarita. Das sete amostras de argila analisadas, observa-se que uma única amostra do grupo 6, ao qual pertencem as argilas coletadas, forma parte do grupo 2 das cerâmicas, e isto permite afirmar que esta argila foi usada como fonte de matéria-prima para a fabricação das cerâmicas do grupo 2, em virtude da similaridade existente entre as composições químicas destas cerâmicas e da argila.

A Figura 13 mostra o mapa da localização da amostra de argila (ponto CSQE41) coletada e o sítio Hatahara. Este ponto situa-se a $6 \mathrm{~km}$ a sudoeste do sítio Hatahara, na Ilha da Paciência, na forma de barrancos nas margens do canal principal. A argila deste local está inserida nos depósitos da planície aluvial do rio Solimões (SOARES et al, 2001; SOARES, 2007). O aspecto argiloso dos depósitos do ponto CSQE-41, sua forma de exposição e a proximidade deste depósito com o sítio Hatahara provavelmente facilitaram o local de escolha da matéria-prima pelas comunidades da época.

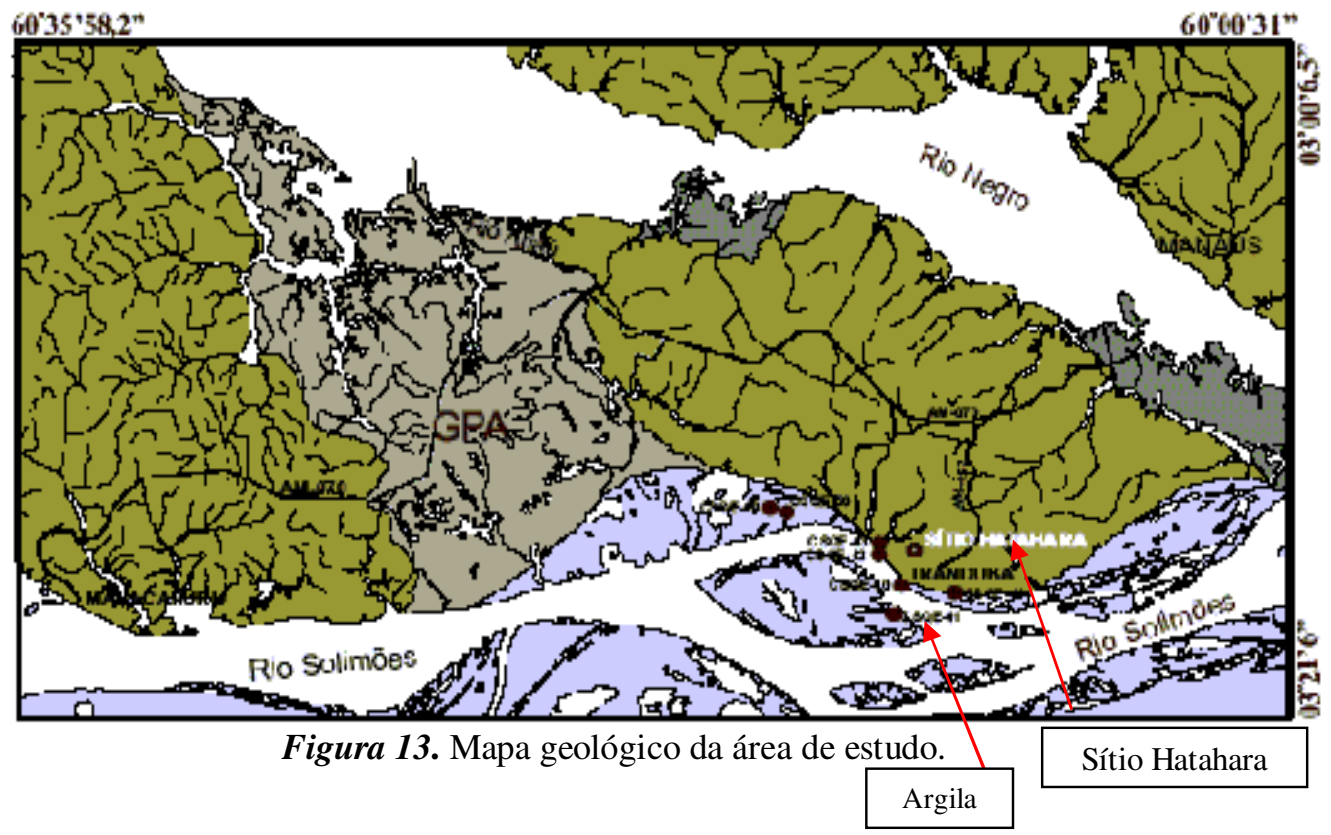


6.2 Resultados obtidos na datação dos fragmentos cerâmicos por TL

A Figura 14 mostra um exemplo de curva de emissão TL obtida para amostra 72.

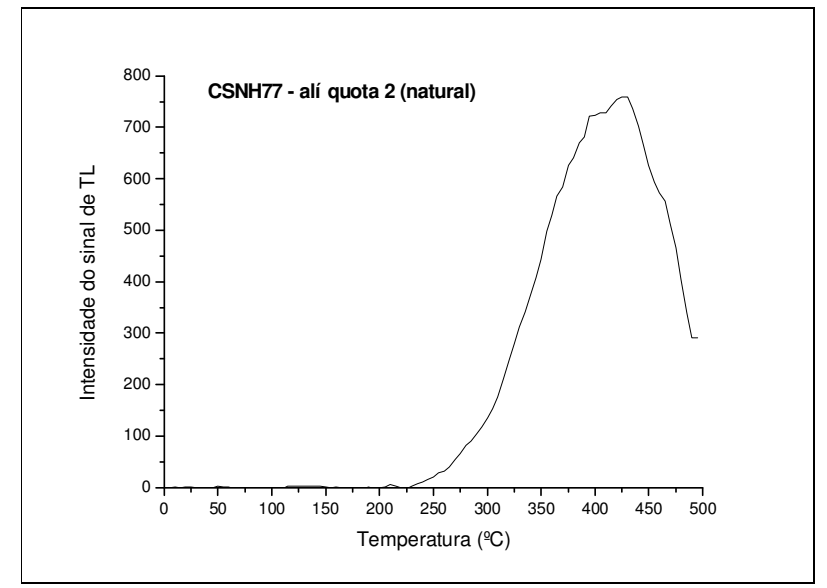

Figura 14. Curva de emissão da intensidade do sinal TL do pico de $375^{\circ} \mathrm{C}$ para a amostra 72 .

Nas Figuras 15, 16 e 17, estão apresentadas as curvas de emissão TL obtidas para cada uma das amostras datadas. Cada curva dentro de cada gráfico representa uma determinada alíquota cujo sinal de emissão TL foi medido.

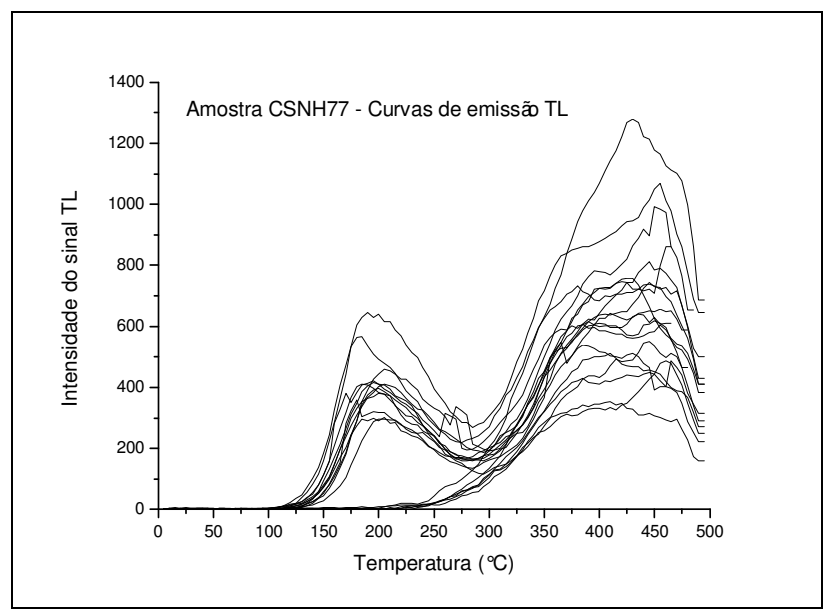

Figura 15. Curvas de emissão TL de todas as alíquotas para a amostra 72. 


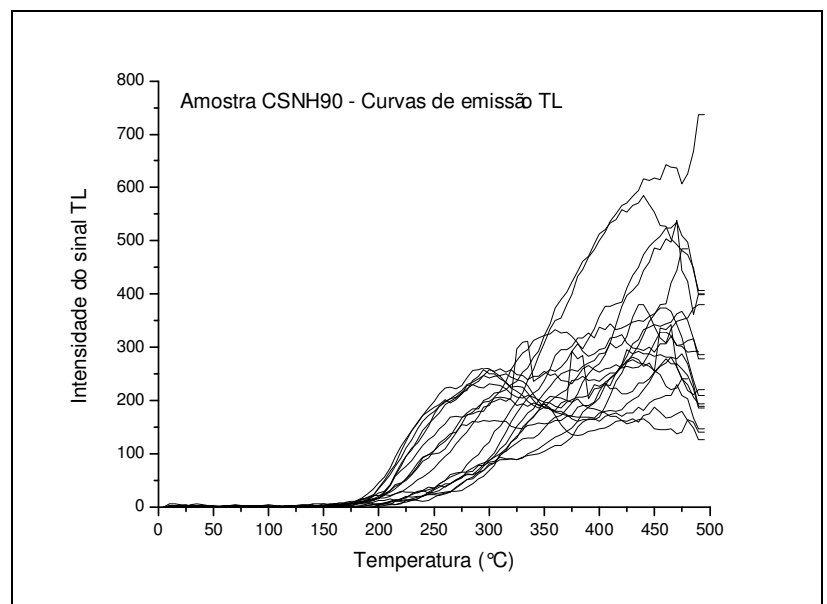

Figura 16. Curvas de emissão TL de todas as alíquotas para a amostra 85.

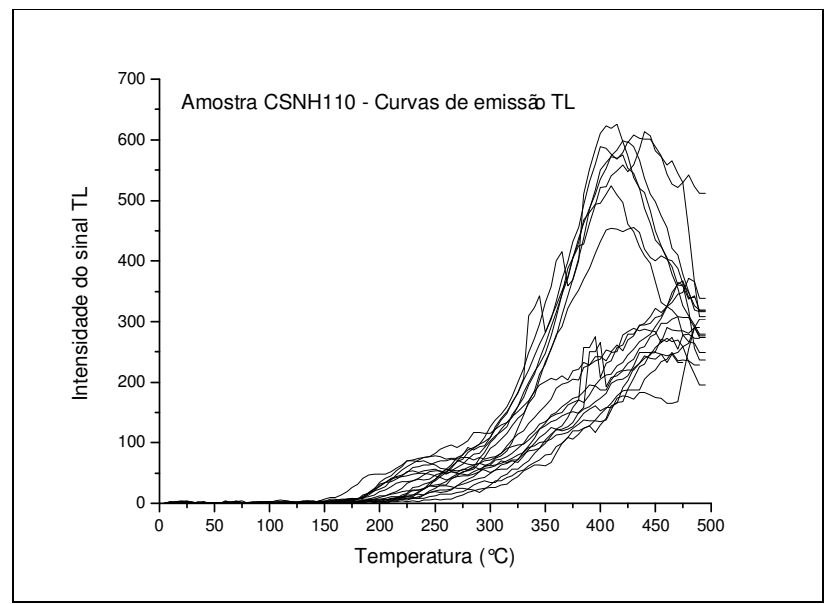

Figura 17. Curvas de emissão TL de todas as alíquotas para a amostra 104.

As Figuras 18, 19 e 20 mostram as curvas de crescimento obtidas para cada amostra datada. Estão representados no gráfico, todos os sinais obtidos de todas as alíquotas medidas.

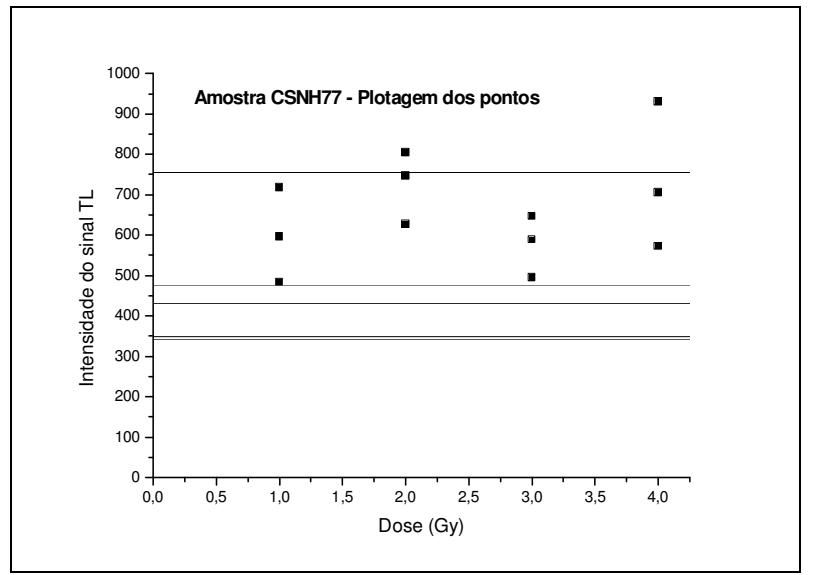

Figura 18. Representação dos sinais de todas as alíquotas para a amostra 72. 


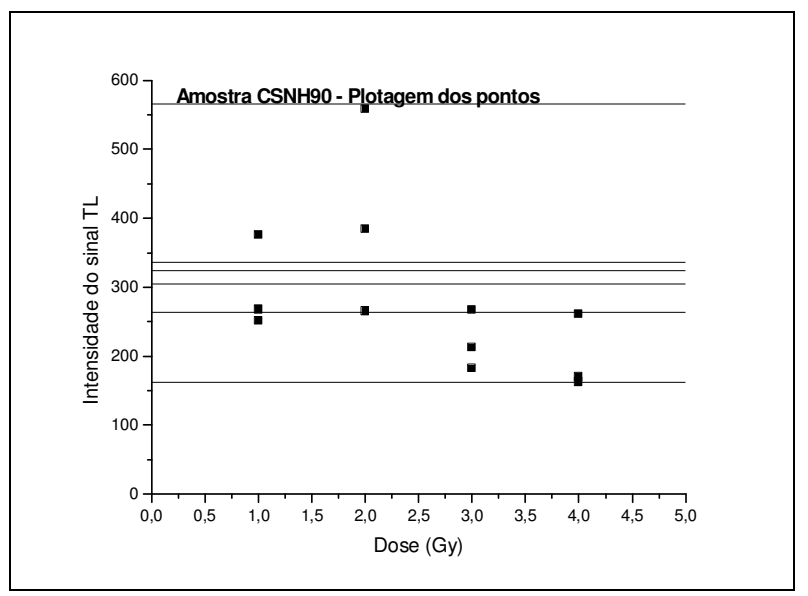

Figura 19. Representação dos sinais de todas as alíquotas para a amostra 85.

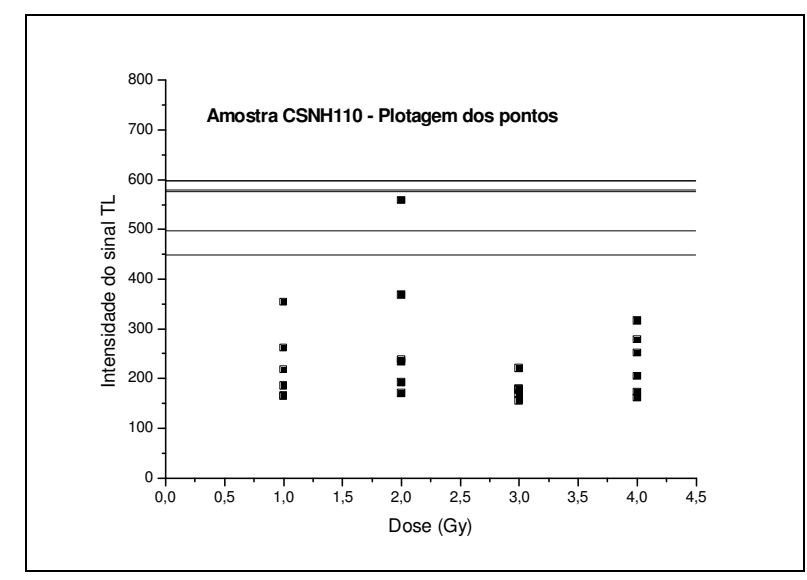

Figura 20. Representação dos sinais de todas as alíquotas para a amostra 104.

Foi observado a partir da leitura dos gráficos 18, 19 e 20, que não houve um crescimento linear da intensidade do sinal de TL em função das doses aplicadas para as alíquotas de todas as amostras.

Para a amostra 72, houve um crescimento sublinear para as doses aplicadas em laboratório, com exceção à dose de 3 Gy cujo valor de intensidade não seguiu o padrão de crescimento observado para as demais doses. Para a amostra 85 também foi observado que não houve um crescimento linear da intensidade do sinal de TL em função da dose aplicada. Observa-se que para as doses de 3 e 4 Gy, ao contrário do esperado, houve uma redução na intensidade do sinal de TL, se comparada às doses menores aplicadas, isto é, com relação às doses de 1 e 2 Gy.

Com relação à amostra 104 (Figura 20), observou-se, também, que de uma maneira geral, não houve um crescimento do sinal de TL em função da dose aplicada. 
Ainda para esta amostra, é observada uma maior quantidade de pontos para construção da curva de crescimento. Por esta razão, realizou-se uma segunda medida com alíquotas com doses de laboratório a fim de confirmar se o comportamento da curva era aquele mesmo, ou se era devido a algum erro de procedimento realizado durante a primeira medição. Foi constatado devido ao comportamento dos pontos, que o erro não estava no procedimento e sim, proveniente da própria amostra.

Ainda com relação às amostras 85 e 104 (Figuras 19 e 20), não foi observado o crescimento do sinal de TL para as doses mais altas. Este fato pode ser explicado pela presença de grande quantidade de "espículas" na amostra datada.

Espículas são partículas de sílica amorfa em formato de "agulhas", conforme pode ser observado nas Figuras 21 e 22, ao contrário do quartzo que é uma sílica cristalina. As espículas, ao contrário dos grãos de quartzo, não possuem uma resposta de TL proporcional à dose de radiação que recebem. Portanto, o sinal proveniente destas partículas não pode ser considerado na datação.

Com o auxílio de fotografia feita junto ao microscópio, estas espículas podem ser vistas na amostra entre os grãos de quartzo. As espículas são estruturas formadas por carbonato de cálcio ou sílica e constituem o esqueleto das esponjas de água doce (talvez o cauixi). Estas são comumente usadas como tempero para a fabricação das cerâmicas da Fase Paredão e Manacapuru, e sendo assim, foram adicionadas durante o processo de produção destes artefatos.

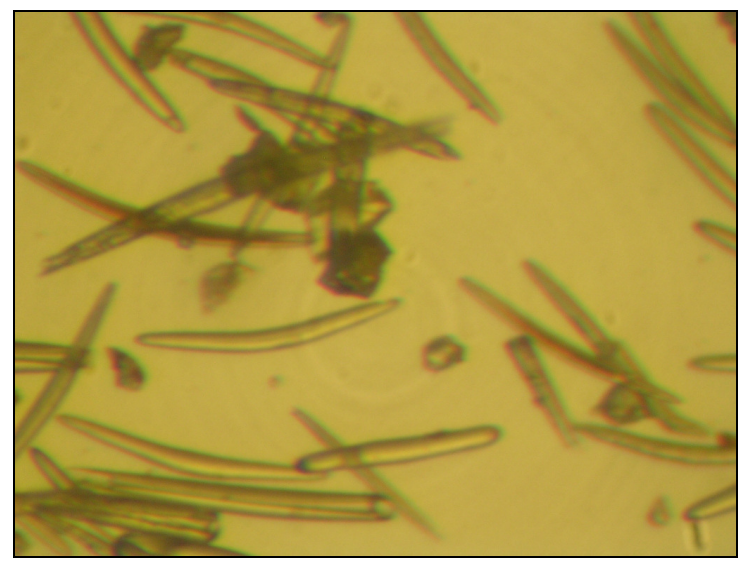

Figura 21. Fotografia de microscopia óptica por transmissão da amostra 85. Observa-se presença de grande número de espículas entre os grãos de quartzo. 


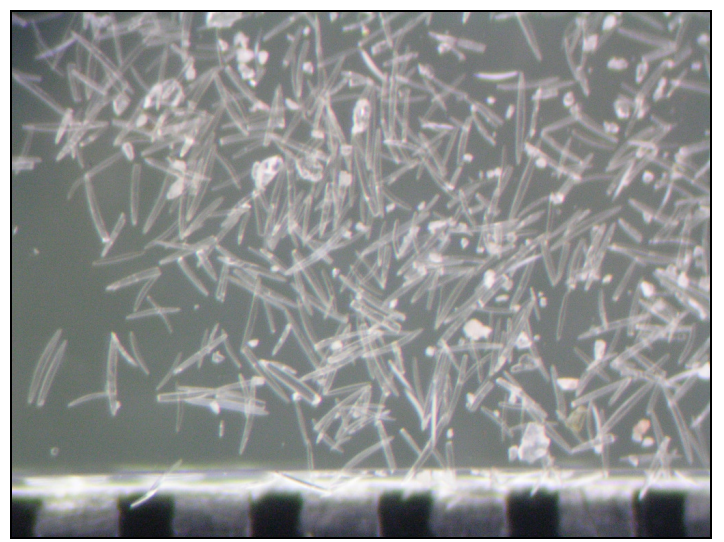

Figura 22. Fotografia de microscopia óptica por reflexão da amostra 104. Observa-se grande presença de espículas entre os grãos de quartzo. Na parte inferior da Figura, a distância entre cada faixa preta equivale a distância de $0,5 \mathrm{~mm}$.

A fim de minimizar o efeito das espículas sobre a curva de crescimento, os pontos cuja intensidade não seguiu o padrão de crescimento esperado foram eliminados, sendo construídas novas curvas de crescimento para as três amostras datadas levando em consideração os pontos considerados "corretos". Concluiu-se que, provavelmente a ausência do crescimento do sinal de algumas alíquotas se comparada a outras alíquotas que receberam a mesma dose seria devido à maior presença de espículas nas mesmas.

Com relação às alíquotas naturais, foi considerado o sinal daquelas que forneceram valores de intensidade próximos uma das outras, sendo que o sinal proveniente das demais alíquotas cujos sinais obtidos foram discrepantes em relação à "média" das alíquotas naturais de uma mesma amostra, foram descartados. Com os pontos considerados foram ajustadas as seguintes curvas de crescimento conforme as Figuras 23, 24 e 25.

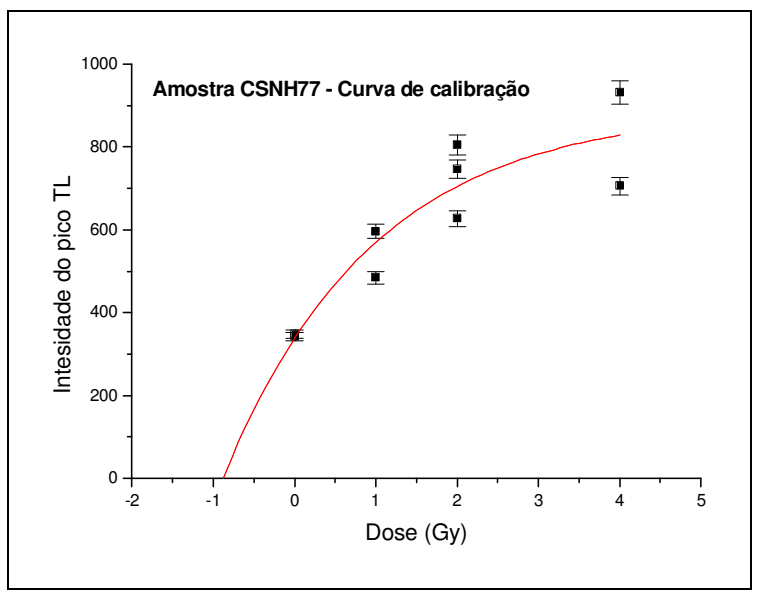

Figura 23. Curvas de crescimento com pontos ajustados para a amostra 72. 


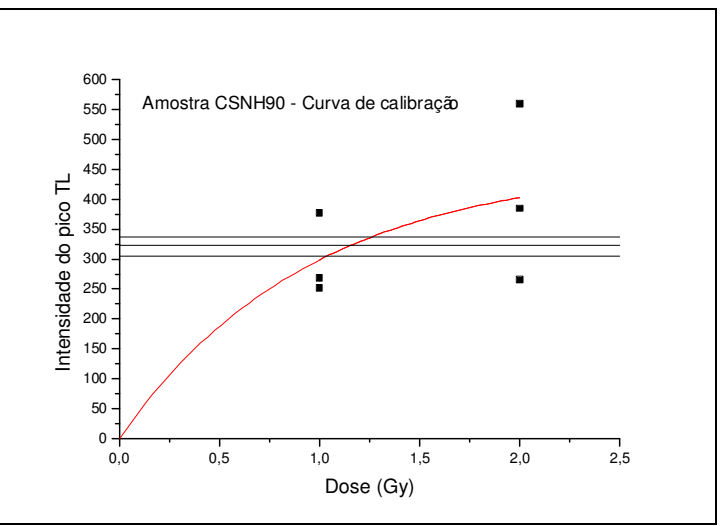

Figura 24. Curvas de crescimento com pontos ajustados para a amostra 85.

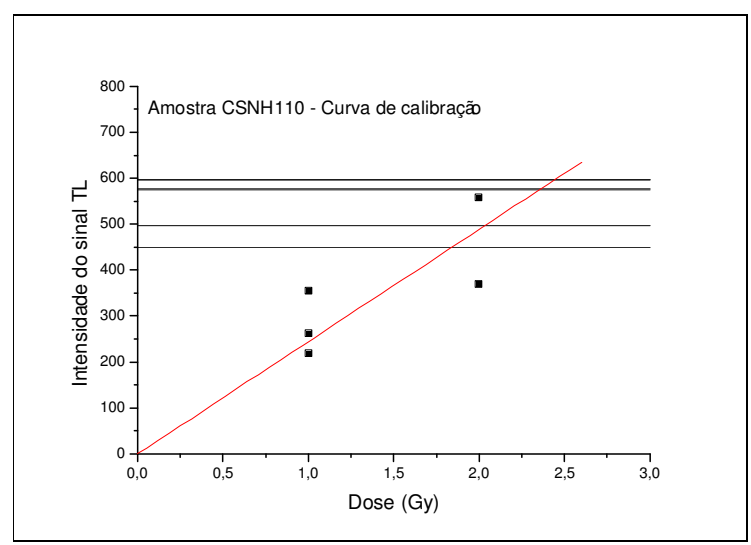

Figura 25. Curvas de crescimento com pontos ajustados para a amostra 104.

Por meio da interpretação dos gráficos acima, pôde-se calcular a Dose equivalente para a amostra 72, como também a Paleodose média (n) para as amostras 85 e 104. Com base nestes valores e o valor da Dose anual já calculada para as três amostras, foram obtidas as idades para estas amostras. Na Tabela 5 e 6 estão apresentados todos os parâmetros para o cálculo das idades, bem como, as idades calculadas.

Tabela 5. Parâmetros usados para o cálculo da idade pelo método da Dose equivalente.

Amostra 72

\begin{tabular}{cccccc}
\hline $\begin{array}{c}\text { Dose } \\
\text { equivalente } \\
(\mathrm{Gy})\end{array}$ & Incerteza & $\begin{array}{c}\text { Dose Anual } \\
(\mu \mathrm{Gy} / \mathrm{ano})\end{array}$ & $\begin{array}{c}\text { Incerteza DA } \\
(\mathrm{mGy} / \mathrm{ano})\end{array}$ & Idade (anos) & $\begin{array}{c}\text { Incerteza da } \\
\text { idade (anos) }\end{array}$ \\
0,88 & 0,088 & 2,10 & 0,32 & 419 & 106 \\
\hline
\end{tabular}


Tabela 6. Parâmetros usados para o cálculo das idades pelo método da Paleodose.

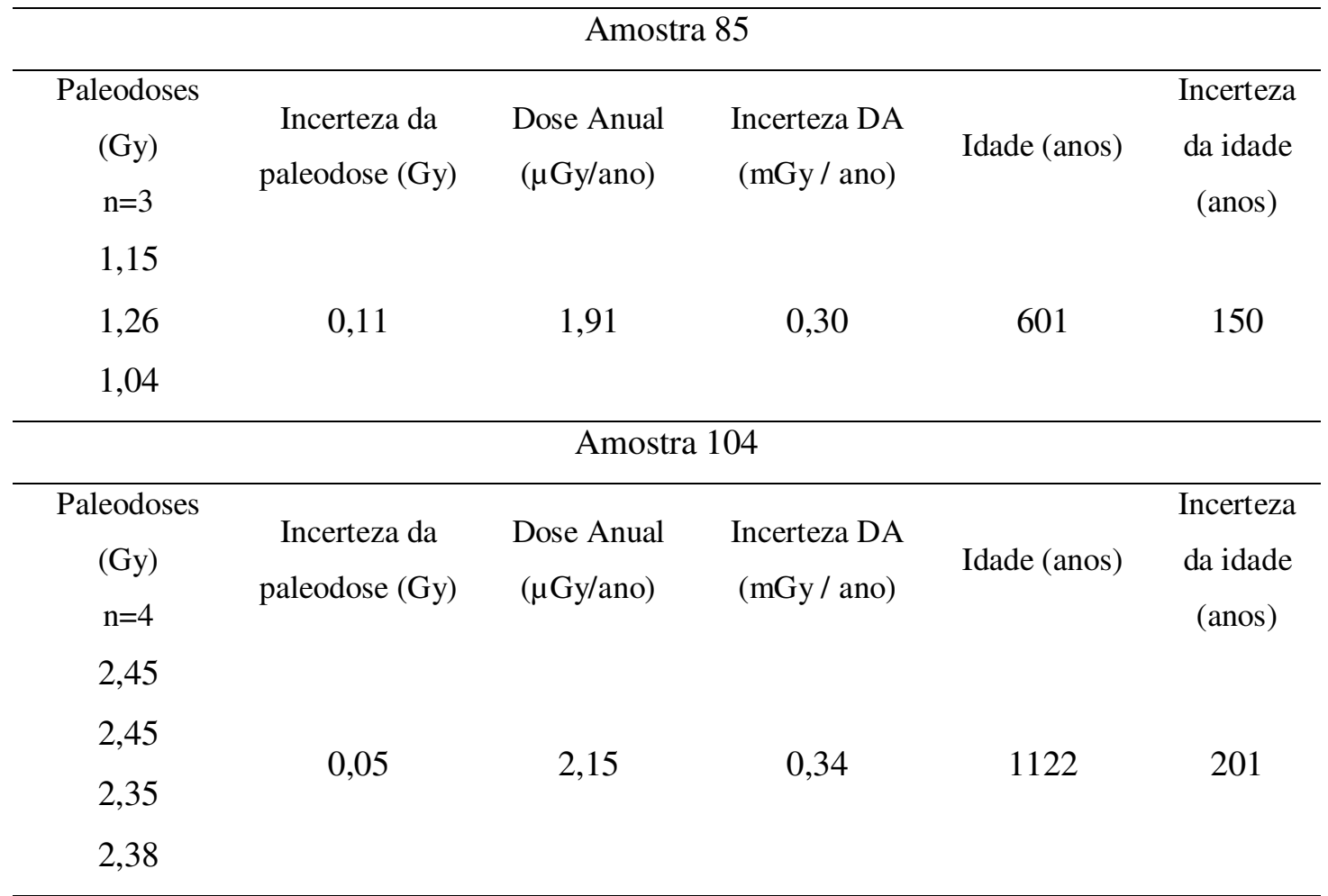

A idade determinada por TL para o fragmento cerâmico 72 foi $420 \pm 106$ anos. Segundo informação arqueológica este fragmento pertence à Fase Paredão, e, desta forma, seria esperado um resultado que estivesse dentro do intervalo estabelecido entre os séculos VII e XI. Sendo assim, mesmo usando a incerteza de 106 anos, não se afirmar que este fragmento pertence à Fase Paredão. Para este caso, a datação por TL forneceu um resultado que não pôde confirmar a interpretação arqueológica.

Com relação ao fragmento 85, a idade obtida por TL para esta amostra é $601 \pm$ 150 anos. O resultado não confirma a interpretação arqueológica com relação à Fase em que este fragmento foi produzido, a Fase Manacapuru, cujo período de ocupação no sítio Hatahara ocorreu entre os séculos V e IX.

Quanto à idade determinada por TL para o fragmento 104, foi obtido o resultado de $1122 \pm 201$ anos. E segundo a informação arqueológica este fragmento pertence à Fase Manacapuru. Neste caso, o resultado permitiu confirmar a interpretação arqueológica quanto à Fase a qual pertence o fragmento cerâmico datado. 


\subsection{Resultados obtidos para temperatura de queima das cerâmicas por RPE}

Em materiais cerâmicos, os sinais devido à absorção de microondas estão relacionados essencialmente às espécies paramagnéticas como o $\mathrm{Fe}^{3+}$. Estas espécies estão presentes nas amostras e são sensíveis ao processo de aquecimento. A temperatura de queima das cerâmicas foi então obtida efetuando o sucessivo aquecimento destes materiais a diferentes temperaturas monitoradas por RPE até que o valor de $g$ sofresse uma certa variação. A temperatura em que ocorreu esta variação foi a temperatura na qual a cerâmica foi queimada.

Desta forma, quando a temperatura de queima de uma determinada amostra for ultrapassada, a estrutura do material será afetada e o espectro de RPE resultante mostrará tal variação no valor de $g$ (BENSIMON, 1998). O sinal de RPE a ser analisado tem grande largura de linha e é atribuído a óxido ou hidróxidos de ferro encontrados na argila. Na Figura 26, tem-se o exemplo do sinal de ressonância da amostra 70, mostrando que o fator $g$ foi calculado tomando como base a variação do fator $g$ na região indicada por II.

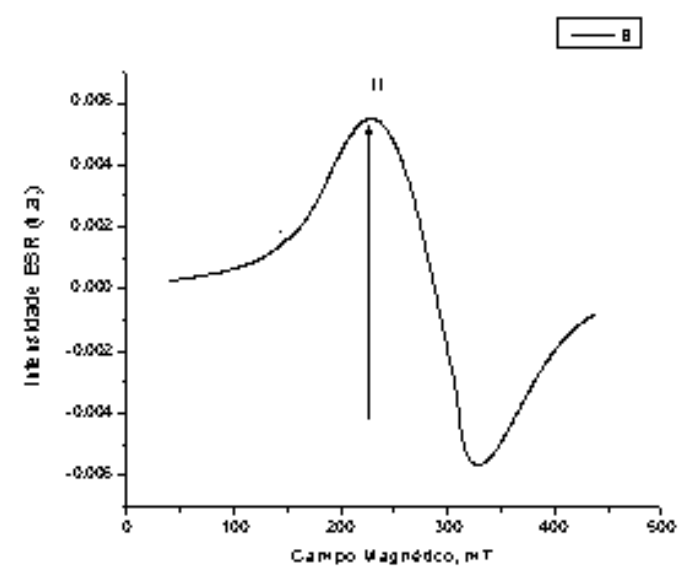

Figura 26. Sinal EPR da amostra 70.

Nas Figuras 27, 28, 29 e 30 estão apresentados os gráficos com os valores experimentais de $g$ expressos em função das temperaturas de reaquecimento para as amostras 69, 70, 95 e 103. Por meio das representações gráficas, é possível observar os valores obtidos para a temperatura de queima de todas as amostras. 


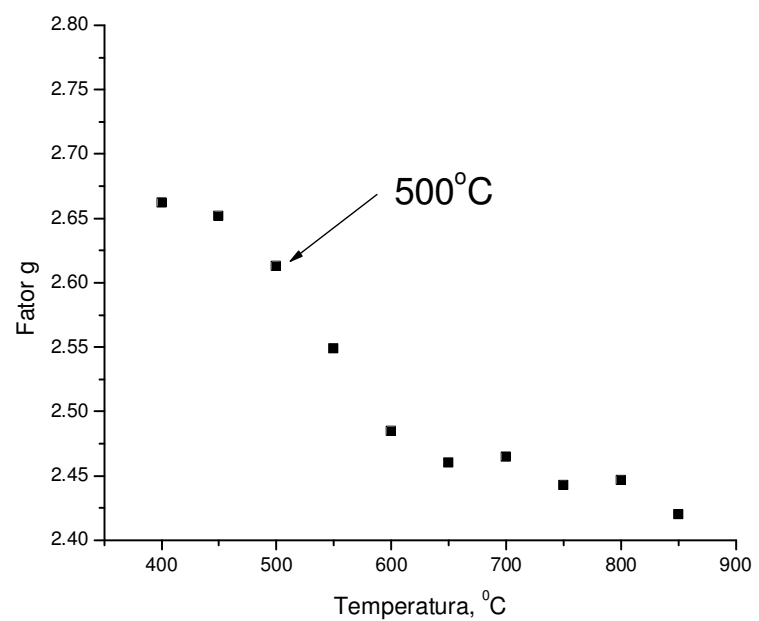

Figura 27. Valor experimental de g obtido da amplitude máxima do sinal II em função da temperatura de reaquecimento da amostra 69.

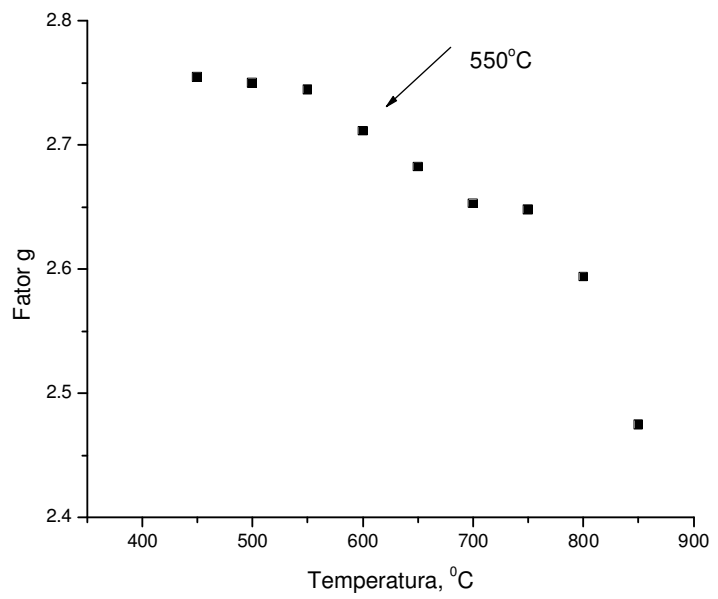

Figura. 28. Valor experimental de g obtido da amplitude máxima do sinal II em função da temperatura de reaquecimento da amostra 70 . 


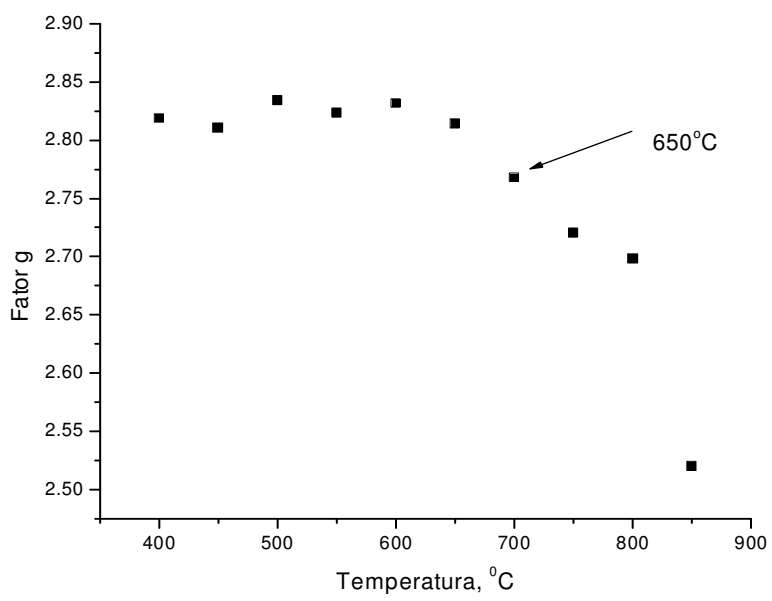

Figura 29. Valor experimental de g obtido da amplitude máxima do sinal II em função da temperatura de reaquecimento da amostra 95.

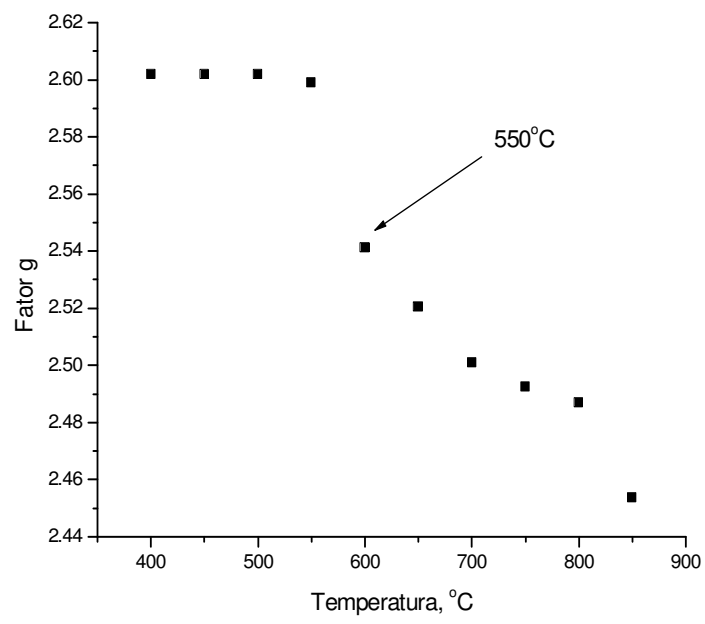

Figura 30. Valor experimental de g obtido da amplitude máxima do sinal II em função da temperatura de reaquecimento da amostra 103.

A Tabela 7 mostra os valores obtidos para a temperatura de queima das amostras de cerâmica.

Tabela 7. Resultados das temperaturas de queima para as amostras analisadas.

\begin{tabular}{cc}
\hline Amostras & Temperatura de queima, ${ }^{\circ} \mathrm{C}$ \\
\hline 69 & $500 \pm 50$ \\
70 & $550 \pm 50$ \\
95 & $650 \pm 50$ \\
103 & $550 \pm 50$ \\
\hline
\end{tabular}




\section{CONCLUSÕES}

O método da análise por ativação com nêutrons é extremamente importante para a determinação de vários elementos químicos encontrados em baixas concentrações em cerâmicas arqueológicas. Os resultados obtidos neste trabalho permitiram concluir que este método analítico é imprescindível para a realização destas análises, apresentando ótima precisão e exatidão. Assim como, o procedimento adotado para o tratamento das amostras de fragmentos cerâmicos também se mostrou bastante adequado.

Em 127 amostras de fragmentos cerâmicos do sítio arqueológico Hatahara, foram utilizadas as concentrações elementares de $\mathrm{Ce}, \mathrm{Cr}, \mathrm{Cs}$, Eu, Fe, Hf, K, La, Lu, Na, Sc, Tb, Th, U e Yb. A interpretação destes dados por meio da aplicação dos métodos estatísticos multivariados, como a análise de agrupamentos e análise discriminante, forneceu informações quanto ao estudo da fonte da matéria-prima ou o processo tecnológico empregado na fabricação dos artefatos cerâmicos encontrados, bem como, confirmou interpretações arqueológicas quanto às quatro Fases distintas e concomitantes de ocupação no sítio.

Também foi possível identificar no grupo de amostras de argila estudado, a existência de uma amostra, como sendo uma das fontes usadas na fabricação de um grupo de 25 fragmentos cerâmicos das Fases Paredão, Manacapuru e Guarita.

Quanto à análise realizada separadamente para 44 fragmentos, esta revelou a provável existência de uma ou mais Fases de ocupação no sítio Hatahara, e que possivelmente estiveram relacionadas à Fase Paredão. Para que se possa confirmar tal ocorrência, se faz necessário a continuidade da investigação destes resultados com análises mais minuciosas, incluindo os mesmos fragmentos cerâmicos, como também, um número maior número de fragmentos.

Com relação ao estabelecimento de uma cronologia para as antigas ocupações do sítio Hatahara, a aplicação da datação por termoluminescência determinou três idades distintas para os fragmentos cerâmicos. Dos três fragmentos cerâmicos datados, a datação por TL tornou possível confirmar a interpretação arqueológica com relação a um único fragmento, o qual pertence à Fase Manacapuru. No caso dos outros dois fragmentos, a datação por TL não permitiu confirmar as interpretações arqueológicas, como também, não 
tornou possível diferenciar estes fragmentos cerâmicos a partir da determinação de suas idades.

Por meio dos resultados de temperatura de queima obtidos, conclui-se que não houve variação significativa quanto às temperaturas em que as cerâmicas de diferentes Fases foram submetidas no momento de sua fabricação. Estes resultados sugerem que tenha sido empregada a mesma tecnologia no processo de queima para a produção destes artefatos.

O presente trabalho contribuiu com os estudos arqueológicos realizados no sítio Hatahara. Os resultados obtidos nesta pesquisa foram acrescentados às interpretações arqueológicas com relação ao estudo dos fragmentos cerâmicos resgatados, de modo a complementá-las. Desta forma, foi possível obter alguns esclarecimentos pertinentes que certamente servirão de apoio à reconstrução do passado humano no sítio arqueológico Hatahara, na região da Amazônia central. 


\section{SUGESTÕES PARA TRABALHOS FUTUROS}

Com o propósito de dar continuidade aos trabalhos de caracterização das cerâmicas do sítio arqueológico Hatahara, sugere-se os seguintes trabalhos:

- Analisar maior quantidade de fragmentos cerâmicos do sítio arqueológico Hatahara, utilizando outras técnicas analíticas como PIGE, XRF, ICP-MS, para realizar uma melhor caracterização química dos artefatos e estudar o processo tecnológico de produção.

- Determinar a idade de maior número de fragmentos cerâmicos por ${ }^{14} \mathrm{C}$ e TL para efeito de comparação de resultados, uma vez que neste trabalho foram datados somente três fragmentos. Neste caso, cabe realizar mais medidas para que estas possam, inclusive, ser comparadas com o grande número de datações já realizadas por ${ }^{14} \mathrm{C}$ sobre as cerâmicas da região do sítio Hatahara. E também, datar novamente os mesmos fragmentos já datados por TL, cujos resultados foram apresentados neste trabalho.

- Realizar a temperatura de queima de maior número de cerâmicas, para estudar em que condições o processo de queima foi executado.

- Realizar também, análise da composição mineralógica das cerâmicas por meio de Difratometria de Raios-X e Microscopia eletrônica de varredura, com o objetivo de diferenciar os fragmentos cerâmicos;

- Continuar associando as características e informações obtidas por estas técnicas às classificações tipológicas das cerâmicas que compõem os grupos distintos. 


\section{REFERÊNCIAS BIBLIOGRÁFICAS}

AITKEN, M.J.; ZIMMERMAN, D.W.; FLEMING, S.J. Termoluminescence dating of ancient ceramics. Nature, v. 219, p. $442-444,1968$.

ASARO, F.; ADAN-BAYEWITZ, D. The history of the Lawrence Berkeley National Laboratory instrumental neutron activation analysis programme for archaeological and geological materials. Archaeometry, v. 49, n. 2, p. 201-214, 2007.

ATTAS, M.; FOSSEY, J. M.; YAFFE, L. Corrections for drill-bit contamination in sampling ancient pottery for neutron activation analysis. Archaeometry, v. 26, n.1, p. 104107, 1984.

BAHN, P. (Ed). The Cambridge illustrated history of archaeology. Cambridge/New York: University Press, 1996, p. 80-115.

BALLA, M.; MOLNÁR, Zs.; KORÖS, Á. Uncertainty budget and validation of NAA using reference materials. Journal of Radioanalytical and Nuclear Chemistry, v. 259, n. 3, p. 395-400, 2004.

BAXTER, M. J. Detecting multivariate outliers in artefact compositional data. Archaeometry, v. 41, n. 2, p. 321-338, 1999.

BAXTER, M. J. A review of supervised and unsupervised pattern recognition in archaeometry. Archaeometry, v. 48, n. 4, p. 671-694, 2006.

BENSIMON, Y.; DEROIDE, B.; CLAVEL, S.; ZANCHETTA, J.V. Electron spin resonance and dilatometric studies of ancient ceramics applied to the determination of firing temperature. Japanese Journal of Applied Physics, v. 37, p. 4367-4372, 1998.

BENSIMON, Y., DEROIDE, B., ZANCHETTA, J.V. Comparison between the electron paramagnetic resonance spectra obtained in X-and W-bands on a fired clay: a preliminary study. Journal of Physics and Chemistry of Solids, v. 60, p. 813-818, 1999.

BISHOP, R.L.; RANDS, G.R.; HALLEY. Ceramic compositional analysis in: archaeological perspective. In: SCHIFFER, M.B. (Ed). Advances in archaeological method and theory, New York: Academic Press, 1982.

BUSTAMANTE, A.; DELGADO, M.; LATINI, R.M.; BELLIDO, A.V.B. Multivariate analysis in provenance studies: Cerrillos obsidians case, Peru. Hyperfine Interactions, v.175, p. 43-48, 2007. 
CARANDINI, A. Archaeologia e cultura materiale. II lavoro senza Gloria nella antichità clásica. Bari, de Donato, 1975, p. 53-93.

CHAPMAN W.R. Arranging ethnology, A.H.L.F. Pitt Rivers and typological tradition. In: STOCKING, G.W. Jr (Ed). Objects and others. Essays on museums and material culture. Madison: University of Wisconsin Press, 1985, pp. 15-48.

CHILDE, G.V. Piecing together the past. ROUTLEDGE and KEGAN, P. (Ed), 1956.

DAMOUR, M.A. Ser la composition des haches in pierre trouveés dan les monuments celtiques et chez les sauvages. Comptes-Rendus de I'Academic des Sciences LXI, v. 61, p. 357-368, 1865.

DIAS, M.I.; PRUDENCIO, M.I. Neutron activation analysis of archaeological materials: an overview of the ITN NAA laboratory, Portugal. Archaeometry, v. 49, n. 2, p. 383-393, 2007.

FELICÍSSIMO, M.P.; PEIXOTO, J.L.; PIREAUX, J.J.; DEMORTIER, G.; RODRIGUES, U.P.F. Estudos arqueométricos de cerâmicas indígenas pré-coloniais das lagoas Castelo e Vermelha, localizadas no Pantanal Sul-Mato-Grossense. Canindé, v. 4, p. 325-368, 2004.

FELICÍSSIMO, M.P.; PEIXOTO, J.L.; BARBOSA, M.S.; DEMORTIER, G.; PIREAUX, J.J.; RODRIGUES FILHO, U.P. PIXE and PIGE analysis of pré-colonial pottery from Patanal - MS Brazil. Journal of Radioanalytical and Nuclear Chemistry, v. 267, n. 1, p. 209-217, 2005.

FORTINA, C.; SANTAGOSTINO BARBONI, A.; TURBANTI MEMMY, I. Sienese 'archaic' majolica: a technological study of ceramic bodies and coatings. Archaeometry, v. 47, n. 3, p. 535-555, 2005.

FRIEDLANDER, G.; KENNEDY, J.W.; MACIAS, E.S., MILLER, J.M.. Nuclear and radiochemistry. 3. ed. Canadá: John Willey \& Sons, Inc., 1981.

GEBHARD, R. Materials analysis in archaeology. Hyperfine Interactions, v. 150, p.1-5, 2003.

GILARDONI, A. X-rays in art: physics-techniques-applications. Italy: Gilardoni, P.A., 1977.

GLASCOCK, M.D.; NEFF, H.; VAUGHN, K.J. Instrumental neutron activation analysis and multivariate statistics for pottery provenance. Hyperfine Interactions, v. 154, p. 95$105,2004$. 
GRUBBS, F.E. Sample criteria for testing outlying observations. Annal of Mathematical Statistics, v. 21, p. 27-58, 1950.

HARBOTTLE, G. Chemical characterization in archaeology. In: ERICSON, J.E.,T.K. (Ed). Contexts for prehistoric exchange, New York, Academic Press, 1982.

HARBOTTLE, G. Neutron activation analysis in archaeological chemistry. Topics in Current Chemistry, v. 157, p. 57-91, 1990.

HARBOTTLE, G.; HOLMES, L. The history of the Brookhaven National Laboratory project in archaeological chemistry, and applying nuclear methods to the fine arts. Archaeometry, v. 49, n. 2, p. 185-199, 2007.

HAYASHIDA, F. Bridging the gap between archaeology and the physical sciences. Hyperfine Interactions, v.150, p. 7-11, 2003.

INTERNATIONAL ATOMIC ENERGY AGENCY. Practical aspects of operating $\boldsymbol{a}$ neutron activation analysis laboratory, IAEA - TECDOC - 564, Vienna, 1990.

IOVINO, M.R.; MANISCALCO, L.; PAPPALARDO, G.; PAPPALARDO, L.; PUGLISI, D.; RIZZO, F.; ROMANO, F.P. Archaeological volcanic glass from the site of Rocchicella (Sicily, Italy). Archaeometry, v. 50, n. 3, p. 474-494, 2008.

JAMES, W.D.; RAULERSON, M.R.; JOHNSON, P.R. Archaeometry at Texas A\&M University: characterization of samoan basalts. Archaeometry, v. 49, n. 2, p. 395-402, 2007.

JOHNSON, R.A.; WICHERN, D.W. Applied multivariate statistical analysis. 3. ed. New Jersey: Prentice Hall, 1992, p. 575-584.

JOLLIFFE, I.T. Rotation of ill-defined principal components. Applied Statistics - Journal of the Royal Statistical Society Series C, v. 38, n. 1, p.139-147, 1989.

JOLLIFFE, I.T.; JONES, B.; MORGAN, B.J.T. Identifying influential observations in hierarquical cluster analysis. Journal of Applied Statistics, v. 22, n. 1, p. 61-80, 1995.

KELLER, C. Radioquímica. 2. ed. Universidade Federal de Pernambuco, Recife: Editora Universitária, 1981, pp. 144-146.

KELLNER, R.; MERMET, J.M.; OTTO, M; WIDMER, H.M. Activation analysis. In: KELLNER, R.; MERMET, J.M; OTTO, M.; WIDMER, H. M. Analytical chemistry: The approved text to the FECS curriculum analytical chemistry. New york: Wheinheim, 1998, p. $490-516$. 
KILIKOGLOU, V.; GRIMANIS, A.P.; TSOLAKIDOU, A.; HEIN, A. Neutron activation patterning of archaeological and national center for scientific research 'Demokritos': the case of black-on-red neolithic pottery from Macedonia, Greece. Archaeometry, v. 49, n. 2, p. 301-319, 2007.

KITTEL, C., Introdução à física do estado sólido. 5. ed. Rio de Janeiro: Guanabara Dois, 1978.

KOUL, D.K.; SINGHVI, A.K.; NAMBI, K.S.V.; BHAT, C.L.; GUPTA, P.K. Feasibility of estimating fire using the $110^{\circ} \mathrm{C}$ TL peak of quartz. Applied Radiation Isotopes, v. $47, \mathrm{n}$. 2, p. 191-194, 1996.

KULEFF, I., DJINGOVA, R. Archaeometric investigations at the university of Sofia, Bulgaria. Archaeometry, v. 49, n. 2, p. 245-253, 2007.

LATINI, R.M.; BELLIDO, A.V.; VASCONCELLOS, M.B.A.; DIAS, O.F. Classificação de cerâmicas arqueológicas da bacia amazônica. Química Nova, v. 24, n. 6, São Paulo, 2001.

LEUTE, U. Archaeometry: a introduction to physical methods in archaeology and the history art. New York: VCH Publishers, 1987.

LEYBOLD PHYSICS LEAFETS: ATOMIC AND NUCLEAR PHYSICS. Electron Spin Resonance (ESR). Germany: Leybold Didatic GMBH, 2000.

LIMA H.P.; NEVES, E.G.; PETERSEN, J.B. La fase Açutuba: um novo complexo cerâmico na Amazônia central. Arqueologia Suramericana, v. 2, n. 1, p. 26-52, 2006.

LOPEZ, F.A.; CATLOWN, C.R.A.; TOWNSEND, P.D. Point defects in materials. London: Academic Press, 1988.

MACHADO, J.S. Montículos artificiais na Amazônia central: um estudo de caso do sítio Hatahara, 2005. Dissertação (Mestrado) - Museu de Arqueologia e Etnologia, Universidade de São Paulo.

MARTINEAU, R.; SIMONNET, A.V.W.; GROBÉTY, B.; BUATIER, M. Clay resources and technical choices for neolithic pottery (Chalai, Jura, France): chemical, mineralogical and grain-size analysis. Archaeometry, v. 49, n. 1, p. 23-52, 2007.

MASSART, D.L.; KAUFMAN, L. The interpretation of analytical chemical data by the use of analysis. New York: John Wiley \& Sons, 1983, p.17-37.

MATSUOKA, M.; TAKATOHI, U.E.; WATANABE, S.; NAKAJIMA, T. TL dating of fish fossil from Brazil. Radiation Protection Dosimetry, v. 6, p.185-188, 1984. 
MIRTI, P.; PERARDI, A.; GULMINI, M.; PREACCO, M.C. A scientific investigation on the provenance and technology of black-figure amphora attributed to the priam group. Archaeometry, v. 48, n. 1, p. 31-43, 2006.

MITTANI, J. C. R. Mecanismo de emissão Tb do pico de $310^{\circ} \mathrm{C}$ no feldspato potássico, 1998. Dissertação (Mestrado) - Instituto de Física, Universidade de São Paulo.

MITTANI, J. C. R. Estudos de difusão e trocas iônicas de vanádio, cromo e manganês, 2003. Tese (Doutorado) - Instituto de Física, Universidade de São Paulo.

MOMMSEN, H.; KREUSER, A.; WEBER, J. A method for grouping pottery by chemical composition. Archaeometry, v. 30, n. 1, p. 47-57, 1988.

MUNITA, C.S.; PAIVA, R.P.; MOMOSE, E.F. Characterization of brazilian prehistoric ceramics part III. In: Third Research Co-ordination Meeting of the Co-ordinated Research Programme on Nuclear Analytical Techniques in Archaeological Investigations, November 6 to 10, Santiago, Chile, 2000.

MUNITA, C.S.; PAIVA, R.P.; ALVES, M.A.; OLIVEIRA, P.M.S.; MOMOSE, E.F. Chemical characterization of brazilian prehistoric ceramics by INAA. In: Nuclear analytical techniques in archaeological investigations. Technical reports series 416 (IAEA), 2003, p. 89-97.

MUNITA, C.S.; NASCIMENTO, A.; SCHREIBER, S.B.; LUNA, S.; OLIVEIRA, P.M.S. Chemical study of some ceramics from brazilian northeast. Journal of Radioanalytical and Nuclear Chemistry, v. 259, n. 2, p. 305-309, 2004.

MUNITA, C. S. Contribuição da análise por ativação com nêutrons a estudos arqueométricos: estudo de caso. Canindé, v. 6, p. 159-181, 2005.

NALIMOV, V. V. The application of mathematical statistic to chemical analysis. Massachussetts: Addison - Wesley Publishing Company Inc. Reading, 1963, p. 58.

NEVES, E.G.; PETERSEN, J.B.; BARTONE, R.N.; SILVA, C.A. Historical and socio cultural origins of amazonian dark earths. In: LEHMANN, J. et al (Eds). Amazonian dark earths origin properties management. Kluwer Academic Publishers: Dordrescht, The Netherlands, 2003, p. 29-50.

NEVES, E.G.; PETERSEN, J.B.; BARTONE, R.B.; HECKENBERGER, M.J. The timing of terra preta formation in the central Amazon: archaeological data from three sites. In: GLASER, B. \& WOODS, W.I. (Eds). Amazonian dark earths: explorations in space and time. Springer; Alemanha, 2004, p. 125-134. 
NUNES, K.P; MUNITA, C.S.; NEVES, E.G. Estudo preliminar da composição química da cerâmica do sítio Hatahara, AM. In: $1^{\circ}$ Simpósio Latino Americano Sobre Métodos Físicos e Químicos em Arqueologia, Arte e Conservação do Patrimônio Cultural, LASMAC, 11 a 16 de Junho, MASP, São Paulo, SP, Brazil, 2007a.

NUNES, K.P.; TOYOTA, R.G.; MUNITA, C.S.; OLIVEIRA, P.M.S.; NEVES, E.G.; SOARES, E.A.A. The utilization of trace chemical composition to correlate ceramics with clay deposits. In: International Nuclear Atlantic conference, INAC, September 30 to October 5, Santos, SP, Brazil, 2007b.

NUNES K.P.; TOYOTA, R.G.; OLIVEIRA, P.M.S.; NEVES, E.G.; MUNITA, C.S. Estudo dos elementos traço nas cerâmicas do sítio arqueológico Hatahara. In: VIII Encontro Latino Americano de Pós-Graduação, 16 e 17 de Outubro - Universidade do Vale do Paraíba, São Paulo, SP, 2008.

OLIVEIRA, P.M.S.; MUNITA, C.S. Influência do valor crítico na detecção de valores discrepantes em arqueometria. In: $48^{a}$ Reunião Anual Região Brasileira da Sociedade Internacional de Biometria, de 07 a 11 de julho, 545-550, Lavras, MG, 2003.

PACE, M.; PREVOT, A.B.; MIRTI, P.; RICCIARDI, R.V. The technology of production of sasanian glazed pottery from veh ardasir (central Iraq). Archaeometry, v. 50, n. 4, p. 591-605, 2008.

PENNY, K.I. Appropriate critical values when testing for a single multivariate outlier by using the Mahalanobis distance. Journal of Applied Statistics, v. 35, p.153-162, 1987.

PERLMAN, I.; ASARO, F. Pottery analysis by neutron activation. In: Science and archaeology, London: R.H. Brill, 1971, p.182-195.

PETRI, W.M.F. Methods and Aims in Archaeology. New York: Benjamin Blom, 1972, p.1-19, p.122-135.

REBELLATO, L. Interpretando a Variabilidade Cerâmica e as Assinaturas Químicas e Físicas do Solo no Sítio Arqueológico Hatahara - AM, 2007. Dissertação de Mestrado Museu de Arqueologia e Etnologia, Universidade de São Paulo.

RICE, P. M. Pottery analysis: a Sourcebook. Chicago: University of Chicago Press, 1987.

SANTOS, J.O. Estudos Arqueométricos de Sítios Arqueológicos do Baixo São Francisco, 2007. Tese de Doutorado - Instituto de Pesquisas Energéticas e Nucleares, IPEN-CNEN/SP.

SENDOVA, M.; ZHELYASKOV, V.; SCALERA, M.; GULLIFORD, C. Micro raman spectroscopy characterization of della robia glazes. Archaeometry, v. 49, n. 4, p. 655-664, 2007. 
SOARES E.A.A.; SILVA, C.L.; NOGUEIRA, A.C.R.; SUGUIO, K.; BARROS, D.S.; SANTOS, W.H.D. Os Depósitos Quaternários na Confluência dos Rios Negro e Solimões, Municípios de Iranduba e Manacapuru, Amazonas. In: SBG, Núcleo Norte, Simpósio de Geologia do Amazonas, Belém, PA, 2001, p. 19-22.

SOARES, E.A.A. Depósitos Pleistocenos da Região de Confluência dos Rios Negro e Solimões, Amazonas, 2007. Tese de Doutorado - Instituto de Geociências, Universidade de São Paulo, 205p.

SPEAKMAN, R.J.; GLASCOCK, M.D. Acknowledging fifty years of neutron activation analysis in archaeology. Archaeometry, v. 49, n. 2, p.179-183, 2007.

SZMUK, P.E.; WATANABE, S. Dating of brazilian indian pottery. TLD Publication IAEA, n² 231, 1971.

TATUMI, S.H.; KOWATA, E.A.; GOZZI, G.; KASSAB, L.R.P.; SUGUIO, K.; BARRETO, A.M.F.; BEZERRA, F.H.R. Optical dating results of beachrock, eolic dunes and sediments applied to sea-level changes study. Journal of luminescence, v. 102-103, 562-565, 2003.

TATUMI, S.H.; KINOSHITA, A.; FUKUMOTO, M.E; COURRIOL, L.C.; KASSAB, L. R.P.; BAFFA, O.; MUNITA, C.S. Study of paramagnetic signals of microcline feldspar. Applied Radiation Isotopes, v. 62, p. 231 - 236, 2005.

TITE, M. S. Ceramic production, provenance and use - a review. Archaeometry, v. 50, n. 2, p. 216-231, 2008.

TOYOTA, R.G.; MUNITA, C.S. Estudo da composição química de cerâmicas do sítio arqueológico Lago Grande. In: XII Simpósio Internacional de Iniciação Científica da USP, 25 e 26 de novembro, São Paulo, 2004.

TOYOTA, R.G.; MUNITA, C.S.; NEVES, E.G.; LUZ, F.A.; OLIVEIRA, P.M.S. Preliminary study of chemical compositional data from Amazon ceramics. In: Internacional Nuclear Atlântic Conference, INAC, August 28 to September 2, Santos SP, Brazil, 2005.

TRAVESI, A. Analisis por activacion neutronica: teoria, prática y aplicaciones. Madrid: Junta de Energia Nuclear, 1975.

VELDE, B.; DRUC, I.C. Archaeological ceramic materials: origin and utilization. Berlim/New York: Springer-Verlag, 1999.

WEIGAND, P.; HARBOTTLE, G.; SAYRE, E.V., In: EARLE, T.K. and ERICSON, J.E. (Eds), Exchange systems in prehistory. New York: Academic Press, 1977, p. 15. 
WILKS, S. S. Multivariate statistical outliers. Sankhya, v. 25, p. 407-426, 1963.

WINTLE, A. G. Fifty years of luminescence dating. Archaeometry, v. 50, n. 2, p. 276-312, 2008 .

YOON, Y.Y.; LEE, K.Y.; CHUNG, K.S.; YANG, M.K.; KIM, K.H. Classification of Korean old potteries by trace elements analysis. Journal of Radioanalytical and Nuclear Chemistry, v. 248, n. 1, p. 89-92, 2001. 